\title{
Analysis of particulate matter concentration and size distribution in heavy-duty vehicle exhaust emissions
}

Zhuyun Xu

West Virginia University

Follow this and additional works at: https://researchrepository.wvu.edu/etd

\section{Recommended Citation}

Xu, Zhuyun, "Analysis of particulate matter concentration and size distribution in heavy-duty vehicle exhaust emissions" (2001). Graduate Theses, Dissertations, and Problem Reports. 1168.

https://researchrepository.wvu.edu/etd/1168

This Thesis is protected by copyright and/or related rights. It has been brought to you by the The Research Repository @ WVU with permission from the rights-holder(s). You are free to use this Thesis in any way that is permitted by the copyright and related rights legislation that applies to your use. For other uses you must obtain permission from the rights-holder(s) directly, unless additional rights are indicated by a Creative Commons license in the record and/ or on the work itself. This Thesis has been accepted for inclusion in WVU Graduate Theses, Dissertations, and Problem Reports collection by an authorized administrator of The Research Repository @ WVU. For more information, please contact researchrepository@mail.wvu.edu. 


\title{
ANALYSIS OF PARTICULATE MATTER CONCENTRATION AND SIZE DISTRIBUTION IN HEAVY-DUTY VEHICLE EXHAUST EMISSIONS
}

\section{Zhuyun Xu}

\author{
Thesis \\ Submitted to the College of Engineering and Mineral Resources \\ at \\ West Virginia University \\ In partial fulfillment of the requirements \\ For the degree of \\ Master of Science in Mechanical Engineering
}

Mridul Gautam, Ph. D., Chair

Charles Stanley, Ph. D.

Micheal McCawley, Ph. D.

MORGANTOWN

WEST VIRGINIA

2001

Keywords: Plume Concentration Field, Cumulative Frequency Fit, Nano-Particles 


\begin{abstract}
ANALYSIS OF PARTICULATE MATTER CONCENTRATION AND SIZE DISTRIBUTION IN HEAVY-DUTY VEHICLE EXHAUST EMISSIONS
\end{abstract}

\title{
Zhuyun Xu
}

This study put forward a method to predict the concentration field in the plume of a heavy-duty truck, operating at highway speed. It provided information regarding computation of dispersion coefficients in the area near a stack.

The numerical cumulative frequency fit method obtained in this study provided an effective and quick means for determining the particle size distribution parameters (the mass median aerodynamic diameters and geometric standard deviations) of sample data for the multi-modal distribution.

The particle size distribution of the compressed natural gas buses tested was characterized by a bi-modal particle size distribution; the clean diesel buses had a unimodal particle size distribution.

The heavy-duty diesel trucks exhibited the Count Median Diameter (CMD) values ranging from $30 \mathrm{~nm}$ to $60 \mathrm{~nm}$. EC-Diesel truck test yielded a CMD of $33 \mathrm{~nm}$ (baseline), a CMD of 37-39 nm (with a JM-CRT), and a CMD of 40-47 nm (with a Engelhard DPX). CARB's baseline was at $56 \mathrm{~nm}$.

The thesis has 7 Chapters, 14 Tables, and 36 Figures. 


\section{ACKNOWLEDGEMENTS}

I would like to express my profound gratitude and indebtness to my advisor, Prof. Gautam, for your guidance, assistance, and encouragement throughout this work. Your unwavering belief in me has made me work harder. Transferred from mining engineering, how new I am at the mechanical engineering! You always call me Dr. Xu, how can I give up?

I must express my gratitude to Sandeep Mehta. You spent twice the effort to teach me how to be a scientist. You are an under appreciated and overworked guy. Somehow, you took time to teach me many things that the textbooks didn't. I wouldn't be going to Langley, Boston and Riverside without your help.

I have to express my sincere thanks to my wife Hongyu Chen. You took the whole burden of the family and back me up throughout the two years. Without your coming to Morgantown with our daughter, I would have gone back to China earlier than last year.

I wish to acknowledge the people that made this work possible: the crew of the mobile lab.; Leo for discussing the MOUDI data reduction method; Drs. Ness, Kulman, Celik, Clark, Ammar, and Fang for teaching me the courses; the on the $3^{\text {rd }}$ floor for all their help. To those who have gone unmentioned by name, my appreciation is no less, but the list too long.

With this, my two-year research associate work at Mechanical and Aerospace Engineering Department, West Virginia University comes to an end. Staying here was so good and would be a part of my memory. 


\section{TABLE OF CONTENTS}

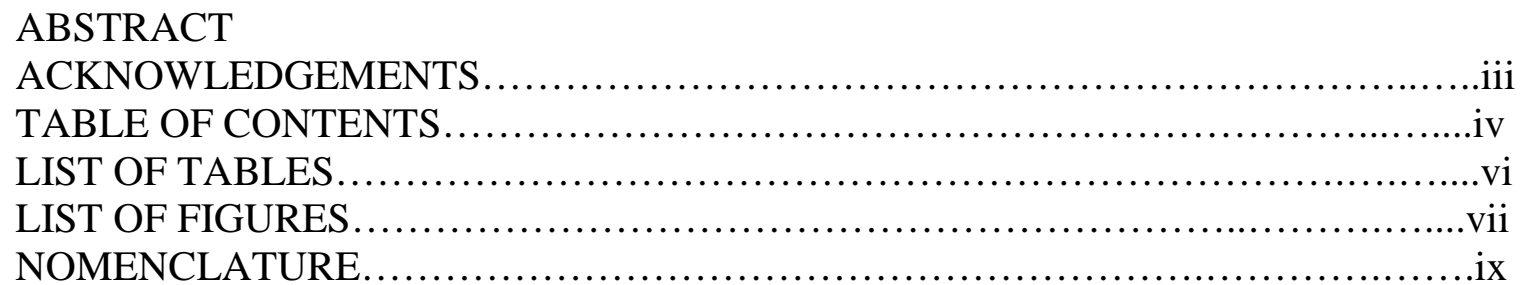

Chapter 1 INTRODUCTION......................................................1

Chapter 2 LITERATURE REVIEW.............................................

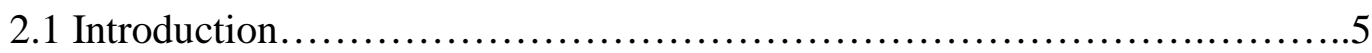

2.2 Plume Concentration Predictor and Dispersion Coefficients..................6

2.3 PM Size Distribution Data Reduction Method.................................8

2.4 Mini Dilution Tunnel for SMPS ....................................

2.5 PM Analyses for Heavy Duty Vehicles..................................10

2.6 Aftertreatment for Diesel Engines and Testing Method.....................12

Chapter 3 EXPERIMENTAL EQUIPMENT AND PROCEDURE....................13

3.1 WVU Transportable Heavy Duty Vehicle Emissions Testing Laboratory.....13

3.2 MOUDI and Cyclone Inlet Sample System.............................24

3.3 SMPS Theory and Sample System.......................................29

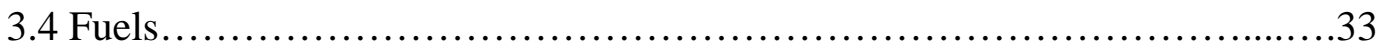

Chapter 4 ASSESSMENT OF REAL-WORLD PLUME DISPERSION FROM A HEAVY-DUTY DIESEL MOBILE SOURCE.......................................34

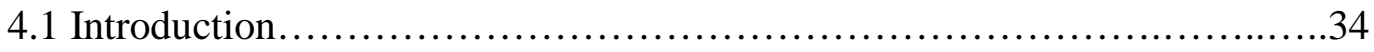

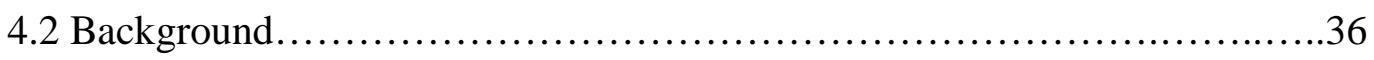

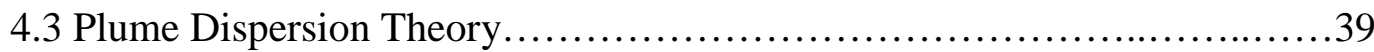


4.4 Wind Tunnel Test.................................................48

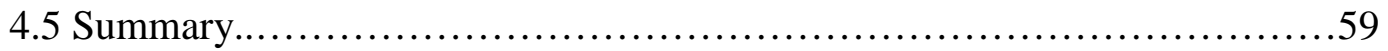

\section{Chapter 5 PARTICULATE MATTER ANALYSIS OF HEAVY-DUTY BUSES OF}

\section{METROPOLITAN BOSTON TRANSIT AUTHORITYY}

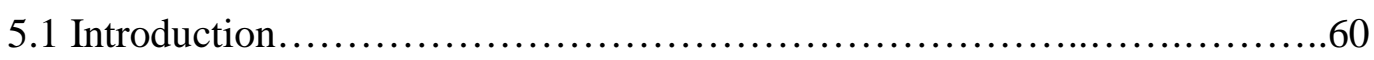

5.2 Test Matrix and Arrangement......................................61

5.3 MOUDI Data Reduction Method.................................6 62

5.4 Cyclone Inlet Sampling Data Reduction Methods........................78

5.5 Bus Exhaust PM Test Result....................................78

5.6 Summary.................................................... 85

\section{Chapter 6 INVESTIGATION OF NANOPARTICLE EMISSIONS FROM}

HEAVY-DUTY DIESEL TRUCKS..............................................92

6.1 Mini-dilution Tunnel and SMPS Sample Systems.....................92

6.2 Stability Analysis of Dilution Ratio for the Two Mini-dilution Systems.....93

6.3 Reliability of the Two Dilution Systems...........................97

6.4 Steady State Test.............................................. 101

6.5 Transient Test.................................................111

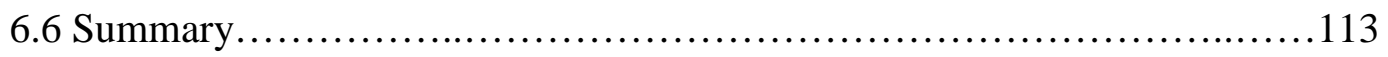

Chapter 7 CONCLUTIONS AND RECOMMENDATIONS........................126

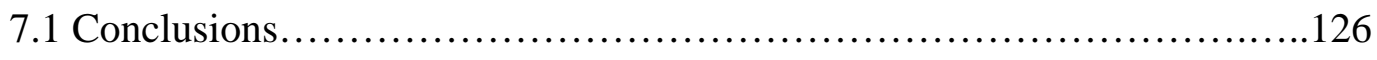

7.2 Recommendations............................................. 127

REFERENCES.....................................................................129 


\section{LIST OF TABLES}

Table 4-1 Measurement cross-section positions...............................49

Table 4-2 Concentration of $\mathrm{CO} 2$ on the plume centerline and dispersion coefficient.....50

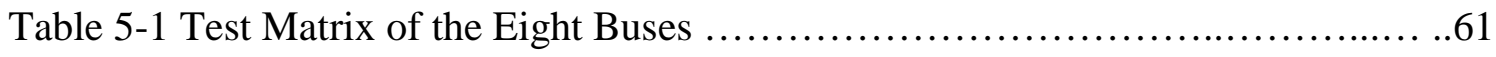

Table 5-2 MMAD and GSD obtained with the two methods for ideal data..............66

Table 5-3 MMAD and GSD obtained with the two methods for actual sampled data....67

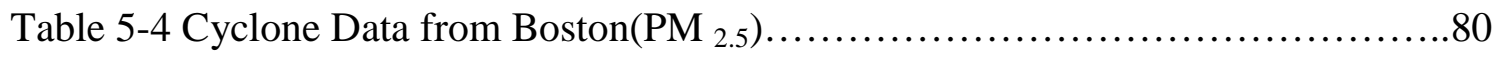

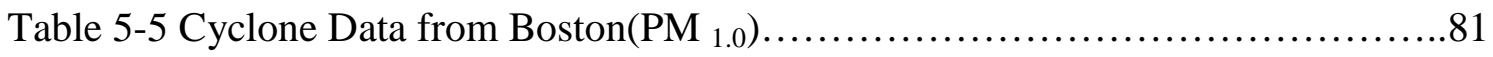

Table 5-6 Mass Emission Rates of MBTA Test Buses............................82

Table 6-1 Rate of change of dilution ratio with $1 \%$ change in the mixed flow rate.......96

Table 6-2 Rate of change of dilution ratio with $1 \%$ change in the exhaust flow rate.....97

Table 6-3 Parameters of ejector TD110HSS................................. 99

Table 6-4 Description of the Trucks Tested................................. 102

Table 6-5 Steady state test data for the DDC series 60 tractors....................109

Table 6-6 Summary of Transient Test Results.................................112 


\section{LIST OF FIGURES}

Figure $3-1$ CSHVR cycle................................................22

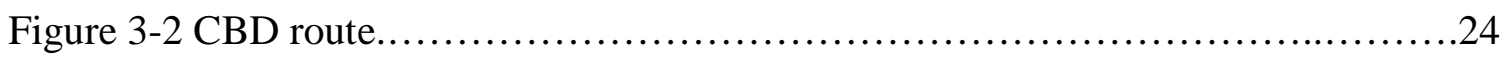

Figure 4-1 Set up at the ODU Full Scale Wind Tunnel Facility........................37

Figure 4-2 Picture of test vehicle, gantry, dynamometer, and other instrumentation......38

Figure 4-3 Circle jet velocity field and plume construction.......................41

Figure 4-4. Extended curves of vertical dispersion coefficient from P-G Model.........43

Figure 4-5. Extended curves of vertical dispersion coefficient from Klug model........44

Figure 4-6. Extrapolated Pasquill- Gifford curve for the y-axis dispersion coefficient...46

Figure 4-7 Modified Pasquill- Gifford curves for the z-axis dispersion coefficient.....47

Figure 4-8. Model estimation of relative concentration on the plume centerline..........53

Figure 4-9. Model estimation of dilution ratio on the plume centerline................54

Figure 4-10. Relative concentration profiles along positive vertical axis...............55

Figure 4-11. Relative concentration profiles along negative vertical axis..............56

Figure 4-12. Concentration profile of leeward area, the new model vs. tests............57

Figure 4-13. Plume centerline and plume rise tests...........................58

Figure 5-1 Comparison for cumulative frequency fit $\&$ frequency fit of ideal data......72

Figure 5-2. Fit lines on log-probability paper of the real sample data................73

Figure 5-3. Comparison for cumulative frequency fit $\&$ frequency fit of sample data....74

Figure 5-4. Bi-modal fit curves on the log-probability scale paper of sample data.......75

Figure 5-5. Bi-modal fit curves on the semi-log scale paper of sample data.............76

Figure 5-6. Tri-modal fit curves on the semi-log scale paper of sample data............77

Figure 5-7 Comparison of Mass Emission Rates of Eight Vehicles...................83

Figure 5-8 Particle Size Distribution of Bus 910X-D1 (1) $\ldots \ldots \ldots \ldots \ldots \ldots \ldots \ldots \ldots \ldots \ldots$ 
Figure 5-9 Particle Size Distribution of Bus 910X-D1 (2).......................... 87

Figure 5-10 Particle Size Distribution of Bus 9848-D1 (1) .........................88

Figure 5-11 Particle Size Distribution of Bus 910X-D1 (2) .........................89

Figure 5-12 Particle Size Distribution of Bus 6001 CNG...........................90

Figure 5-13 Particle Size Distribution of Bus 6000 CNG............................91

Figure 6-1. Mass Flow Controller Based Dilution Systems .........................93

Figure 6-2. Two-stage Ejector Based Dilution System..........................94

Figure 6-3 Steady state test: Particle Size Distribution, 45mph................... 105

Figure 6-4 Steady state test: Particle Size Distribution, 50mph...................106

Figure 6-5 Steady state test: Particle Size Distribution, DPX, 45mph................107

Figure 6-6 Steady state test: Particle Size Distribution, J-M CRT, 30mph............108

Figure 6-7. Transient Test: $2 * 5$ miles J-M CRT ...............................114

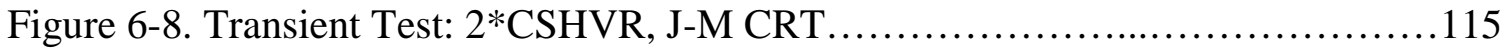

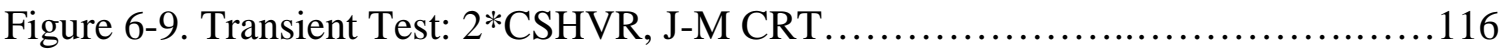

Figure 6-10. Transient Test: $2 *$ CSHVR, J-M CRT .............................117

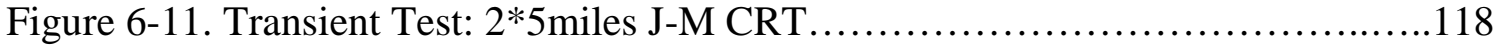

Figure 6-12. Transient Test: CSHVR, No After-treatment Device ....................119

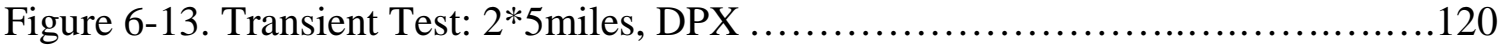

Figure 6-14. Transient Test: $2 * 5$ miles, DPX................................ 121

Figure 6-15. Transient Test : CSHVR, No After-treatment Device .................122

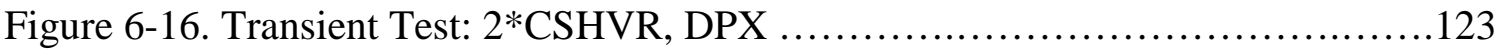

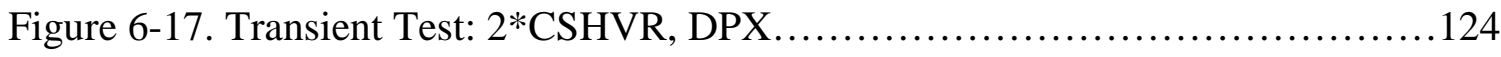

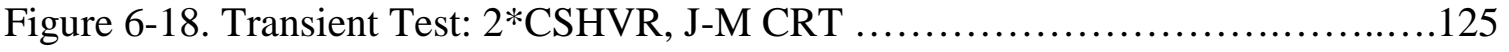




\section{NOMENCLATURE}

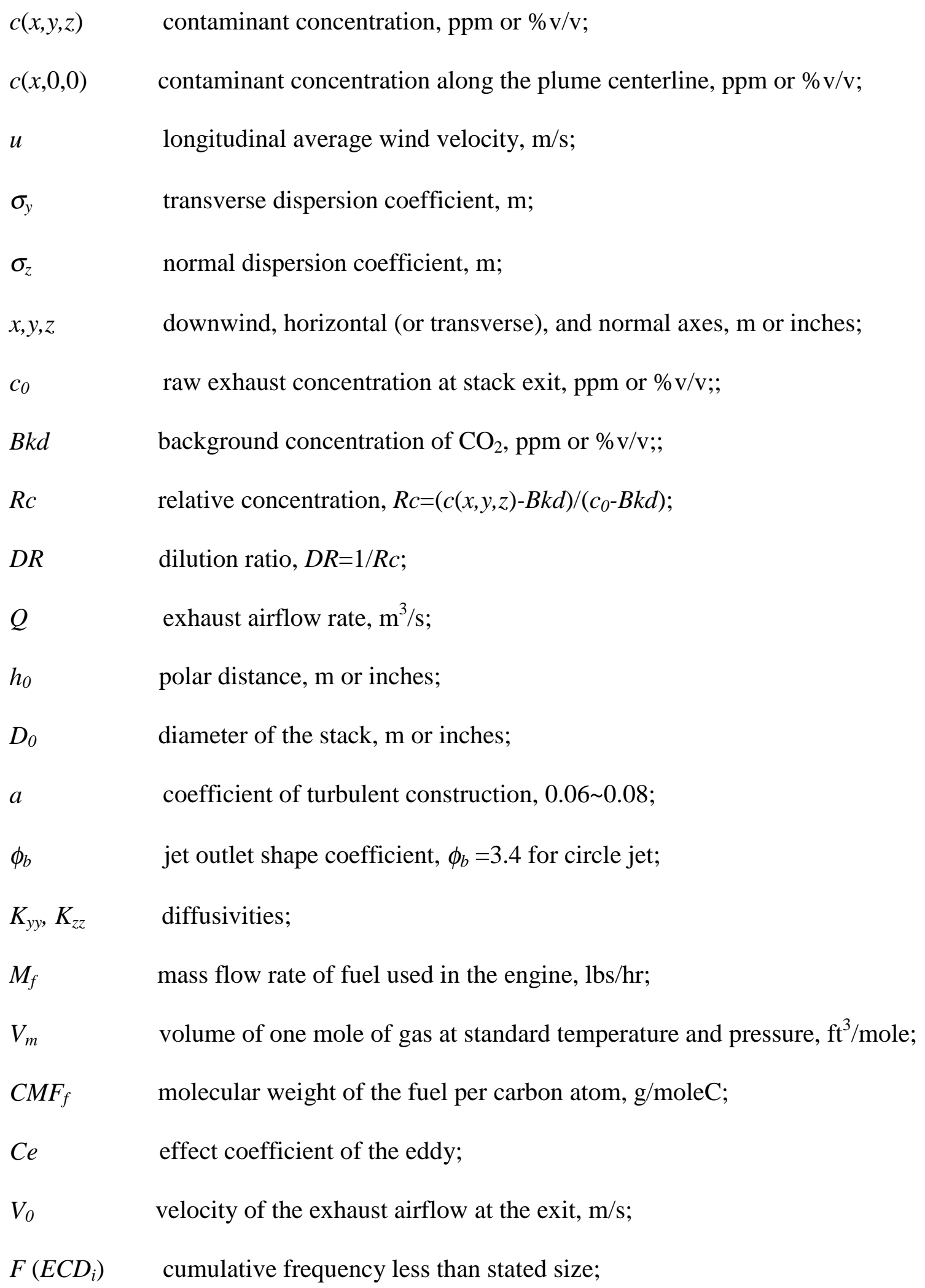




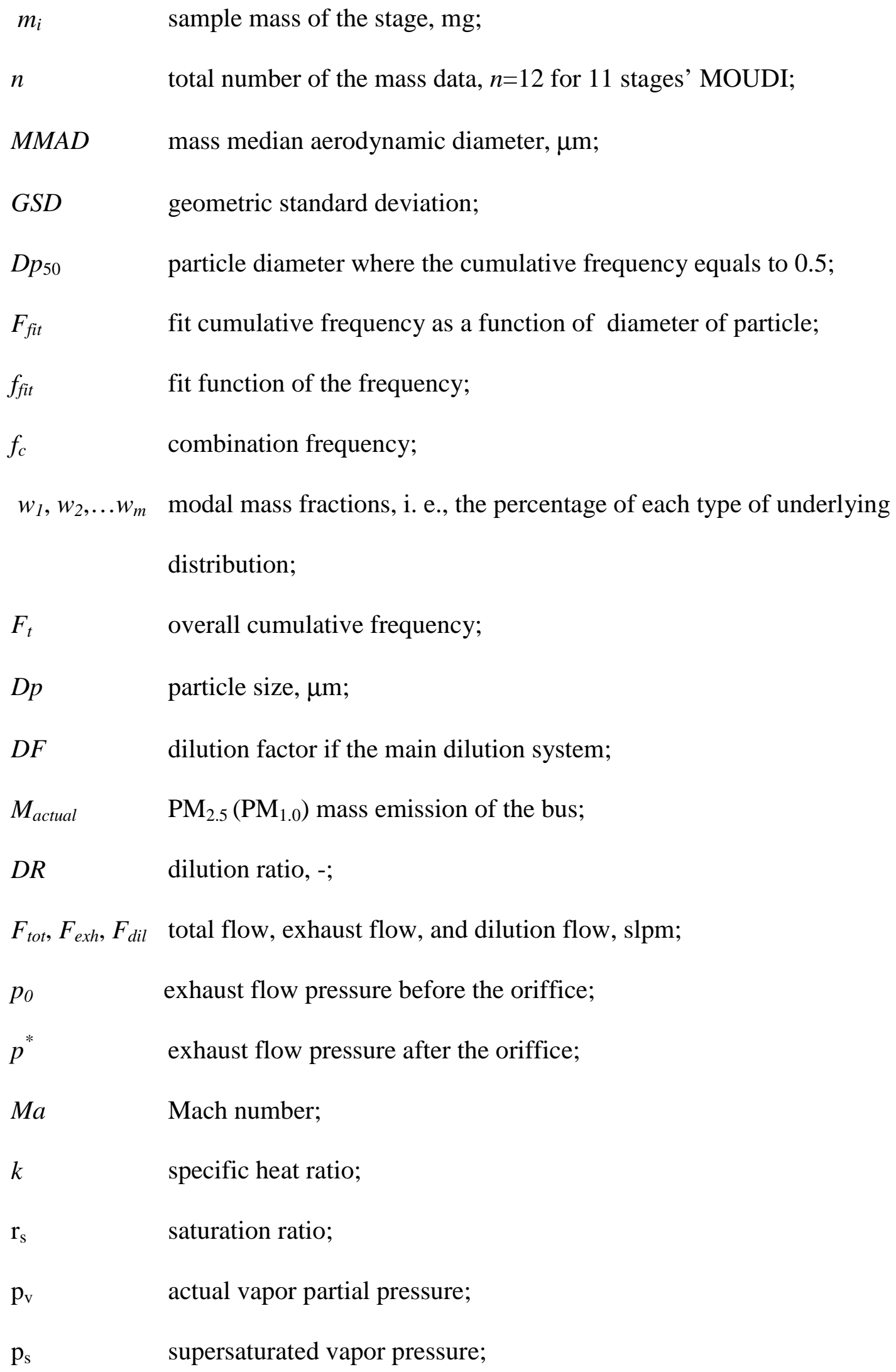




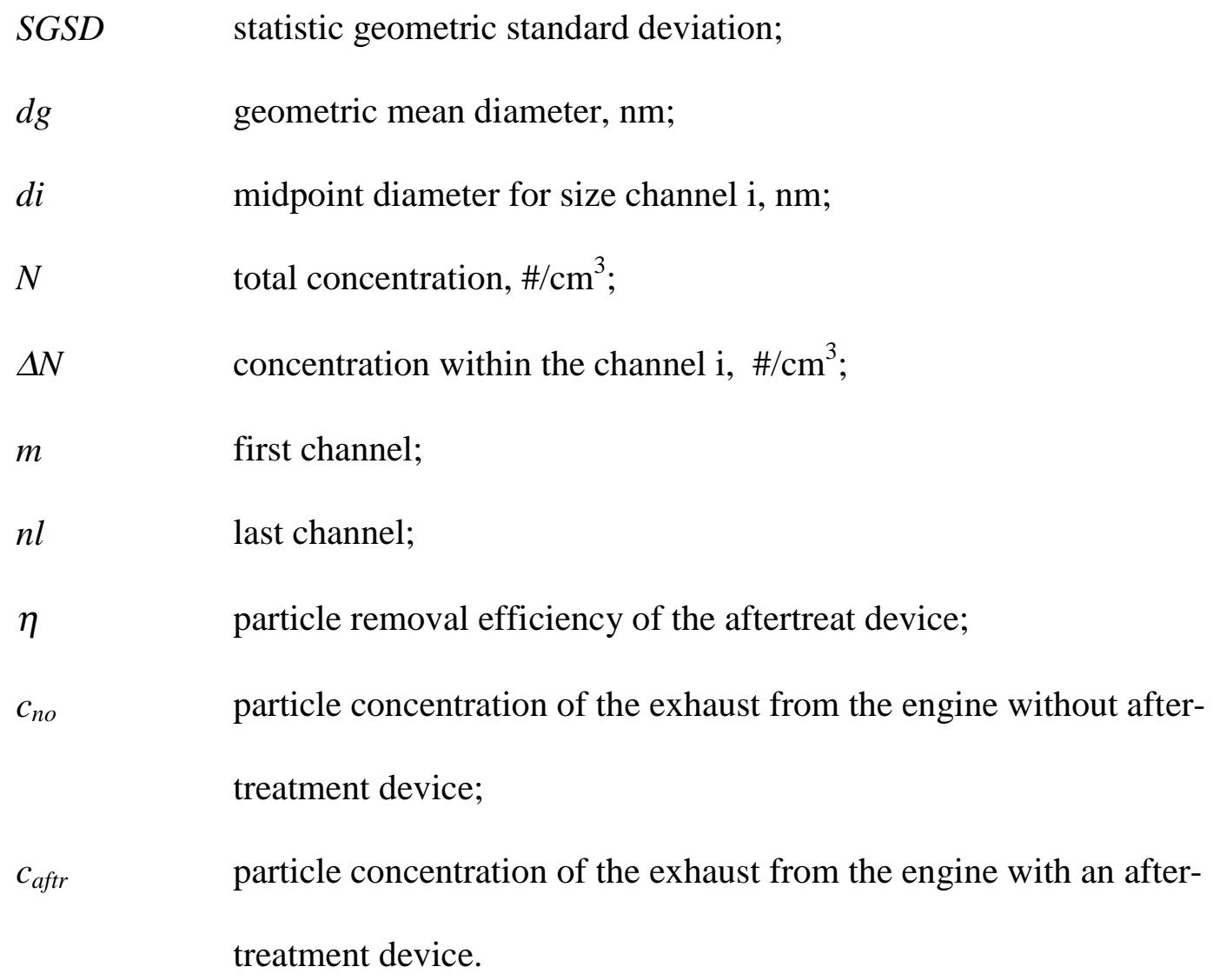




\section{Chapter 1 INTRODUCTION}

In the past two decades, industry and the government have focused their attention on understanding and controlling the amount of particulate matter that is emitted from mobile sources. Heavy-duty vehicles (HDV) represent the majority of the on-road dieselengine population. Recently, the focus has shifted from smoke opacity measurement to making detailed analyses of HDV's exhaust. Prior to that, the main concern was the thick black plumes emitted from tailpipes of vehicles.

General problems and issues associated with HDV exhaust emissions are: (1) the total particulate matter (PM) mass that is generated from the vehicles; (2) the size distribution and concentrations of these particles; (3) the ultimate fate of these particles after they are discharged from the exhaust pipe; (4) the particle transformation process after discharge, and (5) the chemical and physical characteristics of these particles.

Diesel is the common fuel choice for heavy-duty vehicles due to its thermal efficiency, availability and cost. However, diesel fuel combustion has shown to produce the largest amount of PM mass compared to gasoline and alternative fuels. PM mass emissions from natural gas fueled vehicles are nearly an order of magnitude lower than those from diesel fueled vehicles. Today, major efforts are being devoted to comparison of current federal diesel no. 2 with California Air Resources Board (CARB) certification diesel fuel, Fischer-Tropsch diesel, BP-ARCO's ultra low sulfur emission control diesel (ECD with less than 7 ppm sulfur, and ECD-1 with less than 15 ppm sulfur). Emissions from standard diesel-fueled vehicles are also being compared to emissions from hybrid diesel vehicles and natural gas vehicles. Of particular importance are the particulate matter emissions. Not only total PM mass emissions, but also size-selective PM 
emissions are being investigated, such as $\mathrm{PM}_{10}, \mathrm{PM}_{2.5}, \mathrm{PM}_{1.0}$, size distributions; also concentrations of PM, and chemical composition of the size selective PM emission samples are being determined. $\left(\mathrm{PM}_{10}\right.$ sampling is a sample method that collects the particles whose diameters are less than $10 \mu \mathrm{m}, \mathrm{PM}_{2.5}$ less than $2.5 \mu \mathrm{m}$, and so on.)

In an effort to reduce PM emissions from heavy duty diesel vehicles, exhaust aftertreatment devices are being employed. The Engelhard DPX and The JohnsonMatthey CRT are two after-treatment devices used on diesel powered vehicles. The two systems also have the most potential for long-term successes. The question is how well will these devices perform and for how long in field operation.

While emissions from vehicles can be analyzed over a wide range of regulated emissions, the major challenge is our need to know the ultimate fate of the particles in the vehicles exhaust plume, both "young" (few milliseconds after discharge) and dispersing plume. A large number of previous studies have focused on plumes from industrial stacks. However, very little work has been done on HDV exhaust plumes.

In order to solve the special problems mentioned above, appropriate laboratory, equipment, and analysis systems are needed. The Department of Mechanical and Aerospace Engineering at West Virginia University (WVU) has designed and built two Transportable Heavy Duty Vehicle Emissions Test Laboratories (THDVETL) that have been in operation for over ten years. These laboratories are capable of measuring both regulated and non-regulated PM size distributions and concentrations from HDV with Gross Vehicle Weight (GVW) as high as 80,000 lb (35,200 kg).

This study will pass on PM emissions from HD vehicles. The instrumentation used for the PM concentration and size distribution studies were $\mathrm{PM}_{2.5}$ and $\mathrm{PM}_{1.0}$ cyclone 
separators, a Micro-Orifice Uniform Deposit Impactor (MOUDI) and a Scanning Mobility Particle Sizer (SMPS). The SMPS consists of an electrostatic classifier in conjunction with a Condensation Particle Counter (CPC). These instruments operate on different principles and classification techniques. They are extensively used by the research community that is studying exhaust PM emissions. These instruments were chosen for several PM sizing programs in the WVU testing laboratory.

This investigation involved PM emission measurements from HDV's in three different locations in the country. Studies discussed in this report are:

(1) interrogation of the plume of a HDV in a series of emission measurements conducted to investigate the PM analyses of HDVs in the NASA's Langley wind tunnel, (2) PM size distribution and concentrations in the exhaust of eight HD buses operated in Boston on diesel, “clean diesel”, and natural gas, including a hybrid bus, and

(3) PM size distribution and concentration measurements in the exhaust of HD trucks equipped with catalyzed traps operated on CARB certified diesel (without traps) and ARCO's ECD, in Riverside, CA.

The theoretical analysis is primarily plume concentration field prediction equations (including dispersion coefficients for the area near the stack ), a cumulative frequency fitting method (program), and identification of the stability and reliability of the exhaust dilution methods.

Chapter 2 discusses previous research performed in related areas. This includes the applications and limitations of Gaussian plume equations, frequency-fit method for multi-modal size distributions of PM, and the characterization of two different types of exhaust dilution methods (namely, ejector based, and "mass flow controller based). 
Chapter 3 describes the experimental procedures used as well as the operating principles of the instrumentation used in this study. Chapter 4 discusses the results of the nearsource dispersion of the exhaust plume of a tractor truck. Chapter 5 discusses the PM sizing results of buses, in Boston, powered by clean diesel fuel, convention diesel fuel, hybrid fuels and compressed natural gas. Chapter 6 presents the results of nano-particle distributions in the exhaust of trucks in Riverside, CA. Finally, Chapter 7 presents the conclusions and offers recommendations for modifications to testing procedures for future research. 


\section{Chapter 2 LITERATURE REVIEW}

\subsection{Introduction}

This chapter reviews the published literature on size- selective PM measurements, PM size distribution and concentration of combustion generated PM, state-of-the-art PM size and mass measurement instrumentation and techniques, PM size and mass data reduction techniques, and Gaussian plume models.

The concentration field of a species emitted from a stack may be predicted by Gaussian plume equation, Lagrangian particle model, and Computational Fluid Dynamics simulation. Most investigations that employ the Gaussian plume predictor focused on long-distance applications where downwind distances were 100 100,000 meters from industrial stacks.

For the particulate matter size-selective measurement, the most widely used instruments are the Micro-orifice Uniform Deposit Impactor (MOUDI), Electrical Aerosol Analyzer (EEA), Scanning Mobility Particle Sizer (SMPS) and Electrical Low Pressure Impactor (ELPI). PM sampling with cyclones allows investigation of certain ranges size-selective $\mathrm{PM}\left(\mathrm{PM}_{10}, \mathrm{PM}_{2.5}, \mathrm{PM}_{1.0}\right)$. Several studies reported in published literature employed a combination of these devices for the measurement of exhaust emissions from heavy-duty vehicles.

Several data reduction techniques for mass-based size-selective PM impactors are available in published literature (William, 1980; Hinds, 1986; Burkhart, 1987; Marple, 1991). A frequency distribution plot was recommended for determining if a mixed distribution is present ( Marple, 1991; Hinds, 1986; Burkhart, 1987). A microcomputer spreadsheet program was developed to fit a smooth curve to a frequency histogram and to 
generate estimates of the multi-modal parameters (Hewett et al, 1991). However, there has been little attention paid to analyzing the difference between this algorithm and the cumulative frequency fit method that was derived directly from the definition of the main estimate parameter, the Mass Median Aerodynamic Diameter (MMAD). The MMAD is the particle's diameter at cumulative frequency of 0.5 .

It has been reported (Gautam et al., 1999) that on a mass basis natural gas vehicles emit an order of magnitude lower PM than the diesel powered vehicles emit. On a number count basis, the PM emission from natural gas vehicles was either an order of magnitude higher or nearly equal to the PM emissions from diesel powered vehicles. It was suspected that high levels of moisture in the natural gas exhaust might be contributing to the high nano-particle concentrations. However, Gautam et al. (1999) suggested the PM emissions from NG vehicles may have their origins in the lube oil. They also noted that water based nano-particle emissions were primarily less than $20 \mathrm{~nm}$, but NGV PM emissions had a CMD of approximately 30-40 nm.

\subsection{Plume Concentration Predictor and Dispersion Coefficients}

A wealth of information on Gaussian plume predictors is available in the published literature (Seinfeld, 1986). The mean concentration of a species emitted from a stack may be described by the Gaussian plume equation, and by using the experimental dispersion coefficient graphs and empirical equations (Turner, 1969; Martin, 1976; ASME, 1973; Klug, 1969). It should be noted these dispersion coefficients and equations are applicable in a large range of downwind distances from the source of 100 to 100,000 meters. Published literature also exists covering topics pertaining ground surface 
reflection, the effect of the stack height, the plume rise, and so on. Another plume model that has been used is the Lagrangian particle model (Peter et al, 1993). In this model a plume rise formulation is used to calculate the final rise height. The model allows the release of particles from computed heights and subsequently allows them to be dispersed by ambient winds and turbulence.

Several studies were concerned with dispersion predictors in the area near the stacks, because there exists a void in the available dispersion coefficients. Huber (1991) contributed a study determining the dispersion coefficients in wind tunnel experiments, and the relationship between these dispersion coefficients and downwind distances, both with and without the presence of several building configurations. The dispersion coefficients with downwind distances from the stack greater than 50 meters were reported. Profiles of mean velocity and turbulence were measured to characterize the flow. The study covered a range of four flow speeds and four different sized buildings. Measurement methods used in plume dispersion studies include rapid scanning lidar that obtained the plume profiles (Bennett, 1992), and an infrared video camera and recording system which recorded near-source plume rises from a low turbine stack (Rickel et al., 1990). This system provided a real-time, continuous visualization of plume dispersion using a color monitor while the images were recorded with a standard video tape recorder.

Computational fluid dynamics (CFD) techniques have been used to simulate the plume flow field and concentration field. Large-eddy simulation of a turbulent reacting plume is an example of CFD application to plume studies (Sykes et al., 1992). CFD techniques are powerful mathmatical tools for simulating complex flow fields. 
The prediction of plume dispersion still needs further investigations. Due to stack geometries, the exit of a stack is no longer considered as the dispersion point for nearfield plume studies, although it certainly represents the point source for the far-field plume modeling. One related study was on the flow field from jet streams, in which the relationship between the actual flow exit and the imaginary source was found (Jeriee, 1960, see Wang 1994). With the determination of this relationship, jet stream flow field, near the exit was subsequently characterized by the theoretical formula. The jet concentration field may also be modeled theoretically because of the similarity between the transfer of momentum and mass.

\subsection{PM Size Distribution Data Reduction Method}

A typical method of analyzing data, in particular the MOUDI data involves plotting the cumulative mass (or count) data on log-probit/probability paper and estimating the mass mean aerodynamic diameter $(M M A D)$ and geometric standard deviation $(G S D)$ from a straight line fitted through the data points (William, 1980). This method is not valid for a multi-modal distribution, which is actually composed of several lognormal distributions (Hinds, 1986; Marple et al, 1991). A frequency distribution plot was put forward for determining whether a mixed distribution was present ( Marple, 1991; Hinds, 1986; Burkhart, 1987). The standard procedure for plotting a mass or count frequency distribution may be found in several aerosol references (Reist, 1984). The available literature includes descriptions of the "inversion" problem, that is, the problem of starting with grouped data and estimating the distribution from which it was derived (Crump, 1982). Furthermore, a microcomputer spreadsheet program was developed to fit 
a smooth curve to a multi-modal histogram and to generate estimates of the multi-modal parameters (Hewett et al, 1991). However, little attention has been paid to analyzing the difference between the cumulative frequency fit and the frequency fit and determining which of these methods produces a more accurate estimate.

\subsection{Mini Dilution Tunnels for The Scanning Mobility Particle Seizer (SMPS)}

The Swiss Federal Material Testing Labs developed a dilution system called AVL Model 472, for conditioning vehicle exhaust, so that PM size distributions and concentrations could be measured with a SMPS. The system includes a vacuum pump and a compressor for drawing and mixing the exhaust with filtered dilution air (Mayer et al., 1995).

A mass flow controller based dilution tunnel has been used in WVU Transportable Laboratory (Gautam et al., 2000). In this system the tunnel pressures remain close to atmospheric at all times, and yet the mixing is still very efficient. A major drawback is that the dilution ratios are limited to 1:40. Beyond this value, the uncertainties in dilution ratios become very large.

Graskow et al. (1998) described a two-stage ejector based dilution system, in which a compressor and an ejector pump were used to mix the exhaust with dilution air for each stage.

\subsection{Analysis of PM from Heavy Duty Vehicles.}

Combustion generated PM begins to change in size and nature immediately upon exiting the combustion chamber. These particles may grow by condensation, coagulation 
and adsorption, shrink by evaporation and desorption, or additional PM may form by nucleation. Once the particles have been exhausted from the tailpipe to the ambient air of a dilution tunnel, these processes may all occur, thereby altering the original state of the PM emissions. Temperature, saturation ratios, engine design and residence time all affect particle size (Byers, 1999).

Kittelson et al. (1998) found that a majority of particulate mass from diesel engines in the accumulation mode in the size range of 0.05 to 1.0 micrometers. The nuclei mode generally consists of 5 to $50 \mathrm{~nm}$ mobility equivalent diameter particles. The nuclei mode contains only $1 \sim 20 \%$ of the total particle mass, but represents more than $90 \%$ of the number count. The coarse mode is defined as everything beyond the accumulation mode and contains 5 20\% of particle mass.

For diesel powered engines, the exhaust aerosol is largely made up of agglomerated solid carbonaceous material and ash, as well as volatile organics and sulfur compounds (Kittelson et al., 1998). While the quantities of these organic species vary with fuel sulfur content and additives, the formation process remains largely unchanged. The solid carbon, generally referred to as soot, is formed during the combustion process in areas where the fuel spray is not leaned out until considerable cooling of the gases takes place during expansion (Ferguson, 1986). The organic content develops from any process that causes hydrocarbon formation and their partial oxidation products. A portion of the fuel and lube oil does not undergo complete oxidation and appears as volatile or soluble organic compounds (Kittelson et al., 1998).

Nucleation, when new particles form from gaseous organic and inorganic species, is the mechanism for formation of measured nuclei mode particles in exhaust aerosols 
(Kittelson et al., 1998). These particles are comprised primarily of volatile materials and are greatly affected by saturation conditions. If the saturation ratio, defined as the partial pressure of the gaseous organic species divided by the saturation pressure of the total species, is sufficiently high, the new particles will form. If the saturation leveis drop, the volatiles will evaporate back into their previous gaseous state (Baumgard, 1988).

Nucleation and adsorption are inversely related gas-to-particle conversion processes. Adsorption retards nucleation. The large surface area available on carbonaceous agglomerates provides a substrate for adsorption to occur. For older engines, the soluble organic fraction (SOF) in the exhaust will adsorb on the additional surface area of carbon cores created during combustion. This will prevent the saturation levels from reaching the point where nucleation can occur (Kreso et al., 1998). Conversely, with improved fuel atomization by high-pressure injectors in newer engines these carbon cores are decreased in size and surface area. The surface area available may not be sufficient to adsorb the organic species; therefore, nucleation will occur instead and the number of nuclei-mode particles will increase.

Based upon the available data, current understanding is that, 1) under certain conditions, the homogeneous and heterogeneous nucleation may increase the number of small particles; 2) atomization by high-pressure injectors may also increase the small particles; 3) sulfuric acid and heavy-organics are pre-cursors for nucleation, and 4) not only dilution conditions (such as dilution ratios, rates of dilution, dilution air temperature, residence time) bear an impact of nano-particle formation, but also the type of dilution system used can impact PM distribution and concentrations. When a dilution method is evaluated, these factors should be considered. 


\subsection{After-treatment Devices for Diesel Engines}

Recent heavy-duty diesel emission control efforts have focused on filters, SCR, and to a certain extent, non-thermal plasma techniques. Significant tightening of the heavy-duty regulations will probably not occur until 2007-08, so feasible emission control technologies need to be evaluated in the context of projected engine-out emissions (Johnson, 2000). Nearly seven years before implementation of the "Euro V" 2007 heavy-duty diesel regulations, two integrated SCR/filter systems have already met the standard in dynamometer testing on 1998 vintage engines. The challenge from here on will be cost and size reduction. The US2007 proposed regulations are significantly more challenging. However, if today's engines make it to commercialization with no improvements in emission levels, the targets appear achievable with at least filters and SCR technology.

Because of the limitations inherent in engine dynamometer testing (Eastlake, 1999), real- world emission testing of heavy-duty vehicles is becoming necessary. The WVU Transportable Heavy Duty Vehicle Emissions Testing Laboratories have been in the forefront of in-use emissions measurement alternatives. Other real-world emission testing systems were also reported (Mayer, 1995; Kittelson, 1998). The next chapter details the laboratory, equipment, and test procedures that were employed in this study. 


\section{Chapter 3 EXPERIMENTAL EQUIPMENT AND PROCEDURE}

\subsection{WVU Transportable Heavy Duty Vehicle Emissions Testing Laboratory}

The Department of Mechanical and Aerospace Engineering at West Virginia University is currently operating two Transportable Heavy Duty Vehicle Emissions Testing Laboratories. West Virginia University, working with the U.S. Department of Energy and the Office of Transportation Technologies, has designed and constructed these laboratories to monitor engine performance and to test the emissions from heavyduty vehicles operating on conventional and alternative fuels. Because the laboratory can be moved easily from one site to another, the vehicles can be tested at site where they are located and operated, thus minimizing their time out of service.

\subsubsection{Description of the Laboratory}

Each of the two transportable laboratories consists of three vehicle combinations when moved from site to site. A tractor-trailer of 70,000 lb. $(32,000 \mathrm{~kg})$ gross vehicle weight carries the dynamometer while the emissions trailer and the straight truck gross at approximately 45,000 lb. $(20,500 \mathrm{~kg})$. A crew vehicle towing a mobile workshop accompanies these trucks. The dynamometer and emissions trailers are separately described in more detail below.

Most chassis dynamometers are based on rolling road dynamometers and have twin rolls. Chassis dynamometer testing requires the simulation of a standard driving cycle, to a certain degree of accuracy, and the measurement of mass emissions rates of regulated (and unregulated) pollutants. Power is absorbed from the set of rolls upon 
which a vehicle, secured to the test bed frame, is "driven". One of the major limitations of small roller diameter is the tire contact condition, which is very different from that found between the vehicle and the road. Additionally, tire-roller slippage leads to errors in speed data, and internally generated heat can result in tire damage. In the WVU laboratories, four small diameter (12.5 inch, $490 \mathrm{~mm}$ ) rollers support the drive axle, but power is taken from the vehicle by substituting a hub adapter place for the outer wheel, of a dual wheel pair, and connecting this plate to the absorbers via a drive shaft. Each pair of rollers on the same axis is linked with shafts and a coupling so that the speed is the same at the wheels on each side of the vehicle. Further rollers are located aft on the deck to support the rear of a tandem set (when required).

The remainder of the dynamometer is largely symmetrical on each side of the vehicle being tested. Drive shafts and hub adapters are chosen to suit the wheel rim style and vehicle width. Each drive shaft supplies power to a set of flywheels and a power absorber through a 200,000 lb-in. (22,600 Nm) Eaton torque transducer and two transmissions. Driveline speeds are typically $10 \mathrm{rpm}$ per $1 \mathrm{mph}(6 \mathrm{rpm}$ per $1 \mathrm{~km} / \mathrm{hr}$ ), but, naturally, depend upon tire size.

The flywheels must be capable of simulating the inertia of the vehicle as closely as possible. Each set consists of four disks (“drivers") permanently driven by the flywheel shaft, with eight flywheels of varying sizes run in tandem on bearings on the shaft. These flywheels may be attached to the drivers with special fasteners or held still to the flywheel set casing. For a typical tire size of 42 inches $(1.07 \mathrm{~m})$, the flywheels can mimic a test vehicle weight of up to $50,000 \mathrm{lb}(22,000 \mathrm{~kg})$ in approximately $250 \mathrm{lb}$ increments. Additional inertia for acceleration load can be simulated using the power 
absorbers. For example, at acceleration rates of $1 \mathrm{mph} / \mathrm{sec}$. (typical of heavy-duty trucks), the flywheels and absorbers combined can simulate a maximum inertia equivalent to a vehicle weight of over $80,000 \mathrm{lb}(35,200 \mathrm{~kg})$. All vehicle weight classes can therefore be characterized. The flywheels rotate at 3.65 times the hub speed. The absorbers are Mustang air-cooled eddy current power absorbers; each rated at $300 \mathrm{hp}$ $(225 \mathrm{~kW})$ continuous load and over $1000 \mathrm{hp}(750 \mathrm{~kW})$ peak load.

Resisting torque at the power absorbers is controlled by varying current to the absorber coils, and this torque is measured using an arm and load cell of $500 \mathrm{lb}$. (220 kg) or $1000 \mathrm{lb}$. (440 kg) rating. This load cell is calibrated using a set of weights. Shaft encoders monitor the speed of both absorber shafts and rollers beneath the wheels of the tested vehicle. In addition the Eaton torque cells also provide rotational speed information. Speed encoders are calibrated using frequency generators.

The whole chassis dynamometer is transported as a $31 \mathrm{ft} .(9.5 \mathrm{~m})$ semi-trailer. Upon arrival at a site, the tractor and rear tandem dolly are removed from beneath the trailer bed, which is then lowered to the ground using four hydraulic cylinders. In this way the chassis dynamometer rollers are only 13 inches $(0.33 \mathrm{~m})$ above the ground, and the vehicle to be tested can be driven onto the rollers using ramps. The tested vehicle is then leveled, by placing pedestals under the front wheels, and chained down to the dynamometer bed for testing. Protocols have been developed to ensure reproducible tire loading.

The exhaust from the test vehicle is ducted to a total exhaust critical flow venturiconstant volume sampler (CFV-CVS). The exhaust is diluted with ambient air in the primary dilution tunnel and further diluted in the secondary tunnel to ensure a filter face 
temperature of less than $125^{\circ} \mathrm{F}$ to comply with the CFR 40, Part 86, and Subpart $\mathrm{N}$ for particulate sampling. The emissions sampling system is akin to that used for heavy duty engine certification. The diluted exhaust is drawn through the primary tunnel by a $75 \mathrm{hp}$ blower. Annular variable area critical flow venturis (CFV), each with a design sonic flow rate of up to $2000 \mathrm{scfm}$, control the rate of flow through the tunnel. A differential pressure gauge and switch, between the throat and a point downstream of the throat, indicates choked conditions in the venturi. The required overall flow rate at this full flow tunnel is based upon the displacement of the engine being tested and upon the detectable concentrations of the measured species in the sampling zone of the primary tunnel.

The diluted exhaust is sampled and analyzed following the procedures outlined in the CFR 40, Part 86, and Subpart N. For each laboratory, the emissions and control equipment is installed in a 22 foot $(6.6 \mathrm{~m})$ length box trailer that is towed by a flatbed trailer. A $7 \mathrm{~m}$ long, $0.457 \mathrm{~m}$ diameter dilution tunnel is mounted on top of this instrumentation trailer. Gaseous samples are drawn 10 diameters downstream of the exhaust injection zone to allow for thorough mixing in the turbulent duct flow. Four temperature controlled stainless steel probes and lines (one each for carbon monoxide/carbon dioxide $\left(\mathrm{CO} / \mathrm{CO}_{2}\right)$, oxides of nitrogen $\left(\mathrm{NO}_{\mathrm{x}}\right)$, total hydrocarbons $(\mathrm{THC})$ and methanol/formaldehyde), are used to bring the dilute exhaust sample from the tunnel to the analyzers inside the instrumentation trailer. The THC probe and line are maintained at $375^{\circ} \mathrm{F}$ while the $\mathrm{HCHO} / \mathrm{CH}_{3} \mathrm{OH}$ sampling train is heated to $235^{\circ} \mathrm{F}$. All the other lines are maintained at $250^{\circ} \mathrm{F}$ to avoid condensation of moisture in the system.

The regulated emissions are measured on-line using commercially available gas analyzers manufactured by Rosemount Analytical. The $\mathrm{CO}$ (low and high) and the $\mathrm{CO}_{2}$ 
measurements are made using non-depressive infrared detectors (NDIR, Rosemount Model 868). The sample is passed through a refrigerator/dryer before it reaches the NDIR detectors. The heated $\mathrm{NO}_{\mathrm{x}}$ analyzer is a chemiluminescent type (Rosemount Model 955) while the hydrocarbon measurements are made with a heated flame ionization detector (Rosemount Model 402). The mass emissions rates of the gaseous species are determined from the integrated sample concentration and the flow over the test period. The results are corrected for temperature and relative humidity. In addition to continuous emissions analysis for $\mathrm{CO}_{2}, \mathrm{CO}, \mathrm{NO}_{\mathrm{x}}$, and $\mathrm{HC}$, background air and dilute exhaust are collected in separate Tedlar bags and the integrated sample is analyzed after each test. The mass emission rates are corrected for background using the background bag results. The dilute sample bag serves only as a quality control/quality assurance check that provides a method of comparing the results with the continuous sample. Typically, dilute bags are most reliable in verifying $\mathrm{CO}$ and $\mathrm{CO}_{2}$ levels.

Total particulate matter for gravimetric analysis is collected using the double dilution method. A proportional sample of the diluted exhaust is drawn from the primary tunnel and further diluted in the secondary dilution tunnel to achieve a filter face temperature of $51.6^{\circ} \mathrm{C}\left(125^{\circ} \mathrm{F}\right)$. The proportional sample is drawn over a $70-\mathrm{mm}$ fluorocarbon coated glass fiber filters using a computer controlled mass flow controller. The filters are conditioned and weighed before and after the test is performed in an onboard microprocessor controlled environmental chamber. The chamber is maintained at $70^{\circ} \mathrm{F}$ and $50 \%$ relative humidity. A CAHN 32 microbalance with a sensitivity of 0.001 mg is used to weigh the conditioned filters inside the shock mounted environmental chamber. 
Dedicated computers are also housed in the trailer, and used for control and data logging functions. During a test, speeds, torques, load cell readings, gas concentrations, tunnel temperatures and pressures must be logged. Rack mounted signal conditioners and analog-to-digital conversion boards in the computer implement this function. The computer system also provides the time-varying desired torque set point to Dyn-Loc current controllers that control the power absorbers in closed-loop mode and provide the desired speed set point. This required vehicle input is transmitted to a screen placed in front of the tested vehicle's driver. Data recorded during a test, together with data entered on the vehicle, are interpreted by the computer software to yield a test report. The laboratories have demonstrated the capability to run a wide variety of test cycles, and new cycles are entered readily as a speed-time data set.

\subsubsection{Test Methods and Calibrations}

Once the laboratory arrives at the test site it requires two days before vehicle testing can commence. The test site space requirements for the laboratory are $60^{\prime} \mathrm{x} 80^{\prime}$. The surface should be capable of supporting the weight of the dynamometer bed $(55,000$ lbs) and the test vehicle. The preparation involves setting up the chassis dynamometer test bed, emissions trailer, and power generation units with electric cables, CVS blower and connections from the blower/CFV to the dilution tunnel.

The analyzers, environmental chamber, computers and zero-air generator are powered and the relevant systems are allowed to stabilize. The analyzers are calibrated each time the laboratory is set up at a test site by drawing up new calibration curves. The calibrations are carried in accordance with the CFR 40, Part 86, Subpart N. The bulk of 
the set-up time is needed for calibration of all transducers and for emissions measurement analyzer warm-up, stabilization and calibrations.

\subsubsection{Vehicle Documentation and Inspection}

The test vehicle is delivered to the WVU Transportable Laboratory before the testing date. Upon receipt of the vehicle, a pre-test vehicle data sheet is filled out with the following information: vehicle identification number, GVW, model year, manufacturer, mileage (hub and odometer), engine details, vehicle frontal area, tire size, the number of axles and tires and catalytic converter system details (manufacturer, model, year, and non-proprietary information on catalyst type).

The laboratory staff conducts visual and functional inspection of the vehicle to ensure that the vehicle condition does not pose any mechanical or safety hazards during testing. The laboratory staff then checks for engine oil, power steering fluid and coolant levels, check signs of fuel, oil and coolant leaks, check air cleaner for blockage and visually check the exhaust after-treatment devices. The staff also conducts a visual inspection of the condition of wheels and tires (for any cuts and bulges). The vehicle is test driven on a flat ground to check the response of the engine, transmission and brakes.

\subsubsection{Vehicle Preparation, Mounting and Pre-Conditioning}

The vehicle is weighed using wheel scales. The outer dual wheel from the forward-most drive axle of the test vehicle is removed and hub adaptors (test rims) will be installed. When a tandem axle vehicle is tested, power is taken from the forward rears 
and the interaxle power divider is locked. The tires are inflated to the manufacturer's specifications.

The vehicle is then backed up a ramp until the drive axle is centered over the idler rollers. Once in place and level, the vehicle is mounted on the dynamometer and chained down to the chassis dynamometer for security. An equivalent inertia is selected by fixing the appropriate combination of the eight attachable-detachable flywheels to the four permanently fixed flywheels of the chassis dynamometer's inertia system. The exhaust pipe of the test vehicle is connected to the primary dilution tunnel inlet with an insulated stainless steel transfer tube. The laboratory computer system provides the driver of the vehicle with a graphic display of the speed versus time trace of the test schedule on the driver video interface. The computer system also sets the power absorbers to the prescribed torque to simulate the aerodynamic-drag and rolling resistance the test vehicle would encounter under actual operating conditions.

An only hot start is conducted on the vehicles. The actual driving cycle is monitored and the deviation from the scheduled cycle is displayed as a driving error. While the drivers used for driving the vehicles have considerable experience the driving error display helps in minimizing errors. Along with continuous emissions data, background and dilute exhaust gas bags are also collected and analyzed. Continuous torque produced by the test vehicle driving axle at the hub is measured by torque transducers, one on each side of the vehicle. Difference in torque during acceleration, deceleration, top speed, and idle time of the cycle will be monitored and displayed. Road power and chassis dynamometer drive train losses will be monitored and displayed as well. 
The pre-conditioning procedure consists of operating the vehicle through a series of warm-up cycles (generally, the same as the test cycle) in order to stabilize the dynamometer transmission system to $38^{\circ} \mathrm{C}\left(100^{\circ} \mathrm{F}\right)$ and to warm up the test vehicle fluids and lubricant. At the end of the last warm-up cycle the vehicle is shifted into neutral and is allowed to idle for seventeen minutes of the twenty-minute soak period. At the beginning of the actually test cycle, the driver applies the brakes with the vehicle in gear and waits for the system prompt to start the actual test cycle. The vehicle is operated through the specified test cycle. At the end of the test cycle, the driver shifts the transmission into neutral and the engine is allowed to idle. The vehicle goes through this second twenty-minute soak and the second test is initiated following the procedure outlined above.

\subsubsection{Cycles}

The CSHVR (City-Suburban-Highway Vehicle Route), WVU five-mile route, and triple CBD (Central Business District) were used for testing. A speed vs. time trace of the CSHVR is shown below (Figure 3-1). 


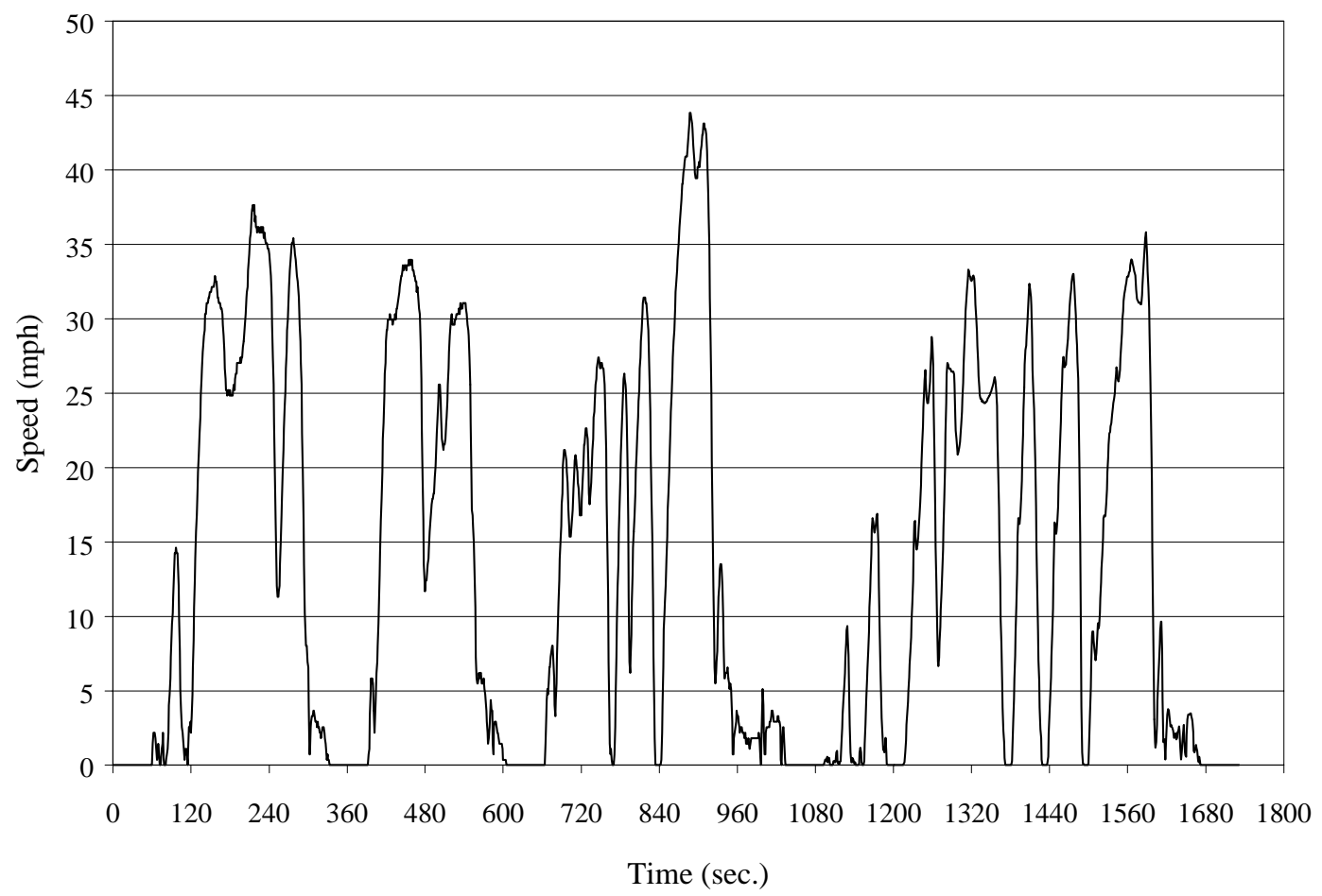

Figure 3-1 SCHVR cycle

Normally, three repeat tests are conducted on each vehicle and the average of the tests is calculated along with standard deviations and coefficient of variation. The decision to run additional repeats is made by the laboratory supervisor based on the coefficient of variance of the repeat tests. Given the low PM mass emissions from natural gas fueled vehicles, each "run" includes two back-to-back cycles. All filters and cartridges samples are collected over the two back-to-back cycles during each "run". The filters and cartridges will be changed out before the next "run" begins.

For urban buses, a Society of Automotive Engineers (SAE) Recommended Practice (J1376) provides a speed verses time schedule that consists of a Central Business District (CBD) section, an Arterial Section and a Freeway section. The CBD is composed of 14 modes ( 2 mile traveled distance) with accelerations from idle to $20 \mathrm{mph}$, 
steady state operation at $20 \mathrm{mph}$, and decelerations to idle, separated by idle periods. The Arterial Section (2 miles long), consisting of four saw tooth cycles involves a maximum speed of $40 \mathrm{mph}$ and the Commuter Section is a single mode, 4 miles long, and requires a vehicle to be accelerated up to a cruising speed of $55 \mathrm{mph}$. Perkins (1982) prescribed a speed verses time schedule that consisted of steady-state speed modes that represented an average speed typical of a delivery area. Among the synthesized cycles described so far the $\mathrm{CBD}$ route has found widespread acceptance for emissions testing of heavy-duty vehicles.

The CBD route is ideally suited to vehicles with automatic transmissions and calls for accelerations that demand a little less than full power from a typical urban bus (about $250 \mathrm{hp}, 32,000 \mathrm{lb}$ test weight). These tests have been used to assess bus fuel consumption on a flat oval driving track. The CBD test schedule has found widespread use for vehicle emissions testing in the USA and Canada. The test is commonly implemented at curb weight plus the weight of the driver and a half of the passengers with a half tank of fuel, and has been widely used in evaluations of diesel and alternatively fueled buses. It should be noted that this schedule has proven unsuitable for the testing of heavy over-the-road trucks, because they cannot keep pace with the required acceleration to $20 \mathrm{mph}$ in less than 10 seconds. The original CBD has been used successfully to test natural gas and diesel fueled garbage packers with automatic transmissions in New York City. Given the low mass emission rates of total PM from natural gas vehicles and trap equipped diesel vehicles, three CBD routes were run in a series. Hence, the name "triple CBD" for such test schedules. 


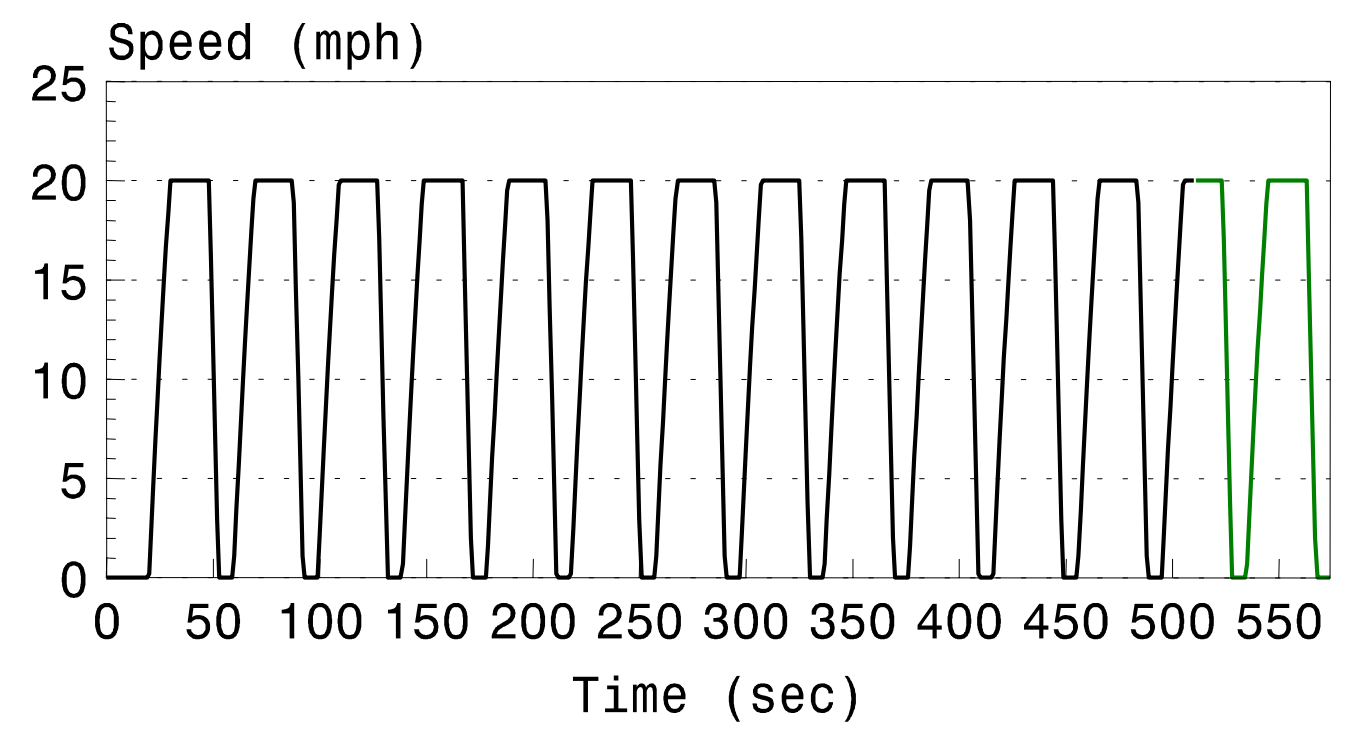

Figure 3-2 CBD route

\subsection{MOUDI and Cyclone Sample Systems}

\subsubsection{Particulate Sampling: MOUDI}

The MOUDI is a ten-stage cascade impactor that classifiers particles by their aerodynamic diameters. A cascade impactor consists of several stages with successively increasing velocities and hence, decreasing cut-sizes to remove particles in discrete size ranges (Marple and Rubow, 1986). The cut-size of an impactor stage, ${ }_{50} \mathrm{~d}_{\mathrm{ae}}$, is the aerodynamic diameter for which 50\% of the particles are removed from the air stream and collected on the collection plate (substrate) by inertial impaction. The MOUDI has a lowest ${ }_{50} \mathrm{~d}_{\mathrm{ae}}$ of $0.052 \mu \mathrm{m}$, and a highest ${ }_{50} \mathrm{~d}_{\mathrm{ae}}$ of $18 \mu \mathrm{m}$. The advantage that the MOUDI offers over other cascade impactors is its ability to collect small particles with a moderate pressure drop and uniform deposit. With these features, it is well suited to measure diluted engine exhaust particulate matter. The MOUDI was chosen because it, like the 
cyclones, can separate particles in prescribed size ranges with the final result being a mass based description with respect to size.

The MOUDI requires a flow rate of $30 \mathrm{lpm}$ (about $1 \mathrm{cfm}$ ), which is controlled by an adjusting valve and monitored by the pressure drop between stages. A 3/4 diameter sample tube was used to draw a sample from the extended primary tunnel. Due to limitations imposed by the existing laboratory setup, the stainless steel sampling tube was 4 feet long and extended from the ports on the primary dilution tunnel extension to the MOUDI.

Samples from the MOUDI were collected on eleven 47-mm aluminum substrates and one 37-mm Gelman Science Teflo filter with a pore size of $2 \mu \mathrm{m}$. This thin Teflon membrane filter with a polyolefin ring collects particles with aerodynamic diameters less than $52 \mathrm{~nm}$. For particles greater than $35 \mathrm{~nm}$ at a face velocity of $23 \mathrm{~cm} / \mathrm{s}$, these filters have a collection efficiency of 99.98\% (Lippmann, 1983).

The aluminum substrates were treated similarly to fluorocarbon coated glass fiber filters in terms of environmental conditioning and handling. The only difference was the use of plastic petri dishes instead of glass and the heightened importance of discharging static buildup. Gelman Sciences 47-mm analyslides were used for holding the filters for storage and transportation.

Static charge builds up readily on the aluminum substrates. It is necessary to neutralize the charge before all weighing is performed. This was done by passing the substrate over (approximately one inch above) a Nucleospot Local Air Ionizer model P2042, manufactured by NRD, Inc. The polonium isotope in the Nucleospot generates an 
equal number of positive and negative ions as it emits alpha particles. This effectively neutralizes the static charge.

One of the major benefits the MOUDI offers is a uniformly deposited sample. This prevents caking of particulate on the substrates. Without this attribute, sampling times would need to be greatly reduced to avoid the problems associated with particle stacking and similar sampling woes.

\subsubsection{MOUDI Operation}

The following discussion provides step-by-step procedure for operating MOUDI.

1) Preparation of substrates

a) Put the substrates into analyslides for conditioning in an environmental chamber set at $70{ }^{\circ} \mathrm{F}$ and $50 \%$ relative humidity. Conditioning should be done for more than $12 \mathrm{hrs}$.

b) Weigh substrates and place them back into their analyslides.

2) Lubricate the o-rings with grease.

a) Take the O-rings and the washers off the stages and clean them carefully with tissue and isopropyl alcohol.

b) Grease the two O-rings of each stage.

3) Install and operate the MOUDI

a) Put the substrates and the after-filter into the holders; install the substrate holders into the stages.

b) Rotate the assembly of stages by switching on the rotator motor. 
c) Switch on the MOUDI pump and adjust the flow rate at $30 \mathrm{lpm}$ by adjusting the pressure drop from the cap to stage 7 at $17.5 \quad \mathrm{H}_{2} \mathrm{O}$. Monitor the pressure drop from stage 7 to filter base $\left(135 \sim 150 \quad \mathrm{H}_{2} \mathrm{O}\right)$.

d) Record the time for which the MOUDI was operated.

4) Record the Mass Data

a) Carefully remove the substrates from the holders.

b) Check for overrun of grease to the substrate holder rings.

c) Put the substrates back into the respective analyslides and condition them for more than 12 hrs.

d) Weigh the substrates and the afterfilter again to get the final weights.

\subsubsection{Calibration of MOUDI}

The MSP Corporation, the manufacturer of MOUDI, provides calibration services for the MOUDI. After a certain use period, MOUDI should be recalibrated. The main purpose of recalibrating is to re-establish the cutpoint of each stage. During usage, the nozzle diameters may change, and this would change the cutpoints.

During usage, the flow rate through MOUDI should be calibrated with an in-line bubble flow meter. When the flow rate reaches $30 \mathrm{lpm}$, the pressure drops indicated by the manometric gages should be recorded and this would be operating pressure while the MOUDI is running. 


\subsubsection{Cyclone PM Sampling System}

A cyclone is an inertial particle separator, which uses centrifugal forces to remove heavier (size larger than a certain value) particles from a gas stream. The flow tangentially enters the cyclone body, where it spirals downward along the tapered cylinder casing in solid body rotation. While making these revolutions, the particles are accelerated outward to the walls where they swirl down to a hopper or the grit pot at the bottom. The double vortex gas-solid flow-field consists of an inner free vortex moving toward the exit and subsequently to a filter, and an outer forced vertex moving in the opposite direction, which contains the heavier particles.

A vacuum pump was used to draw the required flow rate through the cyclone body and in-line filter. The URG cyclones ( $\left.\mathrm{PM}_{2.5}\right)$ and ( $\left.\mathrm{PM}_{1.0}\right)$; employed in this study, operated at $16.7 \mathrm{lpm} . \mathrm{PM}_{2.5}$ and $\mathrm{PM}_{1.0}$ cyclones have ${ }_{50} \mathrm{~d}_{\mathrm{ae}}$ of $2.5 \mathrm{~m}$ and $1.0 \mathrm{~m}$, respectively. Particles exiting the vortex finder were collected an equilibrated and weighed Pall flex T60A20 fluorocarbon coated glass fiber filters. Post-test weighing of the filters yielded the size-selective mass of particles. The TPM sample system was used to record the TPM data so that a comparison could be made between TPM, PM 2.5 and $\mathrm{PM}_{1.0}$.

\subsubsection{Calibration of Cyclone Flow Rate}

Mass flow controllers were used to control the sample flow rates through the cyclones. The flow rate signal is converted to a voltage signal and was recorded in the main computer either in ADC code or engineering unit. The conversion factors were obtained after calibration using a bubble flowmeter, and the factors were stored in the 
computer. During a test, flow rate, temperature, and pressure were recorded at the same time so that the standard mass flow rates could be converted to actual flow rates using the state equation.

3.3 SMPS Theory and Sample Conditioning System

\subsubsection{System Description}

The Scanning Mobility Particle Seizer (SMPS) manufactured by TSI Inc. consists of two main subsystems: an Electrostatic Classifier or Differential Mobility Analyzer and a Condensation Particle Counter (CPC).

The aerosol to be sampled first enters an impactor, which removes particles larger than a known size. These larger particles must be removed because they contribute negatively, that is, they increase the number of multiply charged particles. Once the aerosol passes through the impactor, it enters the electrostatic classifier. The purpose of the electrostatic classifier is to strip particles of a particle size from the incoming polydisperse aerosol.

Prior to entering the electrostatic classifier, the aerosol enters a Kr-85 Bipolar Charger, which exposes the aerosol particles to high concentrations of bipolar ions. The particles and ions undergo frequent collisions due to the random thermal motion of the ions. The particles quickly reach a state of equilibrium, in which the particles carry a bipolar charge distribution.

The charged aerosol passes from the charger into the main portion of the electrostatic classifier. The electrostatic classifier contains two concentric metal cylinders. The polydisperse aerosol and sheath air are introduced at the cylinders. The 
aerosol surrounds the inner core of sheath air, and both laminar streams flow down the annulus with no mixing of the two streams. The inner cylinder, the collector rod, is maintained at a controlled negative voltage, while the outer cylinder is electrically grounded. This creates an electric field between the two cylinders.

The resulting electric field attracts positively charged particles to the negatively charged rod. The location of the precipitating particles depends upon their mobility. Particles within a narrow range of electrical mobilities exit as monodisperse aerosol through a small slit located at the bottom of the collector rod. The axial distance of the aerosol inlet to the outlet slit is $43.6 \mathrm{~cm}$. The distance was selected to provide a residence time, which was long enough for the classification of particles at upper size limit of the instrument and results in reasonable diffusion losses of particles at lower size limit of the instrument.

Particles in the monodisperse aerosol exit the classifier and are transferred to a particle counter to determine the particle concentration. The remaining particles are removed from the classifier via the excess air flow $\left(\mathrm{q}_{\mathrm{e}}\right)$. Once the particles are classified according to electrical mobility, their concentration is measured by a CPC. A software package (SMPS for windows, CPC) provided by TSI, Inc. is used to record and reduce the particle concentration signal sent out from the CPC.

The SMPS and the mini-dilution tunnel were set on a custom-built cart. The cart was stationed inside a conditioned trailer during in-field tests with the Transportable Laboratories. A $3 / 4 \quad$ stainless tubing was used to connect the sample probe and the exhaust inlet of the mini-dilution tunnel. 


\subsubsection{Sampling Conditions in Mini-Dilution Tunnel}

Mini-Dilution Tunnel used in this study will be detailed in the $6^{\text {th }}$ chapter.

The sampling temperature control in the tunnel is briefly discussed here. Dilution air is used to mix and cool the exhaust into the tunnel. In order to avoid overcooling, a heater was wrapped out side the tunnel and a temperature controller was used to maintain the temperature of mixed airflow in tunnel at a certain range expected. During the tests, the temperature of dilution air, the temperature of tunnel, and the temperature of sample airflow were monitored and adjusted. Usually, the temperature of dilution tunnel was set at 70 to $100^{\circ} \mathrm{F}$ according to the tests.

\subsubsection{Calibration of SMPS}

The following discussion provides step-by-step procedures for calibrating the SMPS.

1) Remove the CPC from the flow system

a. Disconnect the CPC from the SMPS external plumbing. Disconnect the Tygon tubing from the system;

b. Disconnect the polyflow tubing from the exhaust of the CPC;

c. Reconnect this tubing to the joint where the Tygon tubing to the CPC was connected.

2) Isolate Sheath and Excess Air flows

a. Open sheath air valve;

b. Close external valve on the pluming;

c. Close excess air valve; 
d. Close monodisperse valve;

e. Cap the aerosol inlet of the polydisperse flow.

3) Calibrate Sheath and Excess Air

a. Remove the filter from the sheath air inlet;

b. Attach bubble flow meter to sheath air inlet;

c. Slowly open excess valve until desired flow is achieved;

d. Turn meter selector knob to excess air;

e. After 30 second warm up period, record new calibration excess air voltage;

f. Turn meter selector knob to sheath air;

g. After 30 second warm up period, record new calibration sheath air voltage;

4) Isolate Polydisperse and Monodisperse Air flows

a. Close excess air valve;

b. Close sheath air valve;

c. Open monodisperse valve.

5) Calibrate Polydisperse pressure drop and Monodisperse Air flow

a. Attach bubble flow meter to the polydisperse sample inlet;

b. Slowly open external valve until desired flow rate is measured;

c. Record pressure drop of the polydisperse flow on the pressure gage;

d. Turn meter selector knob to monodisperse air;

e. After 30 second warm up period, record new calibration monodisperse air voltage;

6) Reset SMPS system

a. Close external valve; 

b. Open sheath air valve;
c. Open monodisperse aerosol valve;
d. Close excess air valve;
e. Reconnect CPC properly;
f. Set flows using new voltage and pressure values.

\subsection{Fuels}

Fuels used in Boston tests were: compressed natural gas (CNG), clean diesel, and conventional diesel, including hybrid buses. Two types of fuels were used in Riverside tests: federal diesel with California Air Resources Board (CARB) certification diesel fuel, and BP-ARCO's ultra low sulfur emission control diesel (ECD).

Natural gas is composed primarily of methane $\left(\mathrm{CH}_{4}\right)$, may also contain some ethane, propane and heavier hydrocarbons. Trace quantities of nitrogen, oxygen, carbon dioxide, sulfur compounds and water may also present. Natural gas is delivered to an engine as a low- pressure vapor.

In comparison, natural gas has lesser Lower Heating Values (LHV) than diesel fuel and is also less efficient on a per gallon basis (114,000 Btu/ equiv. Gallon).

Clean diesel used in this study has very low sulfur fractions $(<0.002 \mathrm{ppm})$. Both clean diesel and hybrid bus diesel ( identificated as D1), are supposed to be cleaner than the conventional diesel. The LHV of diesel fuel is about 129,000 Btu/gallon. 


\section{Chapter 4 ASSESSMENT OF REAL-WORLD PLUME DISPERSION FROM A HEAVY-DUTY DIESEL MOBILE SOURCE}

\subsection{Introduction}

Recently raised health concerns about DPM have resulted in increased activity among the research community to determine what is the "appropriate" sampling method for measuring ambient mobile emissions. The focus has turned primarily to heavy-duty vehicles (HDV) because they represent the majority of the on-road diesel-engine population. In general, it has become increasingly clear that in order to determine risk; consensus must be reached between regulators and the regulated community on the methods to be used to assess the environmental impact of a mobile pollution source. Although HDV's and their engines have been tested extensively for in-use emissions in dynamometers, ambient measurements under realistic on-highway conditions are sparse. This may be attributed to the inherent difficulty in making representative measurements in an environment where the exhaust plume is influenced by the local aerodynamics and the presence of background particles. Intuitively, it may be suggested that the large-scale ambient turbulence which provides mixing and the transport mechanism for the emissions in the plume is also responsible for the complexity in determining actual exposure at a given receptor of interest. As the plume diffuses in the atmosphere, the gaseous and particulate diesel emissions are convected by and interact with an everchanging environment of varying temperature, dilution, and background concentrations. Ultimately, the residence time in the ambient will determine the gas-to-particle 
transformation of the exhaust. The impetus for this chapter is to analyze the in-use behavior of the plume from a HDV during on-highway simulated in the wind tunnel.

For a stationary ground level or elevated point source, a common theoretical framework may be established by the Gaussian description of the plume in the far-field region (receptors located $100 \mathrm{~m}$ or greater downstream from the point source). In this region, atmospheric stratification plays a role in determining plume mixing (Turner,1969; Martin, 1976; ASME, 1973; Klug, 1969;). Accordingly, the receptor concentration is given by the Gaussian plume equation:

$$
c(x, y, z)=\frac{q}{2 \pi u \sigma_{y} \sigma_{z}} \exp \left(-\left(\frac{y^{2}}{2 \sigma_{y}{ }^{2}}+\frac{z^{2}}{2 \sigma_{z}{ }^{2}}\right)\right)
$$

where the source strength is defined as

$$
q=c_{o} Q
$$

For mobile sources such as class 8 HDV's under on-highway conditions, the need to find an equally descriptive predictor suggests that the history and characteristics of the exhaust source and plume should be considered within the context of the local turbulent flow field. The time and spatial scales associated with the transformation of engine exhaust from the gaseous phase into the constituents of DPM are small; hence the desire to determine a semi-empirical predictor applicable to the near-source region. The Gaussian plume model above is restricted to the far field where the exhaust stack can be considered a point source. However, the work described in this chapter suggests that this simple Gaussian expression may be modified slightly and extrapolated into the near-field 
provided that: $i$ ) an equivalent or "virtual" point source is defined inside the stack and $i$ ) the diffusion coefficients are adjusted. Although the results presented here are casespecific and refer to the truck-only configuration tested in the wind tunnel, some general observations were obtained that may help illustrate plume dispersion during on-highway operation.

\subsection{Background}

A heavy-duty vehicle operated in WVU's mobile chassis dynamometer was tested recently at the Old Dominion University (ODU) Full Scale Wind Tunnel Facility to investigate, among other diesel aerosol processes, exhaust plume dispersion. The chassis dynamometer was positioned on the wind tunnel test section as illustrated in Figure 4-1. Steady state and transient tests were patterned after on-highway chase experiments conducted by the University of Minnesota (UMN) in a related effort. The overall test plan called for measurements of exhaust gases and particulate. This included all criteria pollutants, the $\mathrm{CO}_{2}$ tracer gas in the plume and background and size-segregated particulate mass and number counts in the plume and background. The discussions in this chapter are limited to tracer-gas measurements and potential modeling options for plume dispersion.

Plume concentration maps were based on continuous $\mathrm{CO}_{2}$ scans at various crosssections and at predetermined streamwise stations. Each cross-section included nine individual measurements. In addition to plume measurements, raw $\mathrm{CO}_{2}$ concentration at the vehicle stack and background $\mathrm{CO}_{2}$ concentrations were monitored. Overall dilution was determined from measurements of raw and plume $\mathrm{CO}_{2}$. Low (plume \& background) 


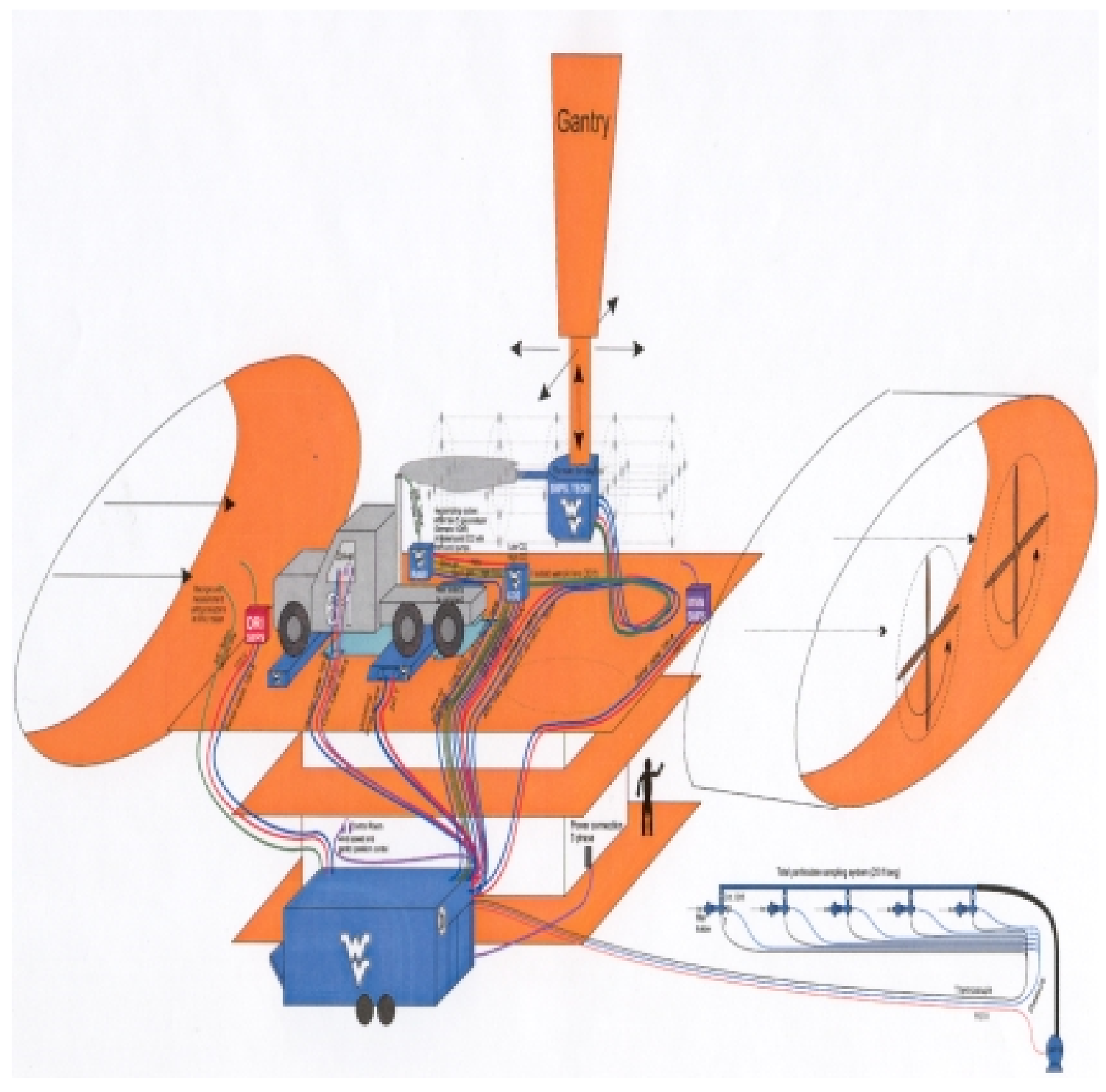

Figure 4-1. Set up at the ODU Full Scale Wind Tunnel Facility 
and high (raw exhaust) concentration measurements were conducted with a California Analytical Analyzer and a Beckman Analyzer, respectively. A photograph of the test vehicle in the wind tunnel test section is shown in Figure 4-2.

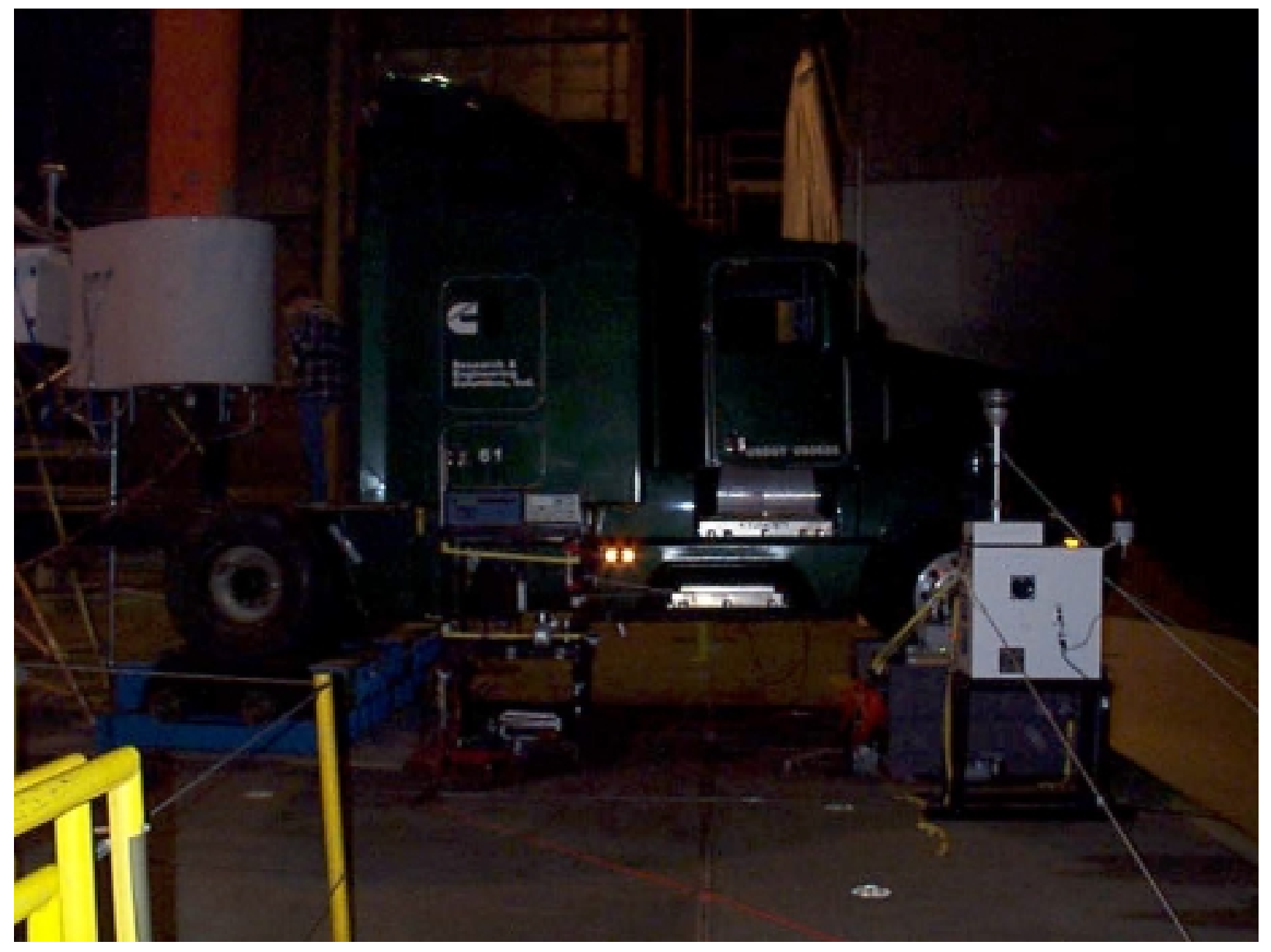

Figure 4-2. Picture of Test Vehicle, Gantry, Dynamometer, and Other Instrumentation in the Wind Tunnel Test Section of the ODU Facility. 


\subsection{Plume Dispersion Theory}

\subsubsection{Concentration Distribution Equations}

The contaminant concentration at certain position in the plume is expressed by the well-known Gaussian plume equation in the slender plume case (Seinfeld, 1986):

$$
\begin{gathered}
c(x, y, z)=\frac{q}{2 \pi u \sigma_{y} \sigma_{z}} \exp \left(-\left(\frac{y^{2}}{2 \sigma_{y}{ }^{2}}+\frac{z^{2}}{2 \sigma_{z}^{2}}\right)\right) \\
q=c_{0} Q
\end{gathered}
$$

Where, the $\mathrm{x}$-axis is set along the plume centerline, and there is also no ground reflection in the area near the stack.

From the Gaussian plume distribution equation, we can obtain the contaminant concentration distribution on the plume centerline:

$$
c(x, 0,0)=\frac{q}{2 \pi u \sigma_{y} \sigma_{z}}
$$

The concentration vs. the $\mathrm{z}$-axis (vertical direction) at certain $\mathrm{x}$ cross-section is expressed by

$$
c(x, 0, z)=\frac{q}{2 \pi u \sigma_{y} \sigma_{z}} \exp \left(-\frac{z^{2}}{2 \sigma_{z}^{2}}\right)
$$

The concentration vs. the $\mathrm{y}$-axis (horizontal direction) at certain $\mathrm{x}$ cross section is expressed by

$$
c(x, y, 0)=\frac{q}{2 \pi u \sigma_{y} \sigma_{z}} \exp \left(-\frac{y^{2}}{2 \sigma_{y}{ }^{2}}\right)
$$


4.3.2 Determining of the Source Point of the Plume

The Gaussian description of a plume is based on the assumption of having a continuous point source. And although this may be a reasonable consideration for the vehicle exhaust stack relative to the far field, when making measurements in the nearsource region, the stack diameter may be of the same order of magnitude as the relative source-to-receptor distance. Analogous to the concentration profile, the jet velocity profile of the exhaust may be introduced to determine a virtual point source. If the exhaust plume is considered a jet as shown in Figure 4-3, point $O$ may be defined as the polar point or virtual location of an equivalent virtual point source located inside the stack at the polar distance $h_{0}$. In this sense, the polar distance may be defined according to Jeriee(see Wang, 1994) as below:

$$
h_{0}=\frac{D_{0}}{2 a \phi_{b}}
$$

In Figure 4-3, x' represents the geometric centerline in the wind tunnel test section, $\mathrm{x}$ " represents the plume centerline and $\mathrm{x}$ is the reference axis for the diffusion coefficients. 


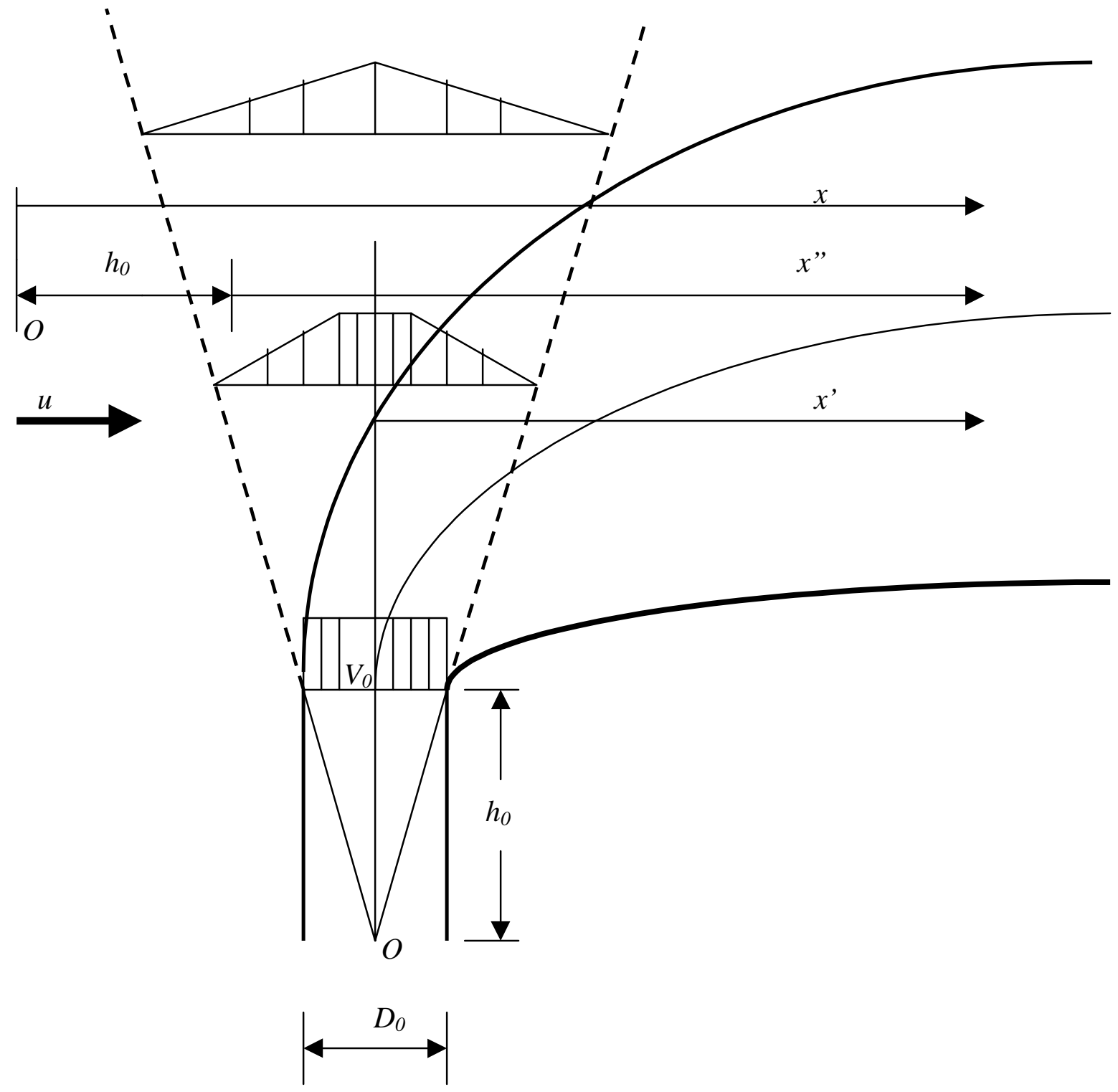

Figure 4-3. Circle Jet Velocity Field and Plume Construction (not to scale) $O$-polar point; $h_{0}$ - polar distance;

$D_{0}$ - diameter of the stack; $u$-longitudinal wind velocity;

$V_{0}$ - exhaust air velocity in the stack exit. 


\subsubsection{Estimate of Dispersion Coefficients}

The diffusion coefficients may be expressed as

$$
\sigma_{y}^{2}=2 K_{y y} x / u, \sigma_{z}^{2}=2 K_{z z} x / u
$$

Because these dispersion coefficients are not constant, but rather are dependent on the Pasquill stability categories, Gifford (1961) developed the $\sigma_{\mathrm{y}}$ and $\sigma_{\mathrm{z}}$ charts recognized as the Pasquill-Gifford curves (applicable at $\mathrm{x}=100-100000$ meters). These coefficients may be represented empirically by the power-law expression (Turner (1969); Martin (1976); ASME (1973); and Klug (1969)).

$$
\begin{array}{ll}
\sigma_{y}=R_{y} x^{r_{y}} & \sigma_{y}=\exp \left[I_{y}+J_{y} \ln x+K_{y}(\ln x)^{2}\right] \\
\sigma_{z}=R_{z} x^{r_{z}} & \sigma_{z}=\exp \left[I_{z}+J_{z} \ln x+K_{z}(\ln x)^{2}\right]
\end{array}
$$

Where $R_{()}, r_{(),} I_{(),} J_{()}$, and $K_{()}$are the fitting coefficients, depend on the stability class and the averaging time.

The Pasquill-Gifford empirical equation for horizontal dispersion coefficient $\sigma_{\mathrm{y}}$ is expressed by (Turner , 1969; Martin ,1976):

$$
\sigma_{y}=R_{y} x^{0.894}
$$

Where, $R_{y}$ equals $0.443,0.324,0.216,0.141,0.105$, and 0.071 corresponding to stability from A to F, respectively. Figure 4-6 is based on the equation (4-9) and is extended to the source point from $x=100 \mathrm{~m}$. It may be applicable to the near field because both the 
equations (4-7) and (4-9) show that the source $(0,0)$ can be considered as a datum point on the curves.

In order to consider whether the empirical equations for vertical dispersion coefficient $\sigma_{\mathrm{z}}$ are applicable to the near field or not, we also need to extend the curves to the near field and see what will happen (Figure 4-4). Figure 4-4 shows that, when $\mathrm{x}$ becomes small, the $\sigma_{z}$ curves of different stability have not converged to the origin $(0,0)$. So the simple extending of Pasquill-Gifford empirical equation is not valid for the near field.

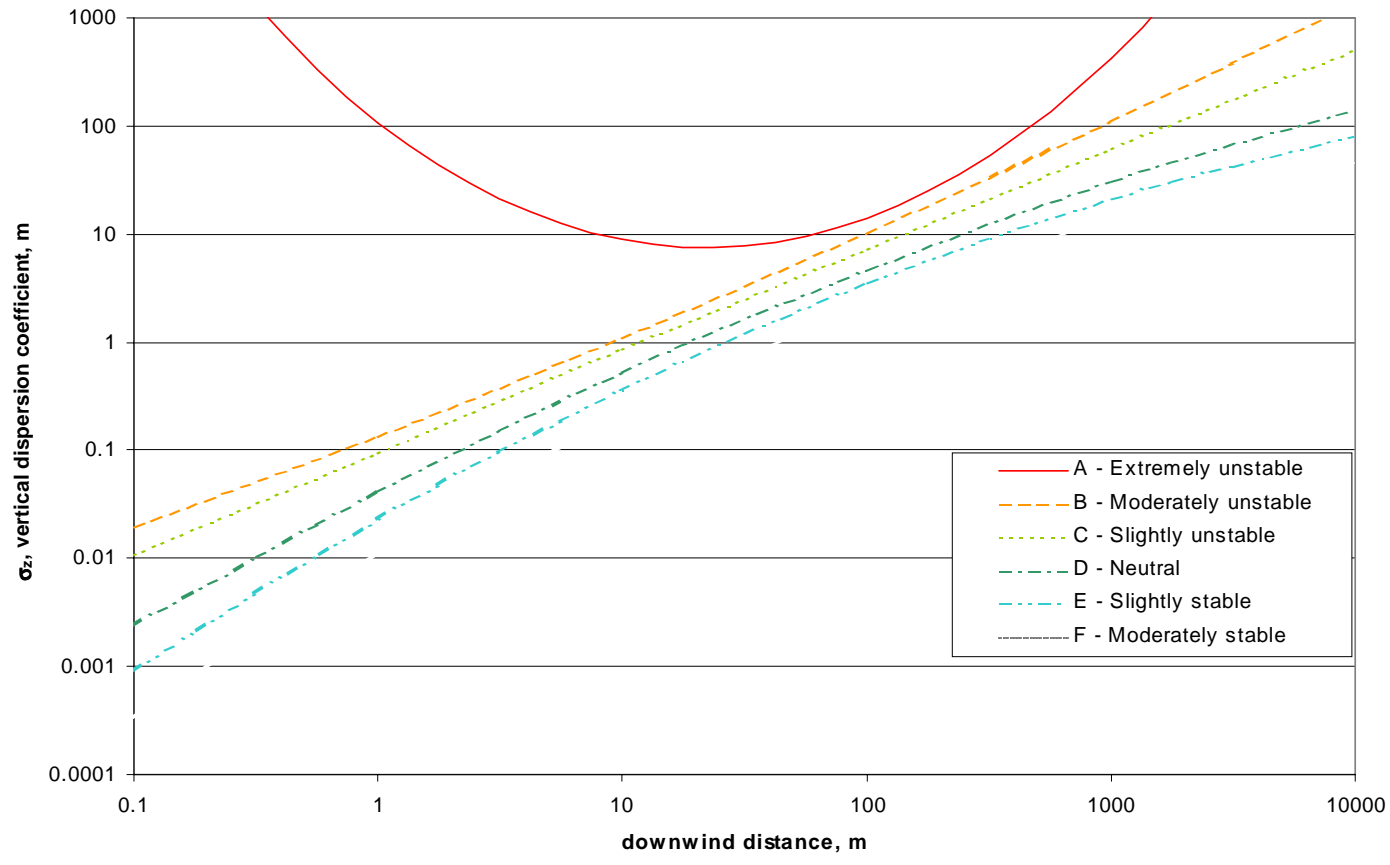

Figure 4-4. Extended Curves of Vertical Dispersion Coefficient from Pasquill-Gifford $\operatorname{Model}\left(\sigma_{z}=\exp \left[I_{z}+J_{Z} \ln x+K_{z}(\ln x)^{2}\right]\right.$, Turner, 1969) 
Extended curves of equation (4-8) with Klug's coefficient are shown in Figure 45. Figure 4-5. shows that extended curves from Klug model to near field is completely inapplicable, because the curves intersect each other.

Recent empirical expression from tunnel tests for diffusion coefficients also have the same form as equation (4-8), but different parameters (Singh, 1994, Huber, 1991). The workers also did not present the applicable charts in the near field.

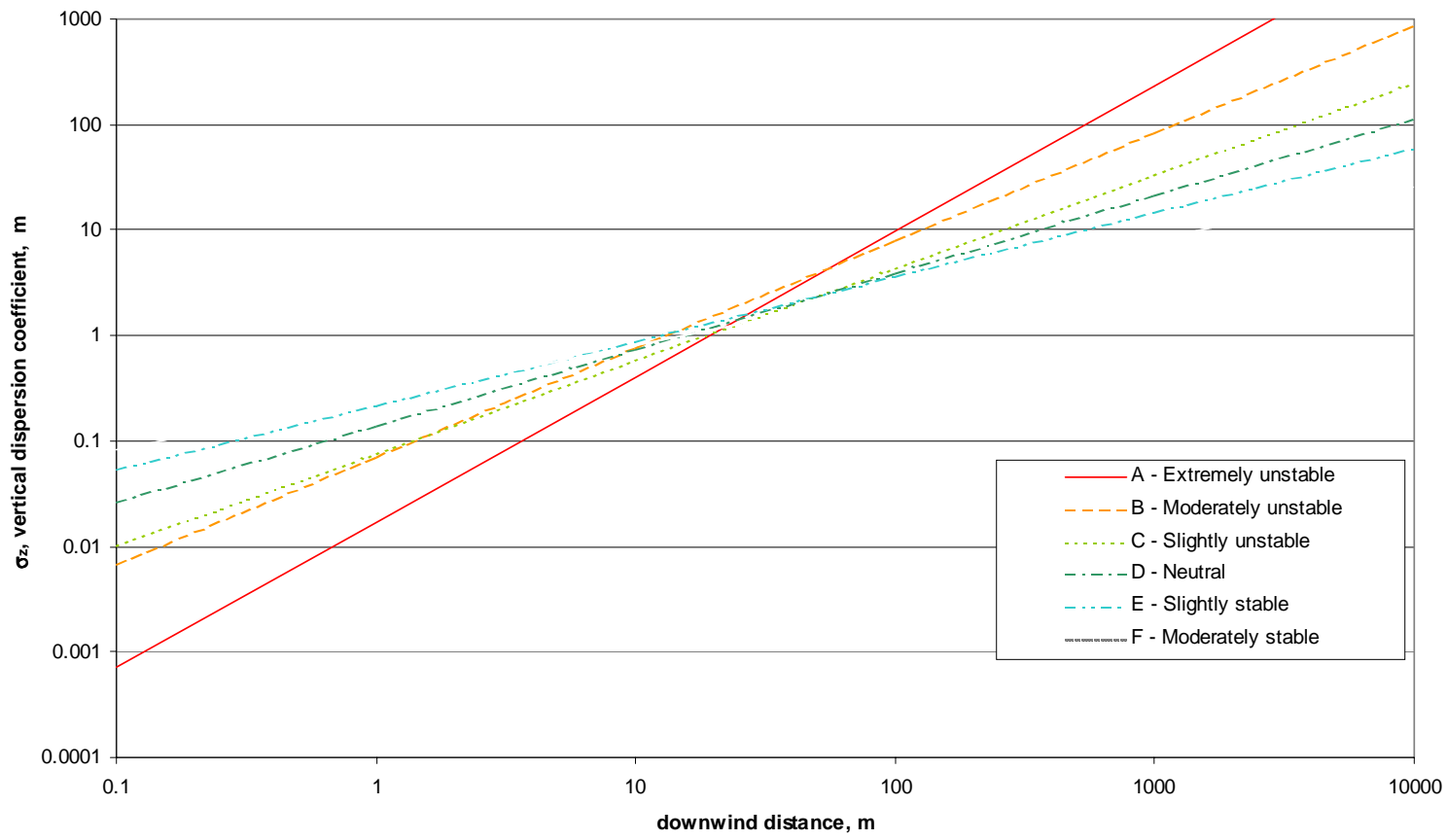

Figure 4-5. Extended Curves of Vertical Dispersion Coefficient from Klug Model $\left(\sigma_{\mathrm{z}}=\mathrm{R}_{\mathrm{z}} \mathrm{x}^{\mathrm{rz}}, \mathrm{Klug}, 1969\right)$ 
We need to find out another way to get the $\sigma_{z}$ for near field. The origin $(0,0)$ now is considered as a datum point. We may connect initial point with the data points of $\mathrm{x}=100$ meters. Compared with the horizontal dispersion coefficient, we can do it in this way: use the slope of curve of stability $\mathrm{C}$ and extrapolate lines from the data points of $\mathrm{x}=100$ meters, straightforward to the origin. The curves obtained by this means are shown in Figure 4-7. The estimate model is called modified Pasquill-Gifford method.

Mathematically, the logarithmic straight-line equation for stability $\mathrm{C}$ is estimated by:

$$
\sigma_{z}=R_{z} x^{0.9165}
$$

Where, $R_{z}$ equals 0.1072 .

Similarly, changing $R_{z}$ to $0.2056,0.1586,0.1072,0.0676,0.0514$ and 0.034 , other $\sigma_{\mathrm{Z}} \mathrm{s}$, corresponding to stability from A to $\mathrm{F}$, can be obtained. The straight-line parts (x from 0.4 to 100 meters) of the curves on Figure 4-7 are based on the equation (4-10). It can be seen that the plot of dispersion coefficient $\sigma_{z}$ (equation 4-10) will converge to the origin when $\mathrm{x}$ goes to zero. 


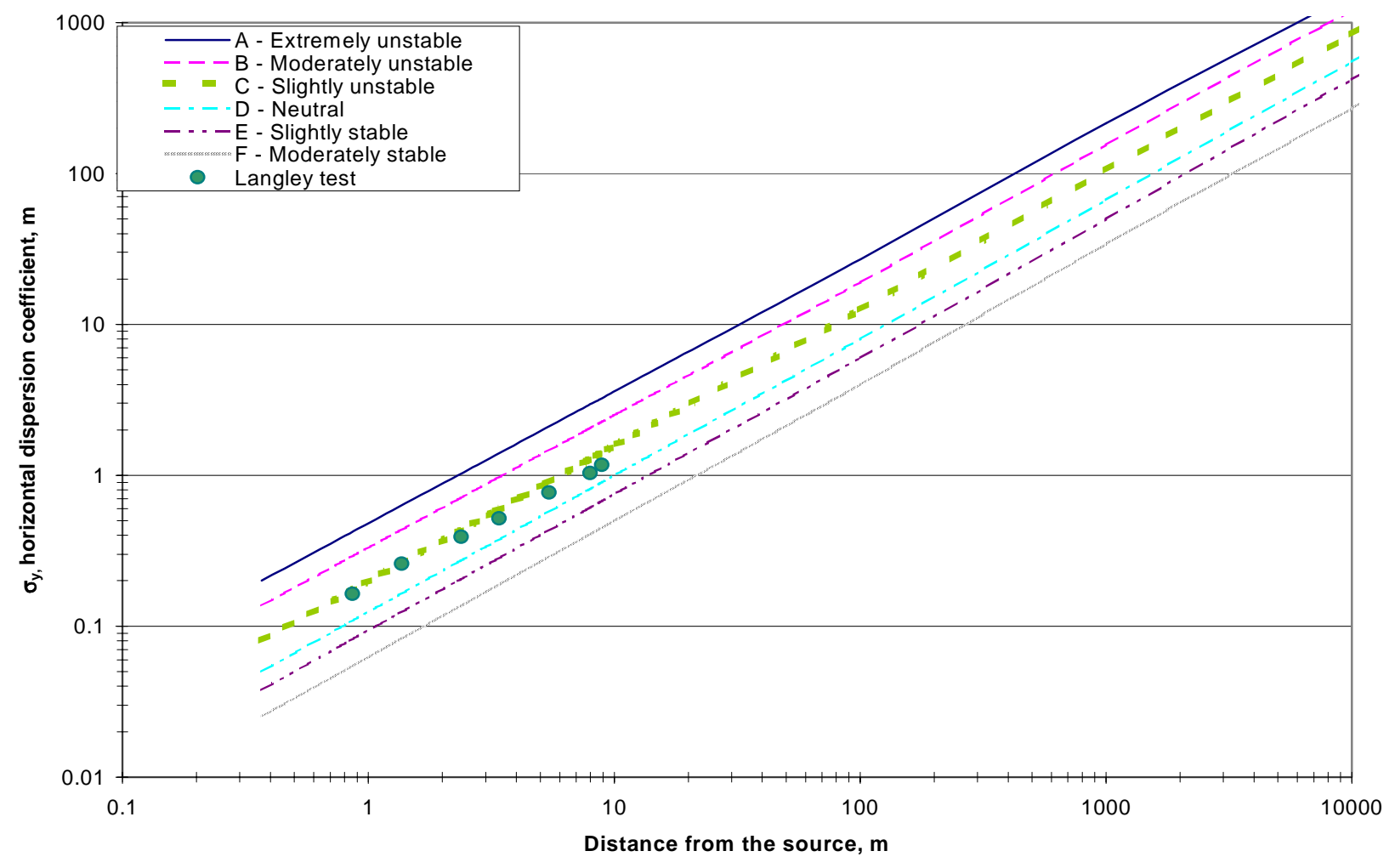

Figure 4-6. Extrapolated Pasquill- Gifford Curve for the Horizontal Dispersion Coefficient $\left(\sigma_{\mathrm{y}}=\mathrm{R}_{\mathrm{y}} \mathrm{X}^{0.894}\right.$, Martin 1976) 


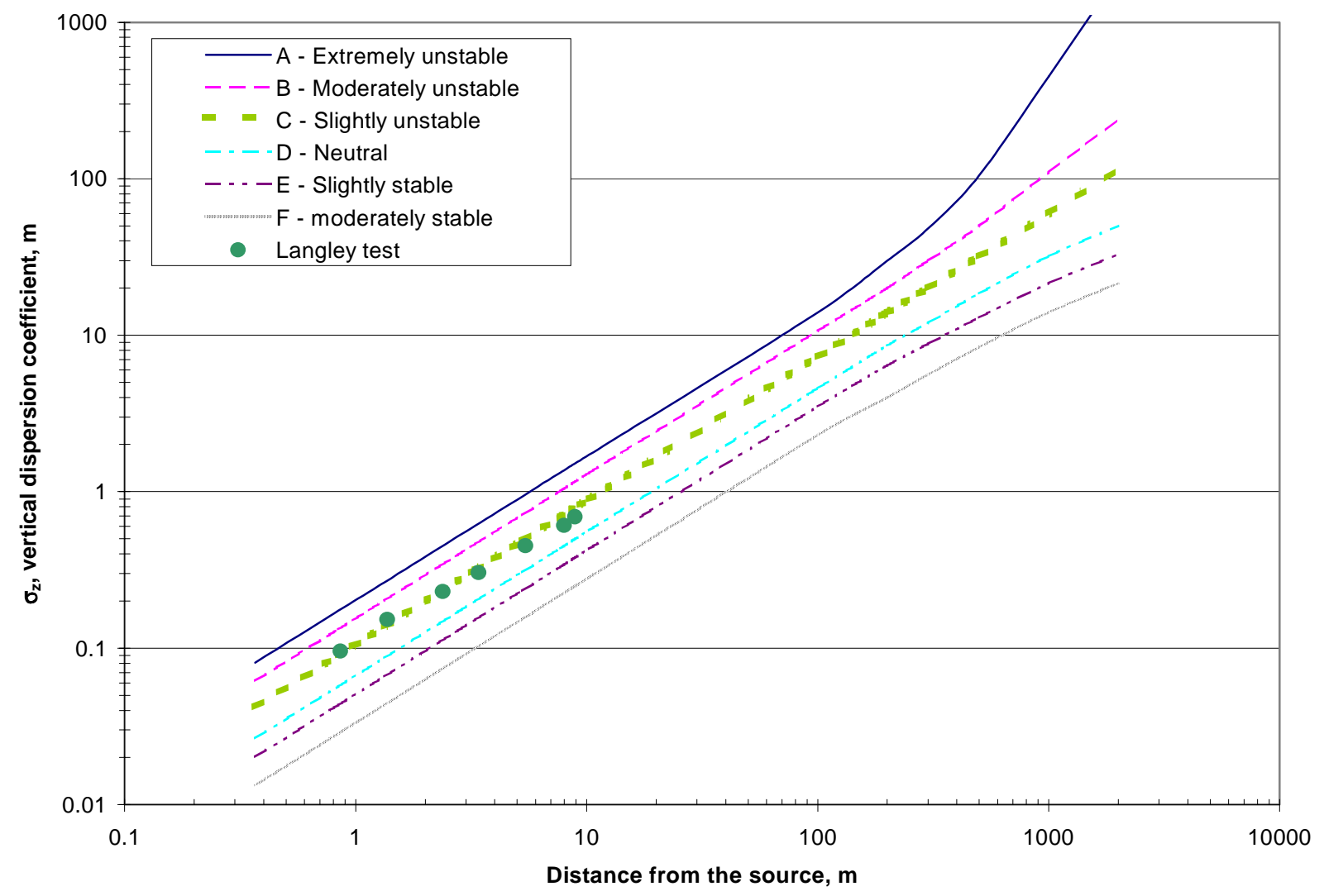

Figure 4-7 Modified Pasquill- Gifford Curves for the Vertical Dispersion Coefficient $\left(\sigma_{\mathrm{Z}}=\mathrm{R}_{\mathrm{z}} \mathrm{x}^{0.9165}\right.$, for $\mathrm{x}<100 \mathrm{~m}, \sigma_{\mathrm{z}}=\exp \left[\mathrm{I}+\mathrm{J}_{\mathrm{Z}} \ln \mathrm{n}+\mathrm{K}_{\mathrm{z}}(\ln \mathrm{x})^{2}\right]$, for $\left.\mathrm{x}>100 \mathrm{~m}\right)$ 


\subsection{Wind Tunnel Test}

The vehicle tested in the ODU wind tunnel had a stack with diameter $D_{0}=5 \mathrm{in}$.

Primarily, steady-state tests were run at $55 \mathrm{mph}(24.6 \mathrm{~m} / \mathrm{s})$. For these conditions, equation (1-6) yields a polar distance of 10.5 in.

$$
h_{0}=\frac{D_{0}}{2 a \phi_{b}}=\frac{5}{2(0.07) 3.4}=10.5(\text { inches })
$$

In addition, although not measured directly, the vehicle exhaust flow was estimated as

$$
\begin{aligned}
& Q=V_{m} M_{f}(453.59) /\left(C M W_{f} c_{0} / 100\right) \\
& =0.79072 * 88 * 453.6 / 13.8144 / 4.74 * 100 / 60=803 f t^{3} / \mathrm{min} .
\end{aligned}
$$

The test location matrix is shown in Table 4-1. Seven discrete measurement stations were chosen to map the plume. The distances given in Table 4-1 are relative to the vehicle stack. $\mathrm{CO}_{2}$ concentration measurements along the transverse cross-sections were conducted continuously. Background concentrations in the tunnel were also monitored regularly. Thus, the data presented and given as relative concentrations, $R c$, have been corrected for background:

$$
R c=\frac{(c(x, y, z)-B k d)}{\left(c_{0}-B k d\right)}
$$

For the model, the background concentrations were considered to be zero. 
Table 4-1 Measurement cross-section positions (see Figure 4-3)

\begin{tabular}{lccccccc}
\hline No. & 1 & 2 & 3 & 4 & 5 & 6 & 7 \\
\hline Distance from stack, x'(in.) & 20 & 40 & 80 & 120 & 200 & 300 & 327 \\
Plume centerline distance, x"(in.) & 23.4 & 43.4 & 83.4 & 123.4 & 203.4 & 303.4 & 340.4 \\
Distance from source point, x (in.) & 33.9 & 53.9 & 93.9 & 133.9 & 213.9 & 313.9 & 350.9 \\
\hline
\end{tabular}

\subsubsection{Calculation of Dispersion Coefficient}

At the ODU wind tunnel test, the wind velocity in the tunnel was stable, but the gantry box often moved and some instruments (MOUDI etc.) were set in the tunnel that disturbed the flow field and made the flow slightly unstable or neutral (stability C or D). For the neutral stability, the ratio of $\sigma_{y}$ to $\sigma_{z}$ is almost constant (Zhang, 1987). This makes it possible to calculate dispersion coefficient with the test data of $\mathrm{CO}_{2}$. From P-G curve at $\mathrm{x}=100 \mathrm{~m}$, we get:

$$
\sigma_{\mathrm{y}}=1.7 \sigma_{\mathrm{z}}
$$

Substituting this into equation (4-3), we can calculate $\sigma_{\mathrm{z}}$ by

$$
\sigma_{z}=\sqrt{\frac{Q}{3.4 \pi u R_{C}}}
$$

The concentration of $\mathrm{CO}_{2}$ on the plume centerline is illustrated in Table 4-2. Dispersion coefficients calculated are shown in Table 4-2 and Figures 4-6 and 4-7. The test points are very close to the extrapolated $\mathrm{P}-\mathrm{G}$ curve of stability $\mathrm{C}$. 
Table 4-2. Concentration of $\mathrm{CO} 2$ on the plume centerline and dispersion coefficient

\begin{tabular}{ccccc}
\hline Distance from the source, $\mathrm{m}$ & $\mathrm{c}(\mathrm{x}, 0,0), \mathrm{ppm}$ & $\mathrm{Rc},{ }^{*}(-)$ & $\sigma_{\mathrm{y}}, \mathrm{m}$ & $\sigma_{\mathrm{z}}, \mathrm{m}$ \\
\hline 0.86 & 9910 & 0.156166 & 0.16318 & 0.095988 \\
1.37 & 4300 & 0.061658 & 0.25970 & 0.152762 \\
2.38 & 2250 & 0.027123 & 0.39156 & 0.230327 \\
3.40 & 1560 & 0.015499 & 0.51798 & 0.304694 \\
5.43 & 1060 & 0.007075 & 0.76662 & 0.450954 \\
7.97 & 870 & 0.003875 & 1.03596 & 0.609387 \\
8.91 & 820 & 0.003032 & 1.17104 & 0.688844 \\
\hline
\end{tabular}

* The background of $\mathrm{CO}_{2}(\mathrm{Bkd})$ is $640 \mathrm{ppm}$. Raw $\mathrm{CO}_{2}\left(c_{0}\right)$ is $60000 \mathrm{ppm}$.

4.4.2 Relative Concentration and Dilution Ratio along the Plume Centerline To predict the concentration of $\mathrm{CO}_{2}$ at the plume centerline using equation (4-3), stability $\mathrm{C}$ is chosen to determine the dispersion coefficients. Figure 4-8 shows that the prediction by this model has a good agreement with the test.

The dilution ratio is the reciprocal of the relative concentration. Figure 4-9 shows that the modified Pasquill-Gifford method could be used to predict the dilution ratio in practice.

\subsubsection{Relative Concentration along Positive z-axis at Certain x Cross Sections}

The modified Pasquill- Gifford method is chosen to estimate the relative concentration along the vertical axis (z). The truck body disturbed the flow field, hence, 
the concentration distribution profiles at certain $\mathrm{x}$ cross sections along positive $\mathrm{z}$-axis have significant difference from those along negative z-axis (non-asymmetric to the plume centerline-axis).

A comparison of relative concentration along positive z-axis at different cross sections is shown in Figure 4-10. It shows that the model's estimate is in good agreement with the test.

\subsubsection{Relative Concentration along Negative z-axis at Certain x Cross Sections}

Figure 4-11 shows that the model estimation is not agreeable with the test along negative $z$-axis, especially for the first 3 cross sections: $x^{\prime}=20,40$, and 80 inches. This could be due to the presence of a very large eddy at the rear of the truck, which causes the accumulation of contaminant. This prevents the decreasing rate of the concentration along the negative z-axis. Observation shown that the effects of the eddy were seen about 100 inches downstream of the stack. Hence, the concentration profiles of other four cross-sections ( $\mathrm{x}^{\prime}=120,200,300$, and 337 inches) are almost asymmetric that is more agreeable with the model estimation.

Quantitative analysis for the concentration profile within the vicinity of the eddy is difficult, though it is even more important to obtain a good estimate of dispersion in this area. Here, we have considered a modified Gaussian equation as follows:

$$
\frac{c(x, 0, z)}{c_{0}}=\frac{Q}{2 \pi u \sigma_{y} \sigma_{z}} \exp \left(-\frac{z^{2}}{2 C_{e} \sigma_{z}^{2}}\right)
$$




$$
C_{e}=1+\frac{50|z|}{x^{\prime}}
$$

The significance of equation (4-13) is that, on the centerline $(\mathrm{z}=0)$, the concentration will remain the same value as equation (4-4); when the position changes in the direction from the centerline, the decreasing rate of the concentration slows down; when the downwind distance $\mathrm{x}$ ' increases, the contaminant accumulation effect will decrease.

A comparison between the modified model estimate (equation (4-12)) and test is shown in Figure 4-12. It seems that equation (4-12), with the empirical equation (4-13) obtained from the test, can provide better estimate of contaminant concentration distribution near the eddy area, although further test is needed to ascertain the suitability of this model to real would situation.

\subsubsection{Plume Centerline and Plume Rise}

The plume centerline measured is shown in Figure 4-13. Unlike the usual cases, the plume rises up first, and then goes down when it has reached some height. This could be due to the negative pressure field in the leeward of the truck cabin, which draws the plume downward. 


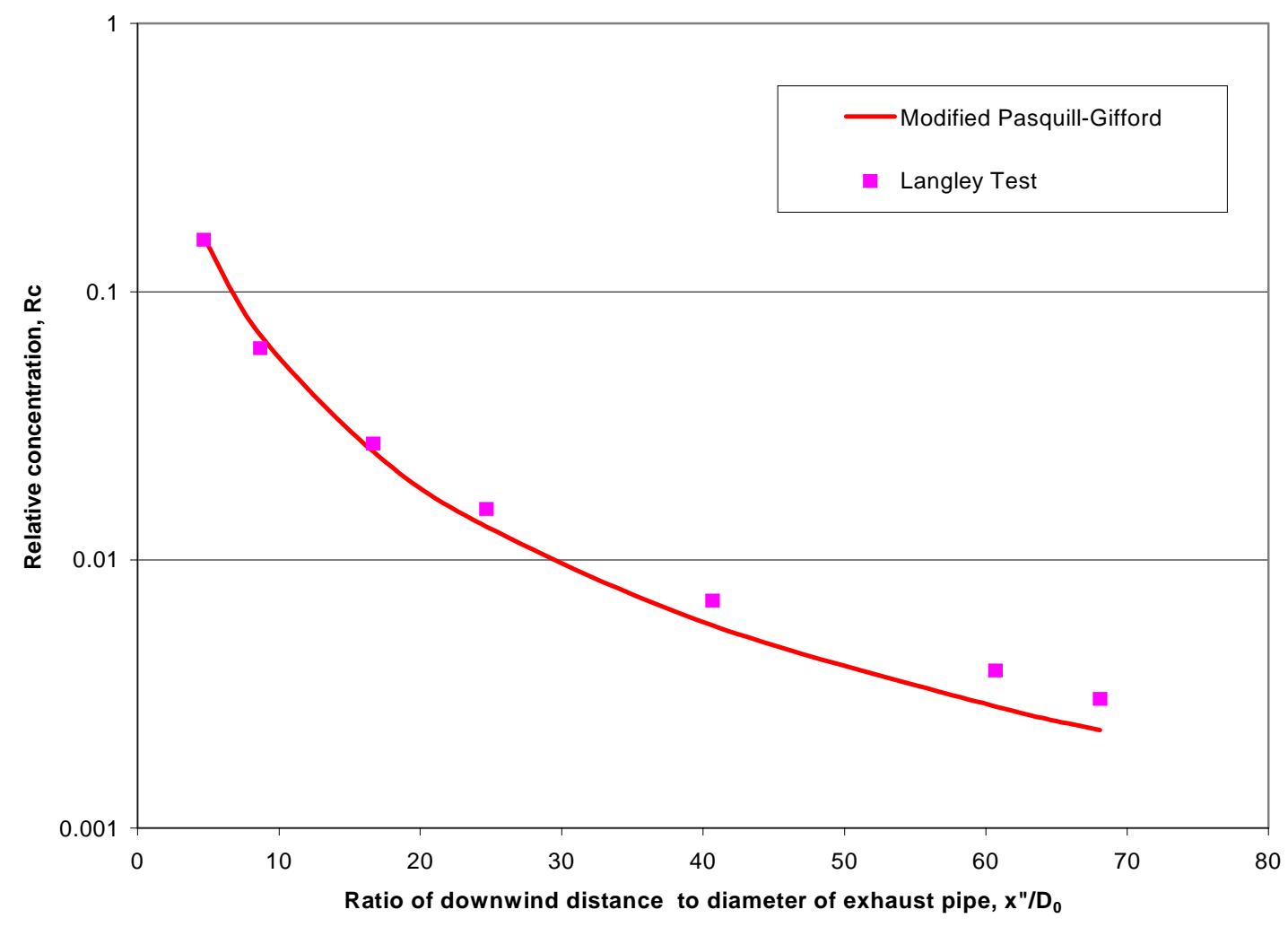

Figure 4-8. Model Estimate of Relative Concentration on the Plume Centerline vs. Test (Modified Pasquill-Gifford, Stability C) 


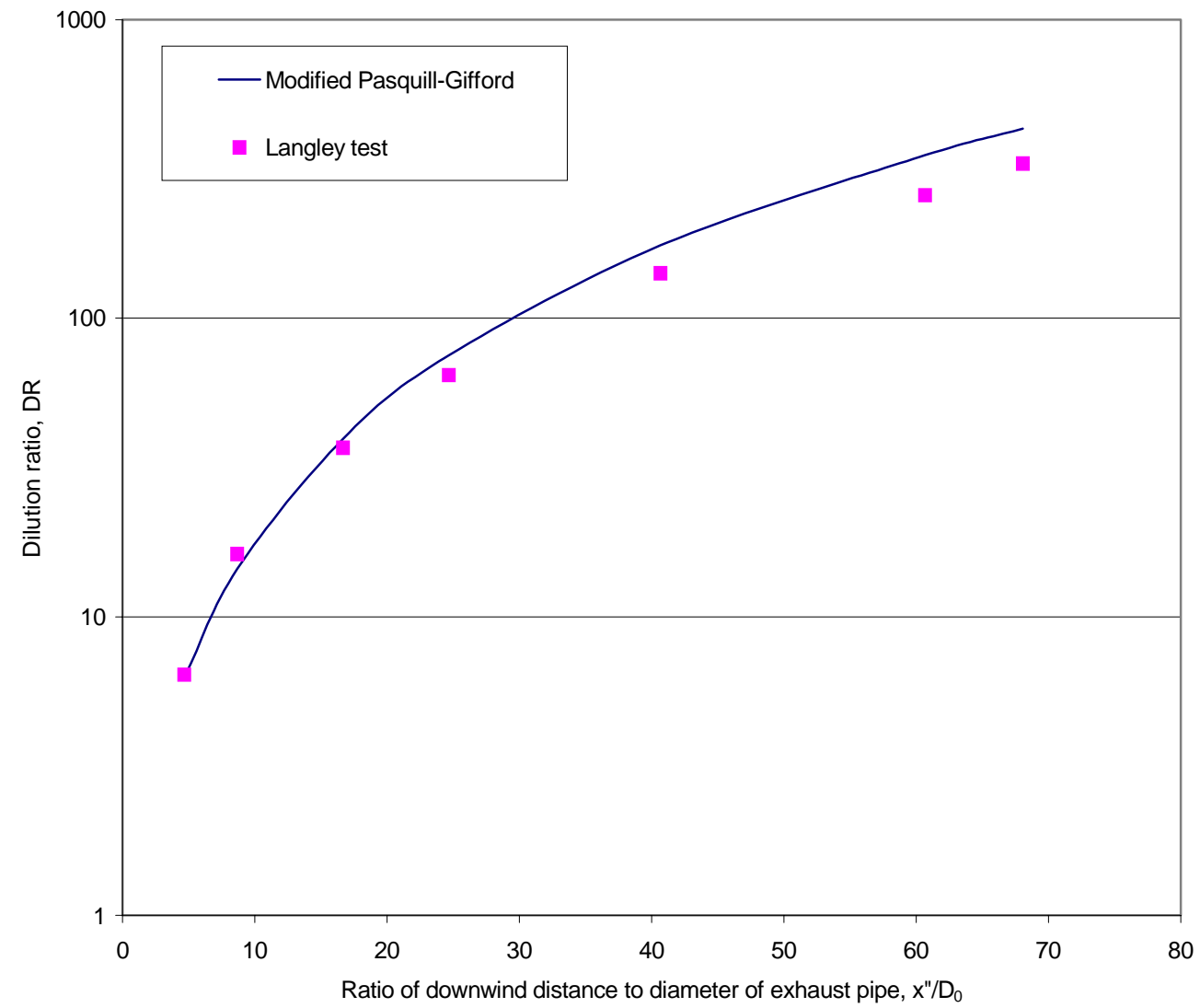

Figure 4-9. Model Estimate of Dilution Ratio on the Plume Centerline vs. Test (Modified Pasquill-Gifford, Stability C) 


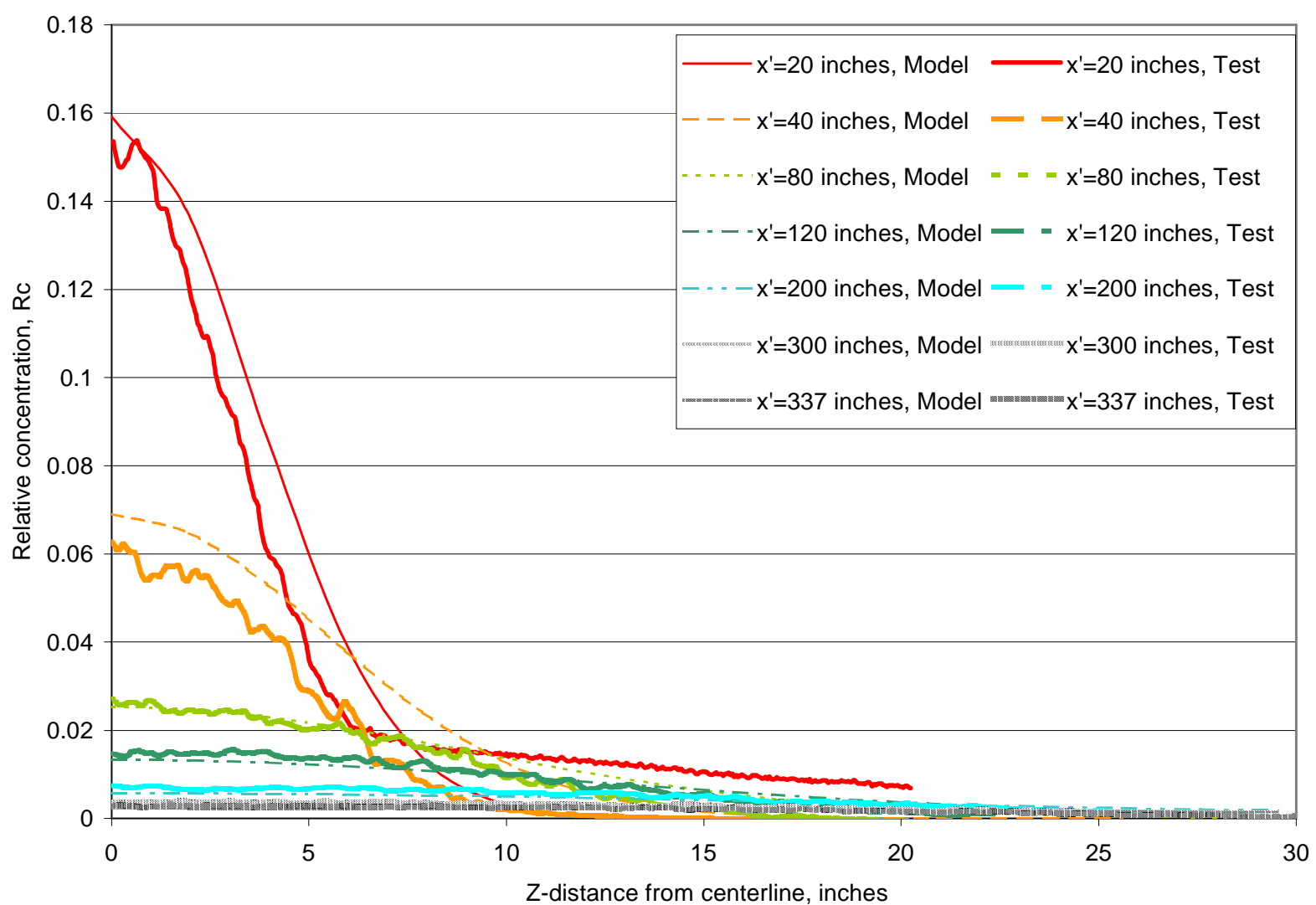

Figure 4-10. Relative Concentration Profiles along Positive Vertical Axis Modified Pasquill-Gifford Estimate (Stability C) vs. Test 


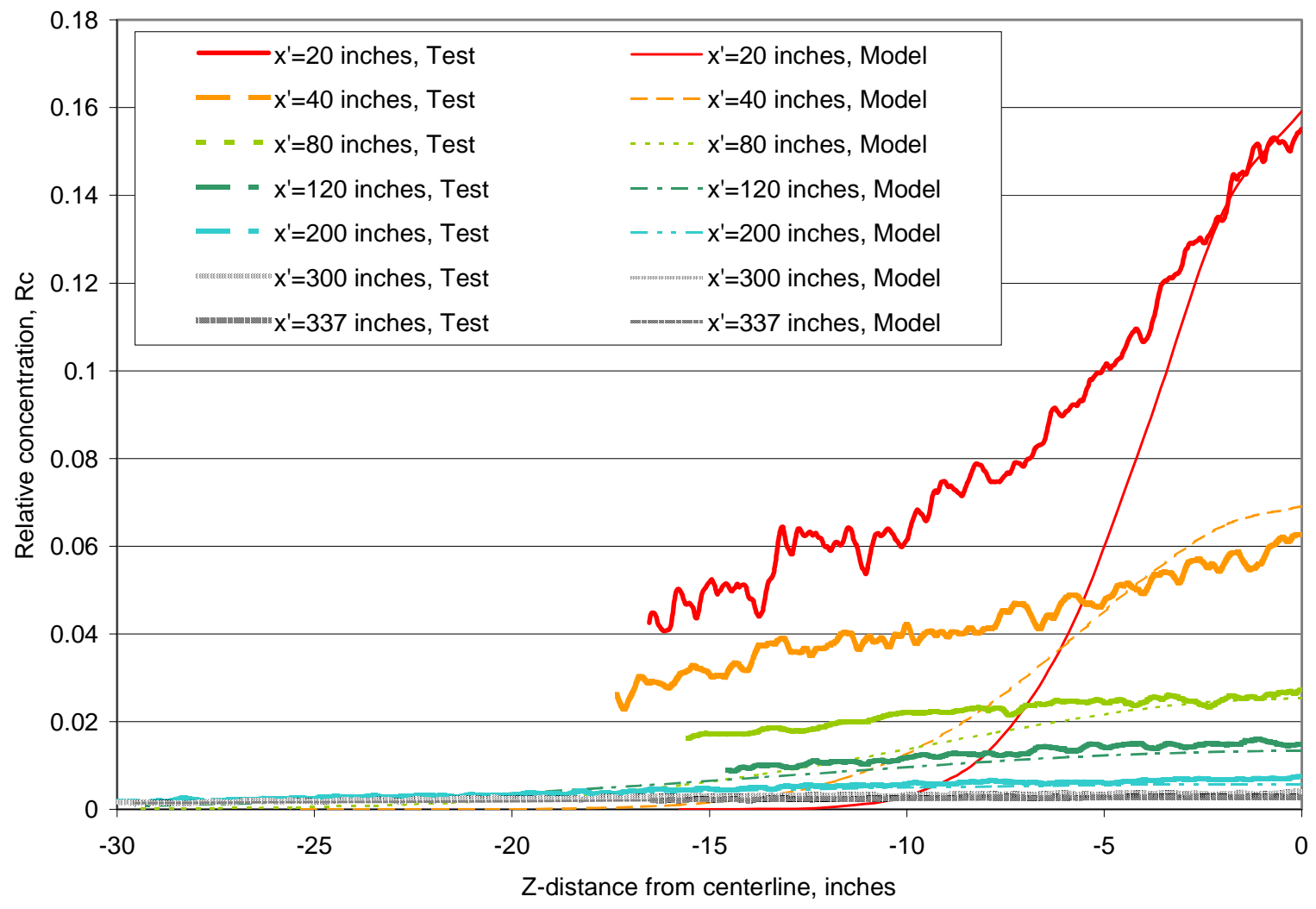

Figure 4-11. Relative Concentration Profiles along Negative Vertical Axis Modified Pasquill-Gifford Estimate (Stability C) vs. Test 


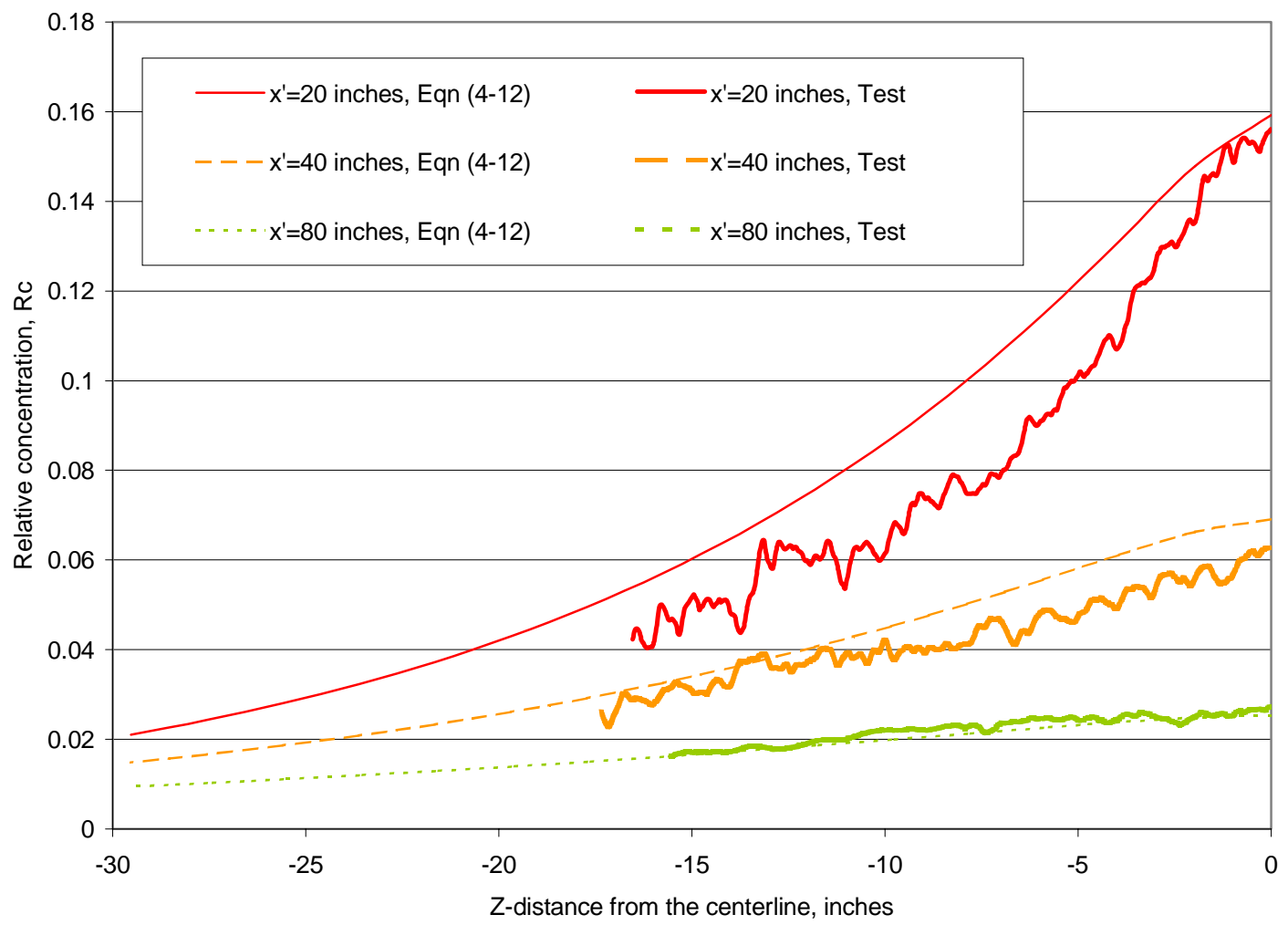

Figure 4-12. Concentration Profile of Leeward Area, the New Model vs. Test (along Negative Vertical Axis, Vertex Area) 


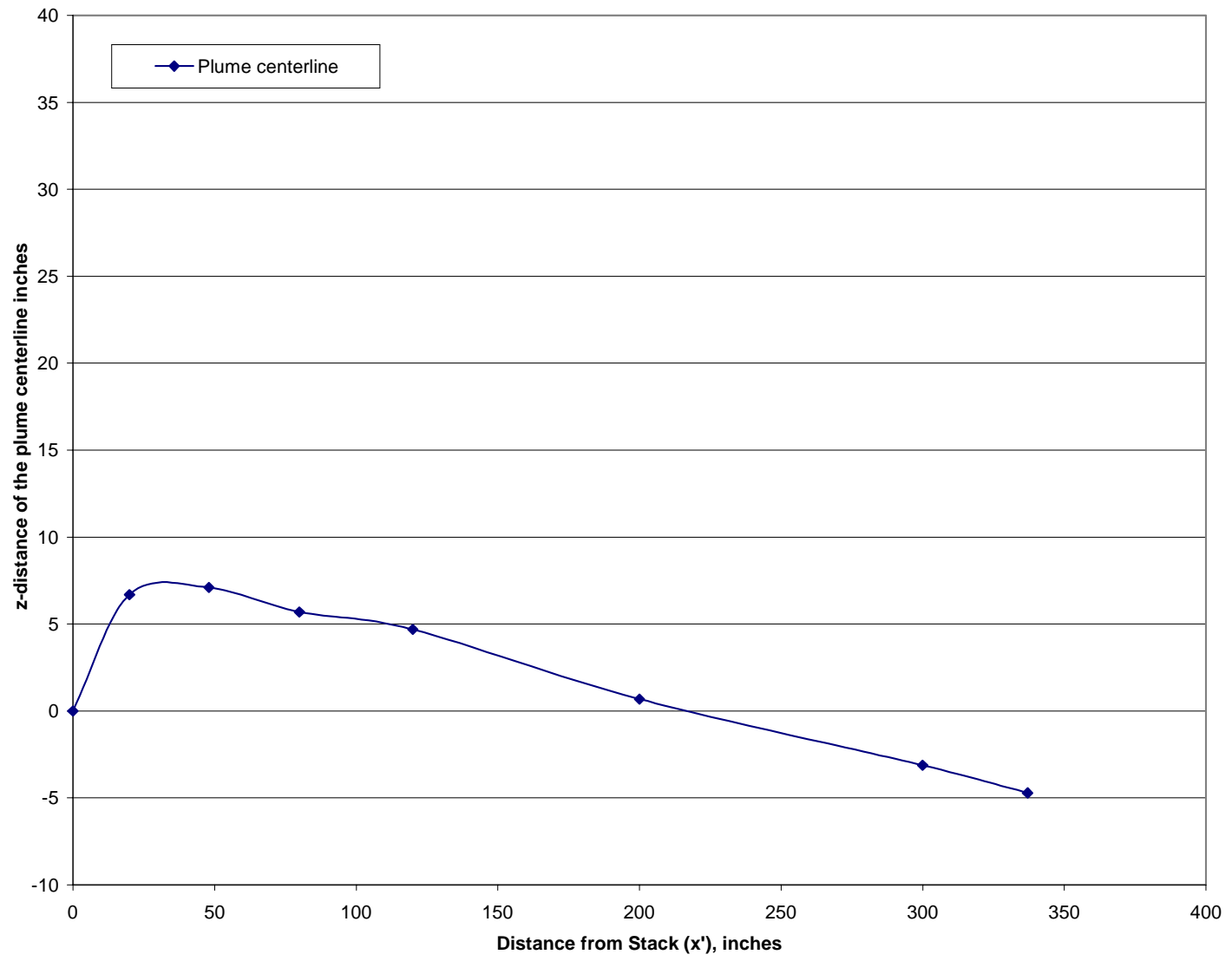

Figure 4-13. Plume Centerline and Plume Rise Test (Geometric Centerline: $\mathrm{z}=0$ ) 


\subsection{Summary}

(1) The dispersion of the exhaust plume within the close proximity of the stack could be well estimated by the Gaussian plume equation. The horizontal dispersion coefficient could be calculated by the Pasquill-Gifford equation:

$$
\sigma_{y}=R_{y} x^{0.894}
$$

and the vertical dispersion coefficient could be calculated by a so called Modified Pasquill-Gifford formula:

$$
\sigma_{z}=R_{z} x^{0.9165}
$$

for the cases with the downwind distance $\leq 100 \mathrm{~m}$.

(2) The eddy that appeared in the leeward of the truck cabin disturbed the plume concentration field. The plume concentration distribution along positive z-axis could be estimated by equation (4-4), that is:

$$
c(x, 0, z)=\frac{q}{2 \pi u \sigma_{y} \sigma_{z}} \exp \left(-\frac{z^{2}}{2 \sigma_{z}^{2}}\right)
$$

and the concentration distribution along negative $\mathrm{z}$-axis could be estimated by following empirical formula:

$$
\begin{gathered}
c(x, 0, z)=\frac{q}{2 \pi u \sigma_{y} \sigma_{z}} \exp \left(-\frac{z^{2}}{2 C_{e} \sigma_{z}^{2}}\right) \\
C_{e}=1+\frac{50|z|}{x^{\prime}}
\end{gathered}
$$

(3) The source point and polar distance could be determined with an analogy to a circle jet velocity field. This played an important role in prediction of the exhaust plume within the vicinity of the stack. The polar distance was about twice of the diameter of the stack. 


\section{Chapter 5 PARTICULATE MATTER ANALYSIS OF HEAVY-DUTY BUSES OF METROPOLITAN BOSTON TRANSIT AUTHORITYY}

\subsection{Introduction}

In an effort to determine the differences in mass-based PM size distributions between natural gas and diesel fueled vehicles, eight transit buses were tested in Metropolitan Boston Transit Authority (MBTA) using the WVU Transportable Heavy Duty Vehicle Emissions Testing Laboratory.

The PM sampling instrumentations used in these tests included MOUDI, $\mathrm{PM}_{2.5}, \mathrm{PM}_{1.0}$ cyclones, and total PM sampling system. However, it was necessary to establish size-selective sampling of PM with a MOUDI from natural gas vehicles. It was suspected that high levels' moisture in natural gas exhaust would pose problems.

For reduction of MOUDI data, a numerical fit method for particle size distributions was developed by minimizing the sum of the squares of cumulative frequency errors. Compared to the frequency fit method, the cumulative frequency fit method was found to be more accurate. Based upon this, a spreadsheet was developed for analyzing multi-modal particle size distributions. The spreadsheet provided a quick and convenient way to do particle size distribution analysis. 


\subsection{Test Matrix and Arrangement}

\subsubsection{Test Vehicles and Test Matrix}

Eight buses selected for testing were classified based upon their fuel type: Natural Gas \#1, Natural Gas \#2, Hybrid \#1, Hybrid \#2, Clean Diesel \#1, Clean Diesel \#2, Diesel \#1 and Diesel \#2. PM sizing tests were performed with MOUDI and cyclone sampling system. The objective of tests was to investigate the size-selective PM mass emissions, and to conduct chemical analysis of the samples. The test matrix is illustrated in Table 51.

Table 5-1 Test Matrix of the Eight Buses.

\begin{tabular}{|c|c|c|}
\hline Vehicle ID & PM $_{1.0}, \mathrm{PM}_{2.5}$, and TPM & MOUDI \\
\hline 6001CNG (CNG\#1) & 3 tri-CBDs, one Background & Run1, Run 3, Background \\
\hline 6000CNG (CNG \#2) & 3 tri-CBDs, one Background & Run1, Run 3, Background \\
\hline 9848-D1 (Clean D \#1) & 3 tri-CBDs, one Background & Run1, Run 3, Background \\
\hline 910X-D1 (Clean D \#1) & 3 tri-CBDs, one Background & Run1, Run 3, Background \\
\hline 5000-D1 (Hybrid \#1) & 3 tri-CBDs, one Background & - \\
\hline 5001-D1 (Hybrid \#2) & 3 tri-CBDs, one Background & - \\
\hline 310-D1 (Diesel \#1) & 3 tri-CBDs, one Background & - \\
\hline 327-D1 (Diesel \#2) & 3 tri-CBDs, one Background & - \\
\hline
\end{tabular}

\subsubsection{Test Arrangement}

Two cyclone sample probes and one MOUDI sample probe were located in an extension to the WVU Transportable Laboratory's main dilution tunnel. With a 3/4 inch stainless steel tubing and a quick disconnect fitting, the MOUDI sample system could be easily set up and the substrate sets could be changed for the different tests. As illustrated in Table 5-1, for the two CNG buses and two clean diesel buses, three repeat runs of the triple CBD test cycle (1707 s) and one background (1138 s) were conducted. Three MOUDI samples were obtained with the $1^{\text {st }}, 3^{\text {rd }}$ run and the background test, respectively. 
The $\mathrm{PM}_{1.0}$ (and $\mathrm{PM}_{2.5}$ ) sampling system consisted of a probe, a cyclone separator, and a filter holder. $47 \mathrm{~mm}$ T60A20 filters were used as primary and secondary PM collection media. A mass flow controller along with a vacuum pump regulated the flow rate. Inlet temperature and pressure were measured that were used by a computer to maintain the actual flow rate through the cyclone separator.

For all the eight vehicles, $\mathrm{PM}_{1.0}$ and $\mathrm{PM}_{2.5}$ samples were conducted with all the repeat runs of the triple CBD test cycle and the background test.

\subsection{MOUDI Data Reduction Method}

The typical method of analysis, particularly for MOUDI data, is to plot the cumulative mass data or count data on log-probit/probability paper (cumulative frequency fit method) and estimate the mass mean aerodynamic diameter (MMAD) and geometric standard deviation $(G S D)$ with a straight line fit through the data points (William, 1980). This method is not applicable for a multi-modal distribution that is composed of several lognormal distributions (Marple et al, 1991; Hinds, 1986). A frequency distribution plot (frequency fit method) has been put forward for determining if a mixed distribution is present ( Marple, 1991; Hinds, 1986; Burkhart, 1987). The standard procedure for plotting a mass or count frequency distribution can be found in some aerosol references (Reist, 1984). The published literature contains several references describing the "inversion" problem; that is, the problem of starting with grouped data and estimating the distribution from which it was derived (Crump, 1982). Furthermore, a microcomputer spreadsheet program was developed to fit a smooth curve to a multi-modal histogram and to generate estimates of the multi-modal parameters (Hewett et al., 1991). However, little 
attention has been paid to analyzing the difference between the cumulative frequency fit and the frequency fit, and to determine which method gives a more accurate estimate.

This section discusses the difference that exist between the cumulative frequency fit and the frequency fit and points out that in some cases, the frequency fit can result in significant amount of under- or over-estimation. Following the cumulative frequency fit criterion, a multi-modal distribution fit spreadsheet program was developed. This method was found to provide a more accurate and straightforward means to analyze particle size distribution data.

Discussed below are the two methods, cumulative frequency fit, frequency fit, and their application to the uni-modal and multi-modal distributions.

\section{3.1 Uni-modal Distribution}

\subsubsection{Cumulative Frequency Fit Method (Method 1)}

The MOUDI data was recorded as mass-weighted data for each stage and the after-filter. Calibration of the MOUDI, by the manufacturer (MSP Corporation), established the effective cut-size aerodynamic diameters $(E C D)$ for each of the stages. ECD, also referred to ${ }_{50} d_{a e}$ in this report, is defined as the aerodynamic particle diameter collected at $50 \%$ efficiency for each stage.

From the mass data $\left(m_{i}\right)$ collected on the MOUDI stages, the cumulative frequency can be calculated by

$$
F\left(E C D_{i}\right)=\frac{\sum_{j=1}^{i} m_{j}}{\sum_{j=1}^{n} m_{j}}
$$


Where, $F\left(E C D_{i}\right): \quad$ cumulative frequency less than stated size;

$m_{i}: \quad$ sample mass of the stage, $\mathrm{mg}$;

$n$ : $\quad$ total number of the mass data, $n=12$ for 11 stages' MOUDI.

It is safe to assume that the particle size distribution can be described by lognormal distribution, and cumulative frequency data group $\left(E C D_{i}, F\left(E C D_{i}\right)\right)$ may be plotted on the log-probability paper. If the plotted points could be fitted with a straight line, then the Mass Median Aerodynamic Diameter $(M M A D)$ and the Geometric Standard Deviation $(G S D)$ of the distribution may be found from the fitted straight line (Zhang, 1987):

$$
\begin{gathered}
M M A D=D p_{50} \\
G S D=\frac{D p_{84.1}}{D p_{50}} \ldots o r \ldots \frac{D p_{50}}{D p_{14.9}}
\end{gathered}
$$

Where, MMAD: $\quad$ mass median aerodynamic diameter, $\mu \mathrm{m}$;

GSD : $\quad$ geometric standard deviation;

$D p_{50}: \quad$ particle diameter where the cumulative frequency equals to 0.5 , that is, $F=0.5$ at that point.

$D p_{84.1}: \quad$ particle diameter at $F=0.841$, and $D p_{14.9}$, at $F=0.149$.

Mathematically, the fitted straight line can be obtained by using the following minimizing technique:

$$
\min \sum\left(F_{f i t}\left(E C D_{i}\right)-F\left(E C D_{i}\right)\right)^{2}
$$


Where, $F_{f i t}$ : fit cumulative frequency as a function of diameter of particle,

$$
\begin{gathered}
\text { which is described by } \\
F_{f i t}=\frac{1}{\sqrt{2 \pi} \log (G S D)} \int_{0.01}^{D p} \exp -\frac{(\ln D p-\ln M M A D)^{2}}{2 \ln ^{2} G S D} d \log D p
\end{gathered}
$$

Optimal MMAD and GSD may be obtained by fitting the data using equation (54). In a spreadsheet, the summation can be used instead of the definite integral in equation (5-5). Equations (5-2) and (5-3) are used when the line is fitted graphically.

\subsubsection{Frequency Fit Method (Method 2)}

Another method to calculate $M M A D$ and $G S D$ is to fit the frequency curve, which was developed for multi-modal distribution analysis (Hinds, 1986; Burkhart, 1987). This method requires the midpoint diameter of every range. The midpoint diameter, $\mathrm{Dmp}_{i}$, can be estimated using the following equation:

$$
\operatorname{Dmp}_{i}=10^{0.5\left(\log E C D_{i}+\log E C D_{i+1}\right)}
$$

The frequency value of each stage is expressed by

$$
f(i)=\frac{m_{i}}{\left(\log E C D_{i+1}-\log E C D_{i}\right) \sum m_{i}}
$$

A curve fitted could be obtained by using the following minimizing equation:

$$
\min \sum\left(f_{f i t}\left(D m p_{i}\right)-f(i)\right)^{2}
$$


Where, $f_{f i t}$ : fit function of the frequency, expressed by equation (5-9):

$$
f_{f i t}=\frac{1}{\sqrt{2 \pi} \log (G S D)} \exp -\frac{\left(\ln D m p_{i}-\ln M M A D\right)^{2}}{2 \ln ^{2} G S D}
$$

\subsubsection{Comparison of the two Methods}

Generally, if the sample data has a distribution close to the standard lognormal distribution, there is no significant difference between the results by these two methods. The following illustrates this point:

Let's choose a group of ' ideal mass data' from the equation (5-5) by specifying a certain $M M A D$ and $G S D$, say $M M A D=0.25 \mu \mathrm{m}, G S D=2.5$. Next, the ' ideal data' may be input into the spreadsheet (with the two methods) to fit them and compare the results obtained.

Table 5-2 shows the comparison between the two methods using the ' ideal data'. Theoretically, the error with method 1 should be negligible, and this can be seen in Table 5-2. The $M M A D$ obtained with method 2 has an error of less than $6 \%$ compared to the exact values.

Table 5-2. MMAD and GSD obtained with the two methods for ideal data

\begin{tabular}{lcccc}
\hline & $M M A D$ & $G S D$ & error & error \\
& $(\mu \mathrm{m})$ & & $($ equation $(5-8))$ & (equation $(5-4))$ \\
------------------------------------- & $2.0 \mathrm{E}-08$ \\
Method 1 & 0.250 & 2.500 & $6.50 \mathrm{E}-03$ & $5.3 \mathrm{E}-04$ \\
Method 2 & 0.265 & 2.542 & $1.96 \mathrm{E}-03$ & \\
\hline
\end{tabular}


Figure 5-1 is a comparison of the semi-log scale charts between the two methods. It shows a very good agreement between the two methods for the ideal data. For the actual sample data (Boston test, clean diesel bus No. 910X-D1), there is an obvious difference in the results obtained with these two methods. Table 5-3 shows the comparison between the two methods for the actual data.

Table 5-3. MMAD and GSD obtained with the two methods for actual sample data

\begin{tabular}{|c|c|c|c|c|}
\hline & $\begin{array}{c}M M A D \\
(\mu \mathrm{m})\end{array}$ & $G S D$ & $\begin{array}{c}\text { error } \\
\text { (equation }(5-8))\end{array}$ & $\begin{array}{c}\text { error } \\
\text { (equation }(5-4))\end{array}$ \\
\hline------ & ----- & ---- & -------- & --------- \\
\hline Method 1 & 0.142 & 2.273 & $1.65 \mathrm{E}-1$ & $1.0 \mathrm{E}-2$ \\
\hline Method 2 & 0.114 & 2.194 & $8.90 \mathrm{E}-2$ & $3.0 \mathrm{E}-2$ \\
\hline
\end{tabular}

Table 5-3 shows that the MMAD from method 1 is greater than the $M M A D$ from method 2. The relative difference is greater than $25 \%$ for the two values of MMAD. However, the two GSD values are in fair agreement.

Figure 5-2 shows a comparison of the fit lines plotted on a log-probability scale. Figure 5-3 shows the comparison on the semi-log scale graph. It can be seen that the cumulative frequency fit (method 1) yields a fit curve that is closer to the cumulative frequency data than method 2.

According to the definition, $M M A D$ is the mass aerodynamic diameter at cumulative frequency of 0.5 . Hence, the cumulative frequency fit method would be more 
suitable than the frequency fit method. The frequency fit may underestimate or overestimate according to different frequency histograms.

\subsubsection{Multi-modal Distribution}

If the sample data has more than one peak on its frequency histogram chart, or when a very large $G S D$ is observed with a uni-modal distribution fit, then it is highly likely that the distribution is a multi-modal.

There are two $M M A D$ and two $G S D$ values a bi-modal distribution. If the data points are plotted on log-probability scale paper they will constitute an $S$ shape curve instead of the straight line. The curve represents the overall distribution. The two asymptotes to the two ends of the curve represent the two underlying distributions (see Figure 5-4). It is not trivial to accurately plot the asymptotes graphically. Hence, it is impossible to get MMADs and GSDs (Burkhart, 1987; Hewett, 1991). Therefore, a better means should be found out with respect to cumulative frequency fit.

There is a basic assumption that multi-modal distribution can be adequately described by a linear combination of weighted, lognormal distributions (Zhang, 1987; Hewett, 1991). Based on this assumption, a spreadsheet using combination fit function can be developed. Let's say the overall distribution consists of $m$ underlying distributions. The $i$ th underlying distribution is characterized by $M M A D_{i}$ and $G S D_{i}$. The frequencies are expressed by equations (5-10):

$$
f_{i}=\frac{1}{\sqrt{2 \pi} \log \left(G S D_{i}\right)} \exp -\frac{\left(\ln D p-\ln M M A D_{i}\right)^{2}}{2 \ln ^{2} G S D_{i}}
$$

Where, $i=1,2, \ldots, m$.

These frequencies may be combined using modal mass fractions:

$$
f_{c}=w_{1} f_{1}+w_{2} f_{2}+\ldots+w_{m} f_{m}
$$


Where, $f_{c}$ : combination frequency;

$w_{1}, w_{2}, \ldots w_{m}: \quad$ modal mass fractions, that is, the percentage of each type of underlying distribution.

Modal mass fractions satisfy equation (5-12):

$$
w_{1}+w_{2}+\ldots+w_{m}=1
$$

Integrating $f_{c}$ with respect to $d \log D p$ from 0.01 to $D p$ to get the overall cumulative frequency:

$$
F_{t}=\int_{0.01}^{D p} f_{c} d \log D p
$$

Where $F_{t}$ : overall cumulative frequency;

Dp : $\quad$ particle size, $\mu \mathrm{m}$.

In the spreadsheet, the summation can be used instead of the definite integral.

Then, MMADs and GSDs may be obtained by:

$$
\min \sum\left(F_{t}\left(E C D_{i}\right)-F\left(E C D_{i}\right)\right)^{2}
$$

Using the same numerical method, the optimal solution can be obtained. Figure 5-4 is an example of bi-modal distribution of log-probability scale chart (Cummins RTD/skip CNG 1013 \#1, Byers, 1999). Figure 5-5 is the same sample plotted on semi-log scale paper. Fiurge 5-6 is a typical tri-modal distribution example (Cummins RTD/skip CNG 1013 \#2, Without Catalyst. Byers, 1999). 
These graphs indicate that the combination function fit can obtain a good fit curve to the data points. The frequency curve drawn according to the solution parameters is also in good agreement to the frequency histogram.

\subsubsection{Fit Procedure}

(1). Input the MOUDI sample data; the spreadsheet will calculate and display the frequency and cumulative frequency distribution historgram graphically.

(2). Determine the number of underlying distributions (m), guess the initial $M M A D$ and $G S D$ of each distribution, and the initial percentage contribution of each distribution to the total distribution by visual inspection (if m- modal distribution is chosen, m-1 initial w's shoud be given, the one left is constrained by equation (5-12)).

(3). Run the solver to get the optimal $M M A D_{i}, G S D_{i}$ and $w_{i}$ (the algorithm is based on equation (5-14)).

\subsubsection{Discussion}

(1) The fit curve with the cumulative frequency fit method for particle size distribution is much closer to the cumulative frequency point of sample data, it still can show a straightforward chart to agree with the frequency histogram of sample data.

(2) If the sample data has a size distribution close to the standard log-normal distribution, the frequency fit method also works, but this case is seldom. In most cases, the cumulative frequency fit method works better than the frequency fit method.

(3) The numerical program of linear combination function fit is suitable for the multi-modal size distribution. It provides a quick and convenient way for the aerosol analysis research. 
(4) According to the definition of the mass mean aerodynamic diameter, the particle size distribution parameters should be fitted by cumulative frequency fit. Because the graphical method on log-probit/probability paper of cumulative frequency fit is no longer valid for multi-modal distribution, many efforts were put into searching frequency fit instead, which is only an approximation means. The technique described in this section solves the problem. 


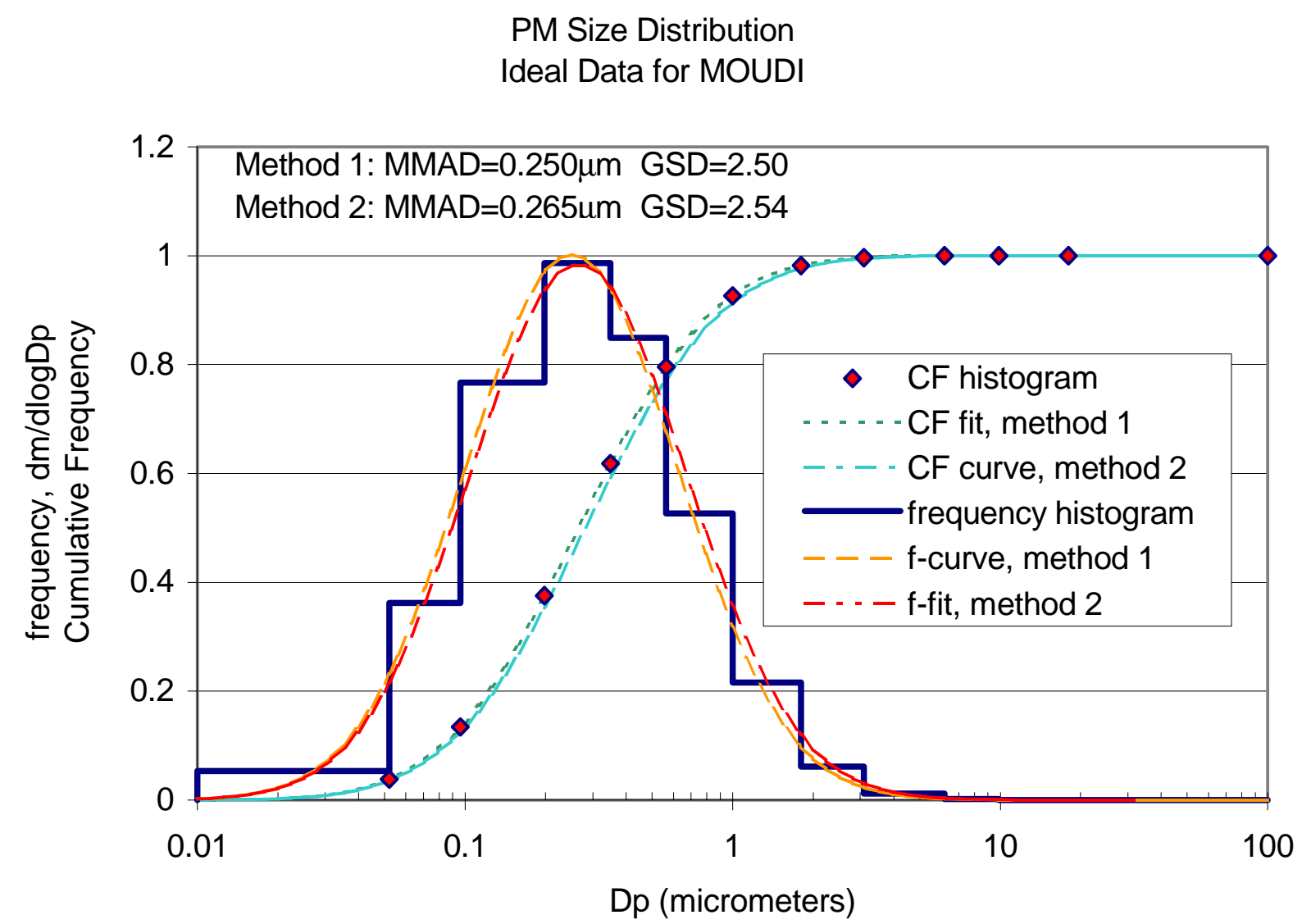

Figure 5-1. A Comparison between Cumulative Frequency Fit and Frequency Fit of Ideal Data (CF in the legend represents Cumulative Frequency)

(Method 1: use cumulative frequency fit, draw frequency curve with the fit result; Method 2: use frequency fit, draw cumulative frequency curve with the fit result) 


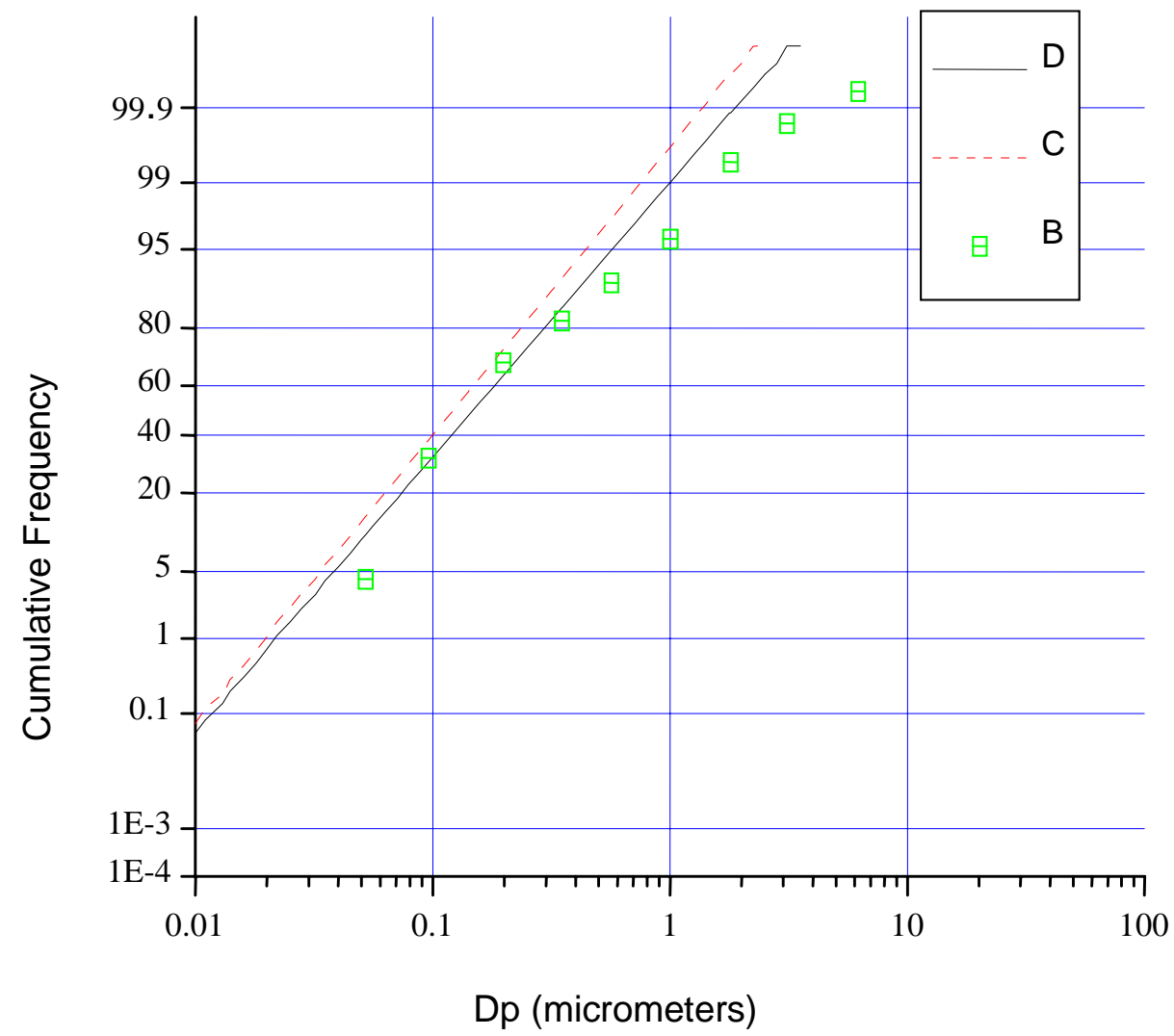

Figure 5-2. Fit Lines on Log-probability Paper of the Real Sample Data (D-cumulative frequency fit, $\mathrm{C}-$ frequency fit, $\mathrm{B}-$ sample data) 


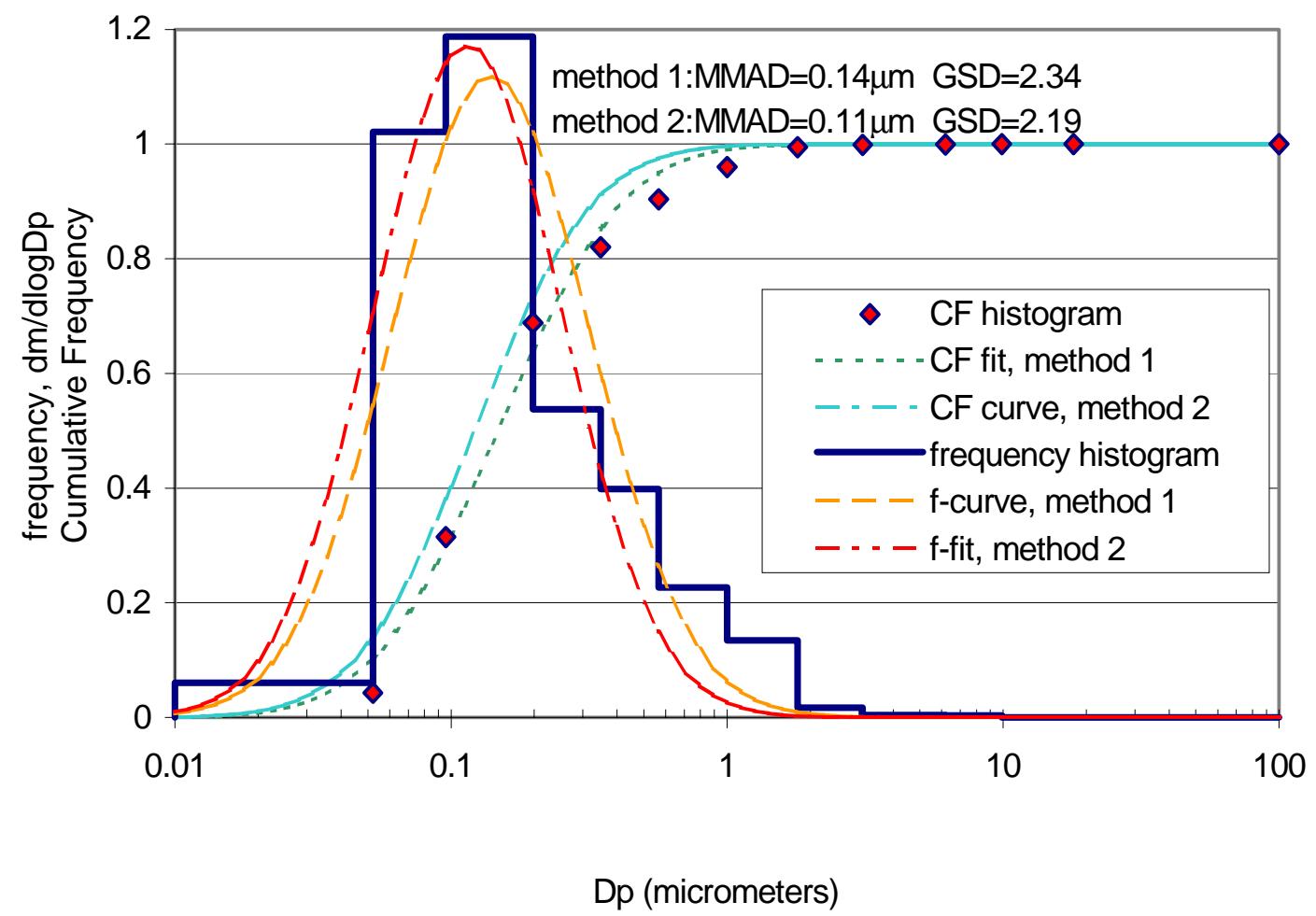

Figure 5-3. A Comparison between Cumulative Frequency Fit and Frequency Fit of Sample Data (CF in the legend represents Cumulative Frequency)

(Method 1: use cumulative frequency fit, draw frequency curve with the fit result; Method 2: use frequency fit, draw cumulative frequency curve with the fit result) 


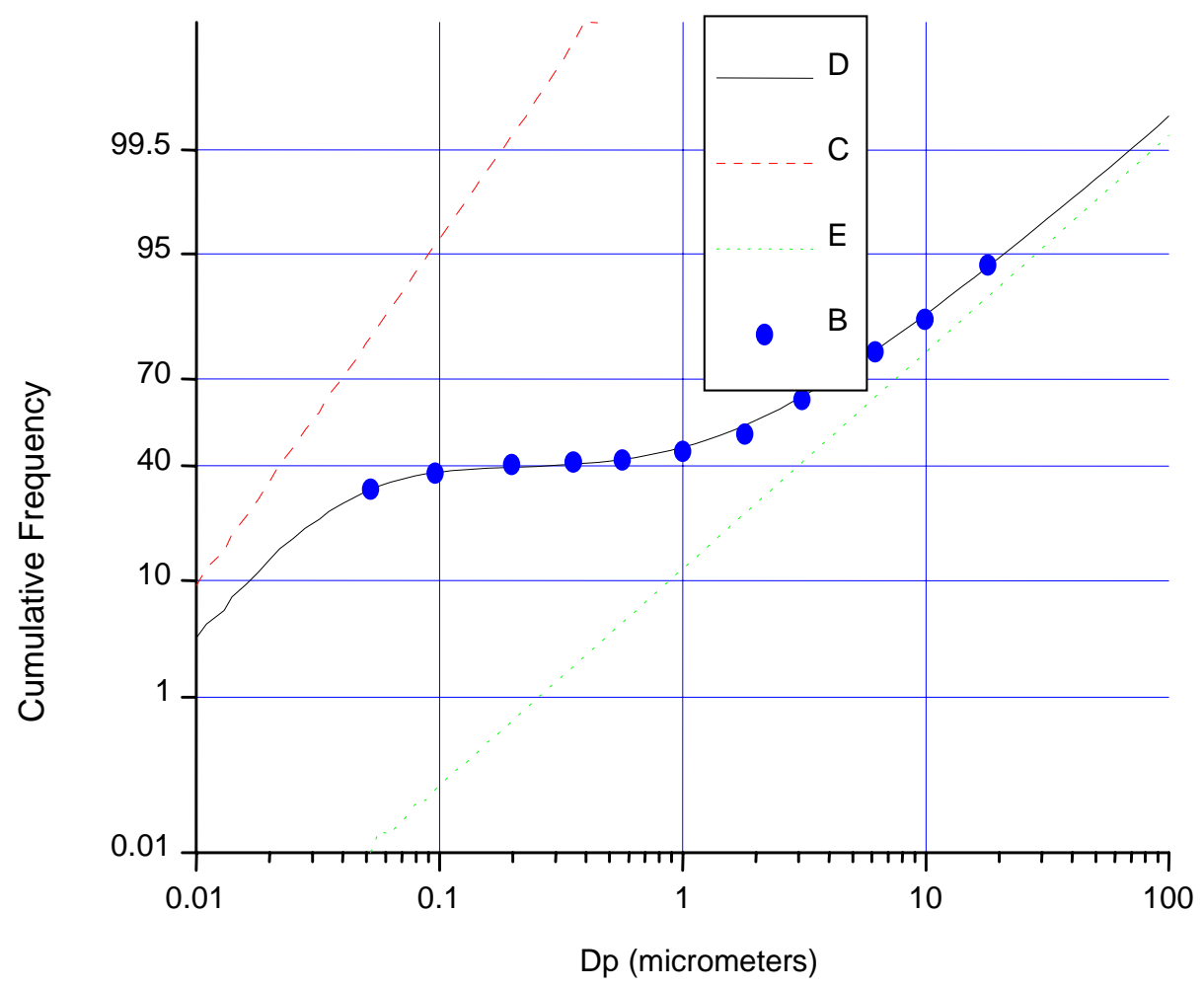

Figure 5-4. Bi-modal Fit Curves on the Log-probability Scale Paper of Sample Data (B-sample data, D-combination cumulative frequency fit $\mathrm{C}$-underlying distribution $1, \mathrm{E}$ - underlying distribution 2) 


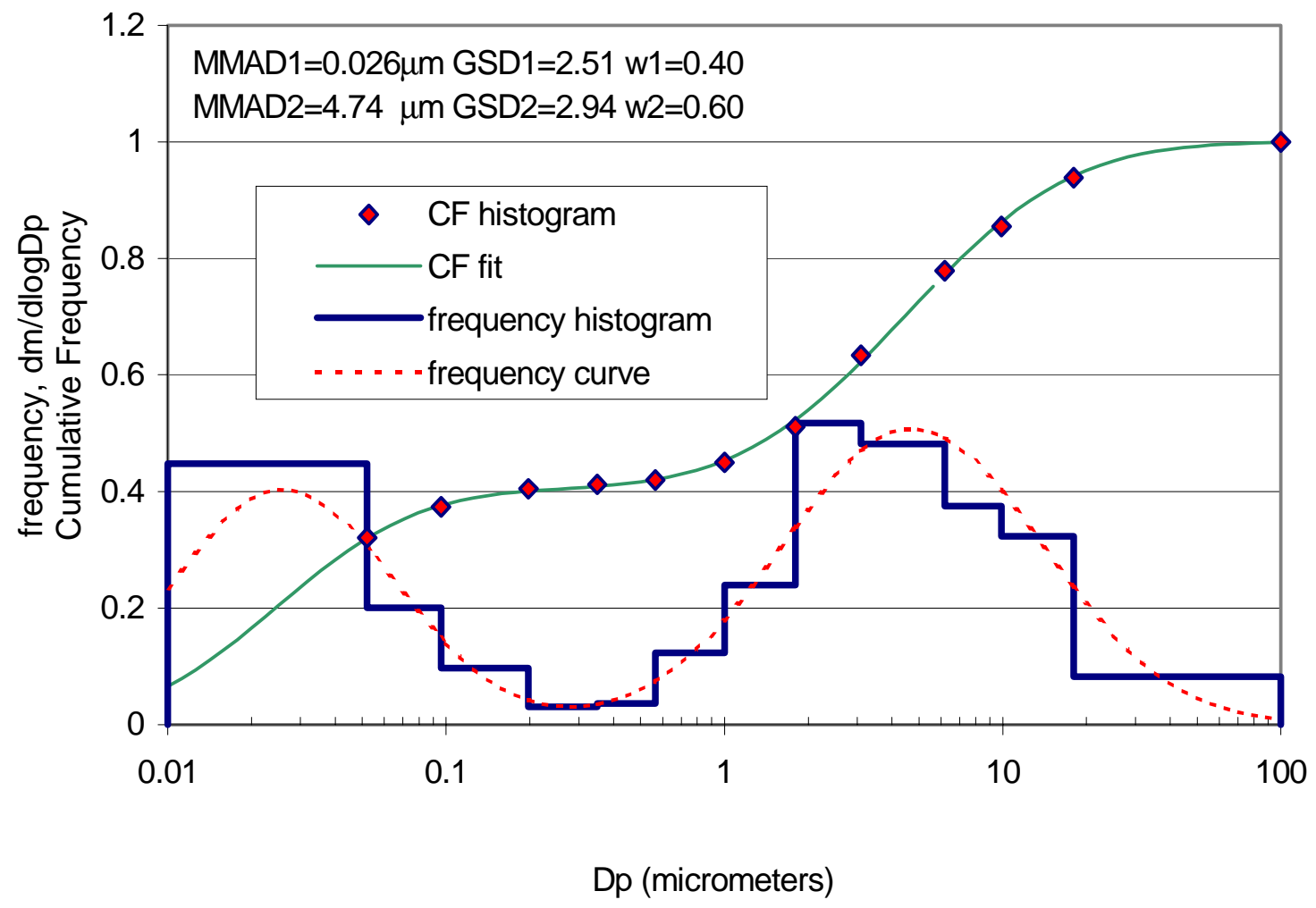

Figure 5-5. Bi-modal Fit Curves on the Semi-log Scale Paper of Sample Data ( $\mathrm{CF}$ in the legend represents Cumulative Frequency)

(Use combination cumulative frequency fit, draw the frequency curve with the result) 


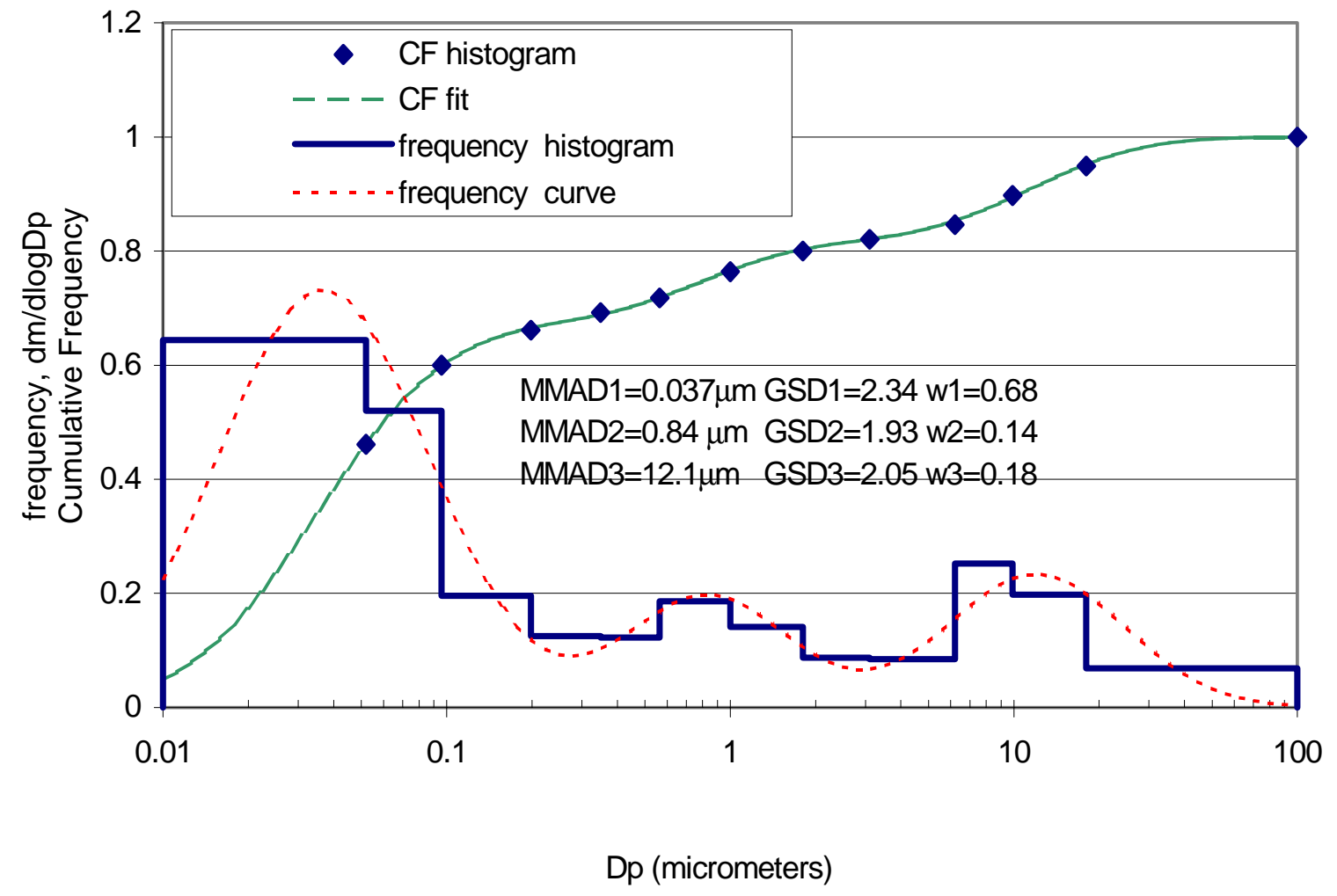

Figure 5-6. Tri-modal Fit Curves on the Semi-log Scale Paper of Sample Data (CF in the legend represents Cumulative Frequency)

(Use combination cumulative frequency fit, draw the frequency curve with the result) 


\subsection{Cyclone Data Reduction Method}

The cyclone filters (primary and secondary) were weighed and mass values were reduced to yield the actual mass of particulate matter. In order to reduce the data using raw mass values from the filters to actual data, the measured mass was first divided by the total sample volume through cyclone. This was found by summing the instantaneous flow rate data recorded by the computer. Also needed are the total volume of the diluted exhaust through the primary dilution tunnel, and the dilution factor, DF. The PM mass emission can be expressed by equation (5-15):

$$
M_{\text {actual }}=\left[\frac{\text { NetWeight }}{\text { SampleVolume }}-\left\{\frac{\text { BackgroundNetWeight }}{\text { BackgroundSampleVolume }} \times\left(1-\frac{1}{D F}\right)\right\} \times V_{\text {tunnel }}\right.
$$

Where, $D F$ : $\quad$ dilution factor of the main dilution tunnel.

$M_{\text {actual }}: \quad \mathrm{PM}_{2.5}\left(\mathrm{PM}_{1.0}\right)$ mass emission of the bus.

$V_{\text {tunnel }}: \quad$ total volume of the diluted exhaust through the primary dilution tunnel.

Compared to the mass weights collected during the vehicle tests, the background mass weights were very small, hence the term including 1/DF was negligible while DF was usually greater than 10 .

\subsection{Bus Exhaust PM Test Result}

\subsubsection{Mass Emission Rates of Eight Vehicles}

The two conventional baseline buses have nearly the same mass emission rates. The other three types of buses have the very different mass emission rates. For the two clean diesel buses, one has nearly three times higher of PM than the other one. For the 
two hybrid buses, the mass emissions have an even larger difference; one has 5 times higher TPM, 3 times higher PM 2.5 and $\mathrm{PM}_{1.0}$ than the other one. The average of TPM emission from the two hybrid buses are $65 \%$ lower than that from the clean diesel buses, $76 \%$ lower than that from the conventional diesel baseline buses, and 2.6 times higher than that from the CNG buses. The order of the mass emission rates of the buses was: conventional diesel > clean diesel > Hybrid > CNG. Only the two CNG and one hybrid buses have the total mass emission rates close to 0.5 gram per mile (see Table 5-4 to Table 5-6 and Figure 5-7). 
Table 5-4 Cyclone Data from Boston ( $\left.\mathrm{PM}_{2.5}\right)$

\begin{tabular}{|c|c|c|c|c|c|c|}
\hline & $\begin{array}{c}\text { Flow rate } \\
\text { (Cyclone) } \\
\text { (lpm) }\end{array}$ & $\begin{array}{c}\text { Flow rate } \\
\text { (Tunnel) } \\
\text { (scf) }\end{array}$ & $\begin{array}{l}\text { Mass } \\
\text { collected } \\
(\mathrm{mg})\end{array}$ & $\begin{array}{l}\text { Concen- } \\
\text { tration } \\
\left(\mathrm{mg} / \mathrm{m}^{3}\right)\end{array}$ & Miles/run & $\begin{array}{l}\text { Mass } \\
\text { emission } \\
\text { (g/mile) }\end{array}$ \\
\hline \multirow[t]{6}{*}{ NG\#1 } & 18.61 & 21.08 & 0.08 & 0.151 & 4.04 & 0.038 \\
\hline & 18.71 & 20.99 & 0.054 & 0.101 & 4.05 & 0.025 \\
\hline & 19.26 & 20.55 & 0.067 & 0.122 & 4.00 & 0.030 \\
\hline & 19.27 & 20.53 & 0.059 & 0.108 & 4.05 & 0.026 \\
\hline & 19.33 & 20.49 & - & - & 4.03 & - \\
\hline & 16.99 & 20.97 & - & - & 4.04 & - \\
\hline average & & & & 0.121 & 1.00 & 0.030 \\
\hline \multirow[t]{5}{*}{ Hybrid\#1 } & 17.81 & 21.57 & 0.276 & 0.545 & 3.97 & 0.143 \\
\hline & 18.00 & 21.45 & 0.334 & 0.652 & 4.04 & 0.167 \\
\hline & 17.74 & 21.69 & 0.2 & 0.396 & 3.95 & 0.105 \\
\hline & 16.67 & 21.70 & - & - & 3.98 & - \\
\hline & 16.73 & 21.59 & - & - & 4.05 & 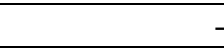 \\
\hline average & & & & 0.531 & 1.00 & 0.139 \\
\hline \multirow[t]{3}{*}{ Hybrid\#2 } & 17.72 & 21.92 & 0.092 & 0.183 & 4.03 & 0.048 \\
\hline & 17.90 & 21.80 & 0.092 & 0.181 & 4.06 & 0.047 \\
\hline & 17.95 & 21.78 & 0.117 & 0.229 & 4.06 & 0.059 \\
\hline average & & & & 0.197 & 1.00 & 0.051 \\
\hline \multirow[t]{4}{*}{ Clean D\#1 } & 17.64 & 22.11 & 0.259 & 0.516 & 4.08 & 0.135 \\
\hline & 17.74 & 22.03 & 0.248 & 0.491 & 4.09 & 0.128 \\
\hline & 17.79 & 21.99 & 0.26 & 0.514 & 4.10 & 0.133 \\
\hline & 17.89 & 21.92 & - & - & 4.07 & - \\
\hline average & & & & 0.507 & 1.00 & 0.132 \\
\hline \multirow[t]{4}{*}{ Clean D\#2 } & 17.84 & 21.52 & - & - & 4.08 & - \\
\hline & 17.95 & 21.39 & 0.733 & 1.435 & 4.09 & 0.363 \\
\hline & 17.87 & 21.34 & 0.675 & 1.328 & 4.08 & 0.336 \\
\hline & 18.16 & 21.18 & - & - & 4.08 & - \\
\hline average & & & & 1.381 & 1.00 & 0.349 \\
\hline \multirow{3}{*}{$\mathrm{NG \# 2}$} & 18.71 & 20.95 & - & - & 4.03 & - \\
\hline & 18.81 & 20.87 & 0.125 & 0.234 & 4.02 & 0.059 \\
\hline & 18.83 & 20.85 & 0.101 & 0.189 & 4.04 & 0.047 \\
\hline average & & & & 0.205 & 1.00 & 0.053 \\
\hline \multirow[t]{3}{*}{ Diesel\#1 } & 17.63 & 21.93 & 0.861 & 1.717 & 4.04 & 0.450 \\
\hline & 17.66 & 21.92 & 0.875 & 1.741 & 4.04 & 0.457 \\
\hline & 17.65 & 21.95 & 0.842 & 1.677 & 4.06 & 0.438 \\
\hline average & & & & 1.711 & 1.00 & 0.448 \\
\hline \multirow[t]{4}{*}{ Diesel\#2 } & 17.64 & 21.95 & - & 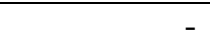 & 4.04 & - \\
\hline & 17.68 & 21.91 & 0.839 & 1.668 & 4.04 & 0.437 \\
\hline & 17.69 & 21.90 & 0.837 & 1.663 & 4.05 & 0.435 \\
\hline & 17.71 & 21.89 & 0.837 & 1.661 & 4.03 & 0.436 \\
\hline average & & & & 1.522 & 1.00 & 0.436 \\
\hline \multirow[t]{4}{*}{ Clean D\#2 } & 17.89 & 21.44 & 0.729 & 1.432 & 4.05 & 0.366 \\
\hline & 17.98 & 21.36 & 0.909 & 1.777 & 4.01 & 0.458 \\
\hline & 17.99 & 21.34 & 0.82 & 1.602 & 4.06 & 0.407 \\
\hline & 18.02 & 21.29 & 0.85 & 1.658 & 4.06 & 0.420 \\
\hline average & & & & 1.617 & & 0.413 \\
\hline
\end{tabular}


Table 5-5 Cyclone Data from Boston ( $\left.\mathrm{PM}_{1.0}\right)$

\begin{tabular}{|c|c|c|c|c|c|c|}
\hline & $\begin{array}{c}\text { Flow rate } \\
\text { (Cyclone) } \\
\text { (lpm) }\end{array}$ & $\begin{array}{c}\text { Flow rate } \\
\text { (Tunnel) } \\
\text { (scf) }\end{array}$ & $\begin{array}{c}\text { Mass } \\
\text { collected } \\
(\mathrm{mg})\end{array}$ & $\begin{array}{c}\begin{array}{c}\text { Concen- } \\
\text { tration } \\
\left(\mathrm{mg} / \mathrm{m}^{3}\right)\end{array} \\
\end{array}$ & Miles/run & $\begin{array}{c}\text { Mass } \\
\text { emission } \\
\text { (g/mile) }\end{array}$ \\
\hline \multirow[t]{6}{*}{ NG\#1 } & 18.33 & 21.08 & 0.052 & 0.100 & 4.04 & 0.025 \\
\hline & 18.43 & 20.99 & 0.042 & 0.080 & 4.05 & 0.020 \\
\hline & 18.97 & 20.55 & 0.032 & 0.059 & 4.00 & 0.015 \\
\hline & 18.98 & 20.53 & 0.055 & 0.102 & 4.05 & 0.025 \\
\hline & 19.04 & 20.49 & - & - & 4.03 & \\
\hline & 16.78 & 20.97 & - & & 4.04 & \\
\hline average & & & & 0.085 & & 0.021 \\
\hline \multirow[t]{5}{*}{ Hybrid\#1 } & 17.56 & 21.57 & 0.256 & 0.513 & 3.97 & 0.134 \\
\hline & 17.75 & 21.45 & 0.318 & 0.630 & 4.04 & 0.162 \\
\hline & 17.50 & 21.69 & 0.169 & 0.340 & 3.95 & 0.090 \\
\hline & 16.52 & 21.70 & - & - & 3.98 & 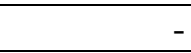 \\
\hline & 16.57 & 21.59 & - & - & 4.05 & \\
\hline average & & & & 0.494 & & 0.129 \\
\hline \multirow{3}{*}{ Hybrid\#2 } & 17.47 & 21.92 & 0.084 & 0.169 & 4.03 & 0.044 \\
\hline & 17.66 & 21.80 & 0.085 & 0.169 & 4.06 & 0.044 \\
\hline & 17.71 & 21.78 & 0.076 & 0.151 & 4.06 & 0.039 \\
\hline average & & & & 0.163 & & 0.043 \\
\hline \multirow[t]{4}{*}{ Clean D\#1 } & 17.39 & 22.11 & 0.232 & 0.469 & 4.08 & 0.123 \\
\hline & 17.49 & 22.03 & 0.233 & 0.468 & 4.09 & 0.122 \\
\hline & 17.54 & 21.99 & 0.23 & 0.461 & 4.10 & 0.119 \\
\hline & 17.61 & 21.92 & - & - & 4.07 & \\
\hline average & & & & 0.466 & & 0.121 \\
\hline \multirow[t]{4}{*}{ Clean D\#2 } & 17.52 & 21.52 & - & - & 4.08 & \\
\hline & 17.67 & 21.39 & 0.603 & 1.201 & 4.09 & 0.304 \\
\hline & 17.68 & 21.34 & 0.552 & 1.098 & 4.08 & 0.278 \\
\hline & 17.86 & 21.18 & - & - & 4.08 & \\
\hline average & & & & 1.149 & & 0.291 \\
\hline \multirow[t]{3}{*}{ NG\#2 } & 18.42 & 20.95 & - & - & 4.03 & \\
\hline & 18.53 & 20.87 & 0.098 & 0.186 & 4.02 & 0.047 \\
\hline & 18.56 & 20.85 & 0.095 & 0.180 & 4.04 & 0.045 \\
\hline average & & & & 0.195 & & 0.046 \\
\hline \multirow[t]{3}{*}{ Diesel\#1 } & 17.36 & 21.93 & 0.74 & 1.500 & 4.04 & 0.393 \\
\hline & 17.38 & 21.92 & 0.75 & 1.517 & 4.04 & 0.398 \\
\hline & 17.37 & 21.95 & 0.724 & 1.466 & 4.06 & 0.383 \\
\hline average & & & & 1.494 & & 0.391 \\
\hline \multirow[t]{4}{*}{ Diesel\#2 } & 17.35 & 21.95 & - & & 4.04 & \\
\hline & 17.39 & 21.91 & 0.69 & 1.395 & 4.04 & 0.365 \\
\hline & 17.41 & 21.90 & 0.786 & 1.588 & 4.05 & 0.415 \\
\hline & 17.42 & 21.89 & 0.699 & 1.411 & 4.03 & 0.370 \\
\hline average & & & & 1.441 & & 0.383 \\
\hline \multirow[t]{4}{*}{ Clean D\#2 } & 17.57 & 21.44 & 0.678 & 1.357 & 4.05 & 0.347 \\
\hline & 17.66 & 21.36 & 0.733 & 1.460 & 4.01 & 0.376 \\
\hline & 17.68 & 21.34 & 0.673 & 1.339 & 4.06 & 0.340 \\
\hline & 17.71 & 21.29 & 0.689 & 1.368 & 4.06 & 0.346 \\
\hline average & & & & 1.381 & & 0.352 \\
\hline
\end{tabular}


Table 5-6 Mass Emission Rates of MBTA test buses: g/mile

\begin{tabular}{|c|c|c|c|c|}
\hline Vehicle ID & PM $_{1.0}$ & PM $_{2.5}$ & TPM & Description \\
\hline 6001CNG & 0.021 & 0.030 & 0.047 & CNG \#1 \\
\hline 6000CNG & 0.046 & 0.053 & 0.044 & CNG \#2 \\
\hline 9848-D1 & 0.121 & 0.132 & 0.174 & Clean D \#1 \\
\hline 910X-D1 & 0.352 & 0.413 & 0.51 & Clean D \#2 \\
\hline 5000-D1 & 0.129 & 0.139 & 0.178 & Hybrid \#1 \\
\hline 5001-D1 & 0.043 & 0.051 & 0.036 & Hybrid \#2 \\
\hline 310-D1 & 0.391 & 0.448 & 0.494 & Diesel \#1 \\
\hline 327-D1 & 0.383 & 0.436 & 0.487 & Diesel \#2 \\
\hline
\end{tabular}


MASS Emission Rates

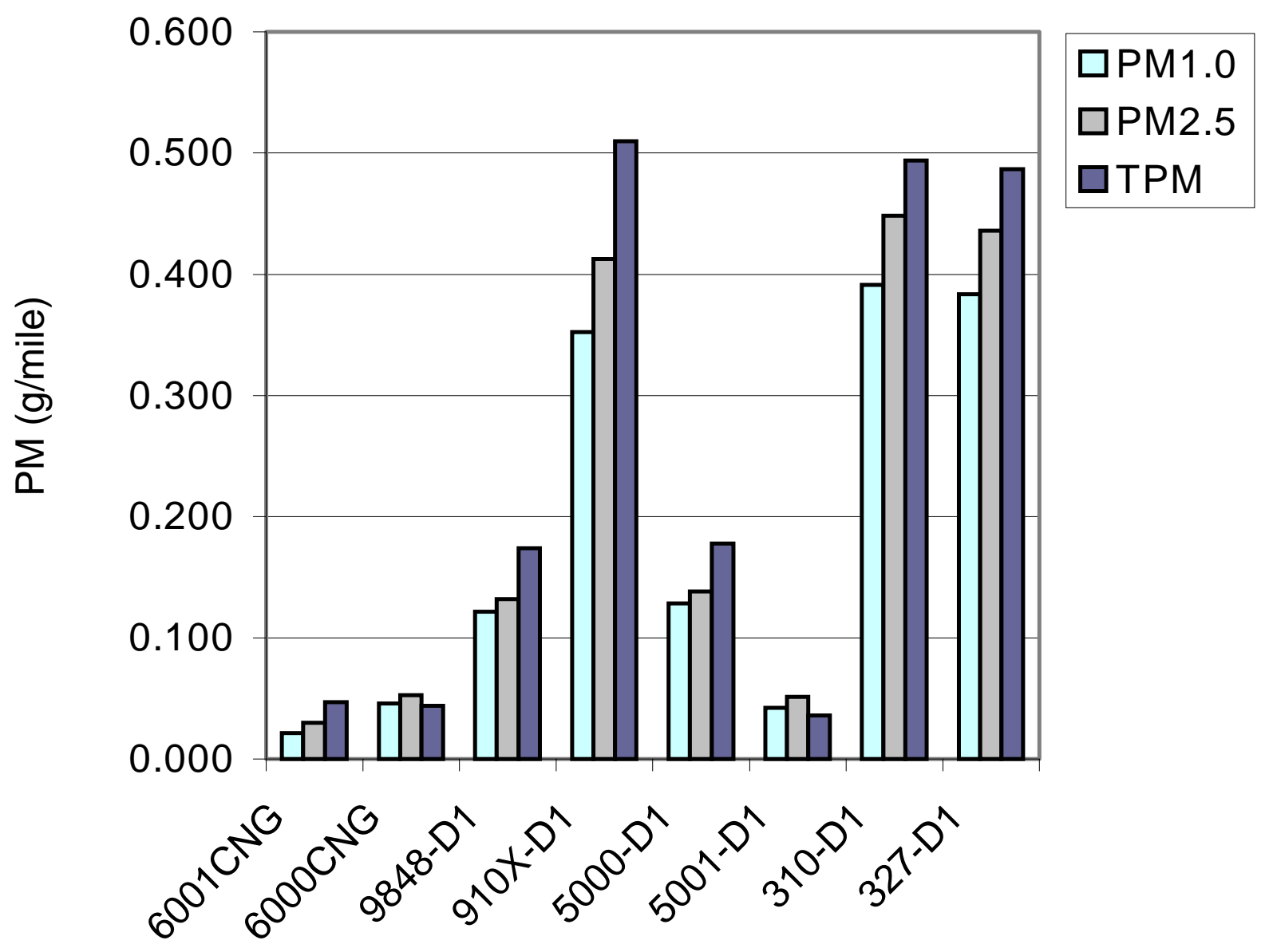

Figure 5-7 Mass Emission Rates of MBTA Test Buses 


\subsubsection{Particle Size Distribution}

During the test, the moisture problem of CNG with the MOUDI operation was found out. The water droplets condensed from the high level moisture could clog the nozzles of some upper stages and caused the increase of the pressure drop from cap to the $7^{\text {th }}$ stage which is used for monitoring the flow rate. If continuously adjusting the valve to maintain a constant monitoring pressure drop, the actual flow would decrease and the pressure drop from the $7^{\text {th }}$ stage to filter base would also decrease. If without doing any adjustment, the monitoring pressure would increase all the way till the end of test, with a 5 inch water increase for the 1st run, 3 inch water for the $2^{\text {nd }}$ run and 1 inch water for the $3^{\text {rd }}$ run. But the pressure drop from the $7^{\text {th }}$ stage to filter base was quiet stable, so the flow through the MOUDI could be considered as acceptable. As the tunnel warm-up, lesser amount of water condensation is observed which prevents the clogging of the nozzles. So the data of the $3^{\text {rd }}$ run could be considered as valid data at least.

The MOUDI data reduction results are shown in Figure 5-8 to Figure 5-13. The particle size distribution of the two CNG buses is characterized by bi-modal distribution, with the smaller MMD (Mass Median Diameter) varying from $0.034 \sim 0.038 \mu \mathrm{m}$ and the larger MMD, 2.2 7.8 $\mu \mathrm{m}$. The two clean diesel buses had uni-modal particle size distribution with the MMD ranging from 0.14 0.17 $\mu \mathrm{m}$ (the bi-modal distributions with the larger CMD ranging from $38-51 \mu \mathrm{m}$, the modal mass fractions are less than 0.30 ).

The particles of all the 4 buses have uni-modal distribution when the mass data are converted to count data. The Count Median Diameters (CMD) for the two CNG buses are 0.018 and $0.022 \mu \mathrm{m}$; the two clean diesel buses, 0.032 and $0.034 \mu \mathrm{m}$. 


\subsection{Summary}

(1) The mass emission rates' order of the buses were: conventional diesel > clean diesel > Hybrid > CNG. Only the two CNG and one Hybrid bus had the total mass emission near to 0.5 gram per mile.

(2) The particle size distribution of the two CNG buses was characterized by bimodal distribution, the smaller MMD (Mass Median Diameter) ranged from $0.034 \mu \mathrm{m}$ to $0.038 \mu \mathrm{m}$ and the larger MMD, 2.2 7.8 $\mu \mathrm{m}$. The two clean diesel buses had a uni-modal particle size distribution with the MMD ranging from 0.14 0.17 $\mu \mathrm{m}$. All the buses above had uni-modal particle size distribution when the mass data were converted to count data. The Count Median Diameters (CMD) for the two CNG buses were 0.018 and $0.022 \mu \mathrm{m}$; the two clean diesel buses, 0.032 and $0.034 \mu \mathrm{m}$.

(3) The cumulative frequency fit method for particle size distribution could yield a much closer fitting curve to the cumulative frequency point of sample data than the frequency fit method. The numerical program of linear combination function fit was suitable for the multi-modal size distribution. It provided a quick and convenient way for the aerosol analysis research. 


\section{MOUDI Size Distribution Clean Diesel \#2, 910X-D1, Run 3}

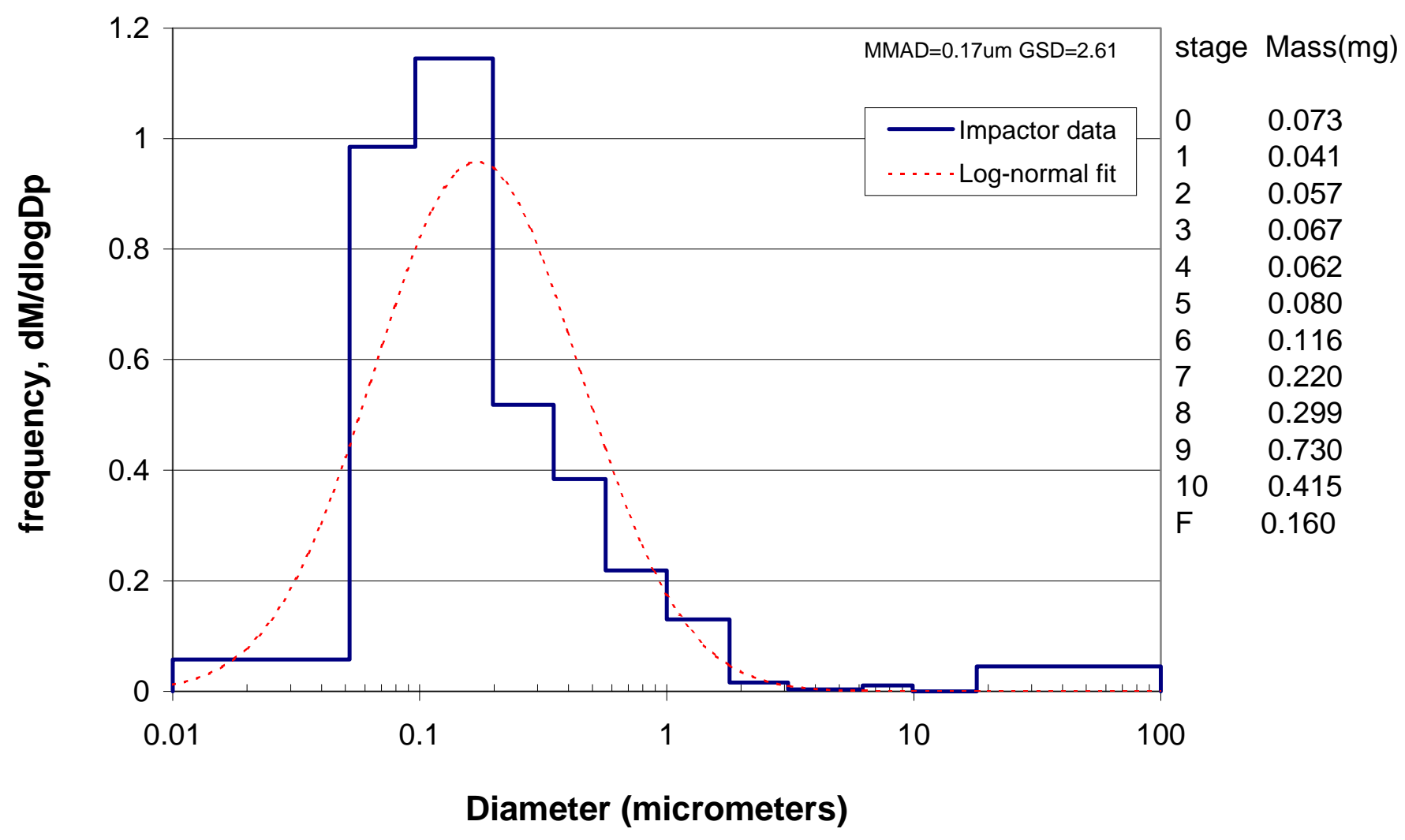

Figure 5-8 Particle Size Distribution of Bus 910X-D1 (1) 


\section{MOUDI Size Distribution Clean Diesel \#2, 910X-D1, Run 1}

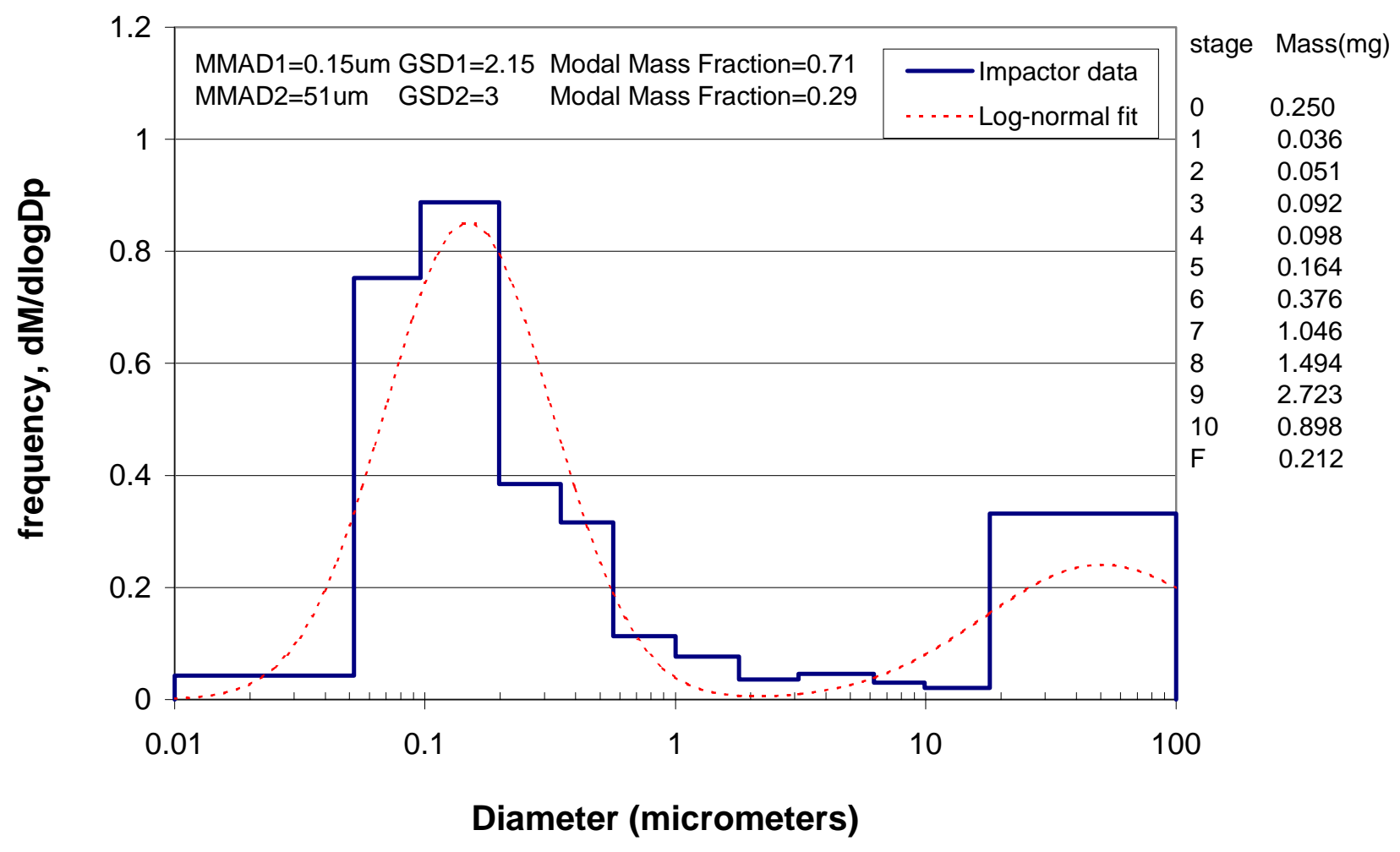

Figure 5-9 Particle Size Distribution of Bus 910X-D1 (2) 


\section{MOUDI Size Distribution Clean Diesel \#1, 9848-D1, Run 3}

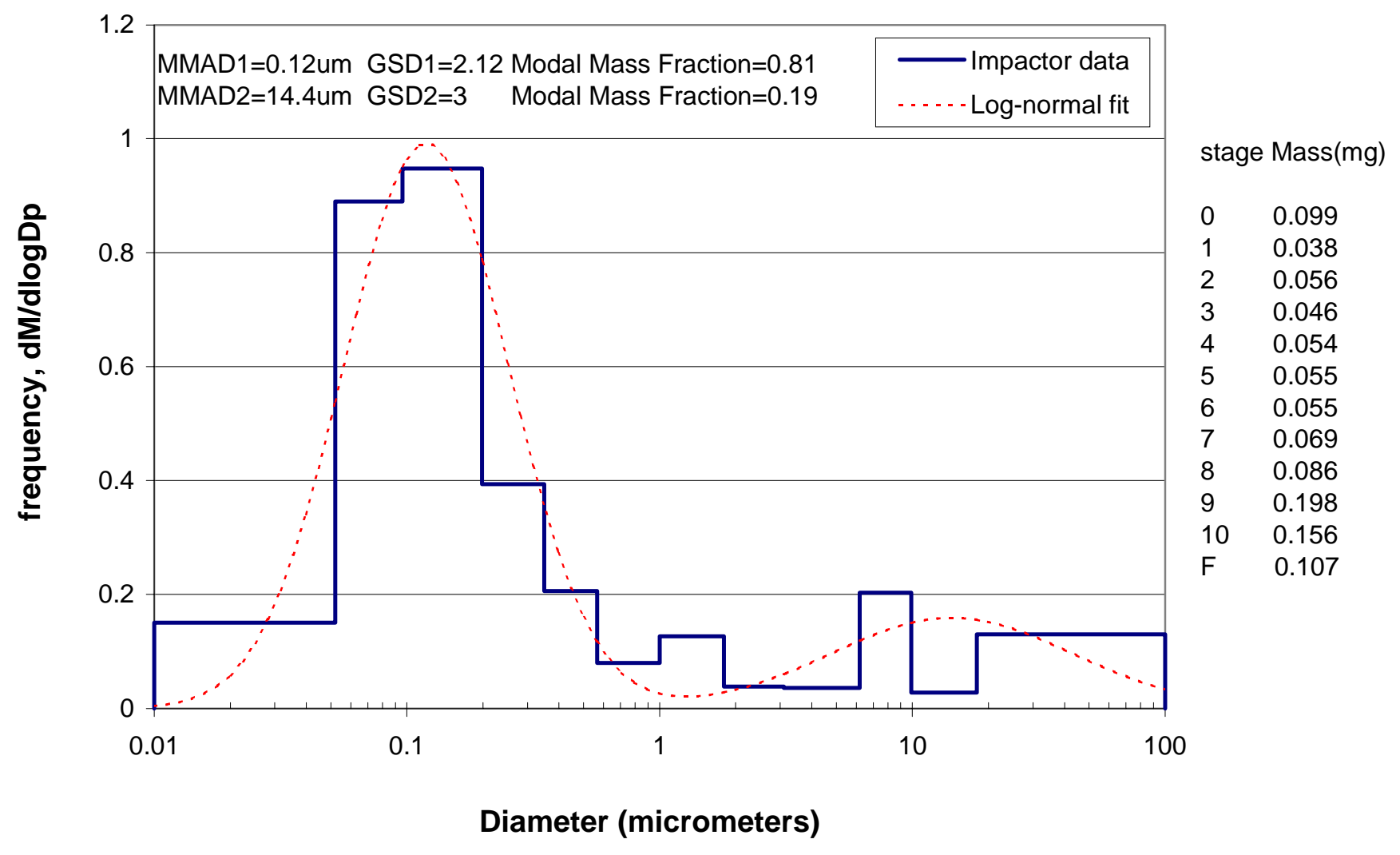

Figure 5-10 Particle Size Distribution of Bus 9848-D1 (1) 


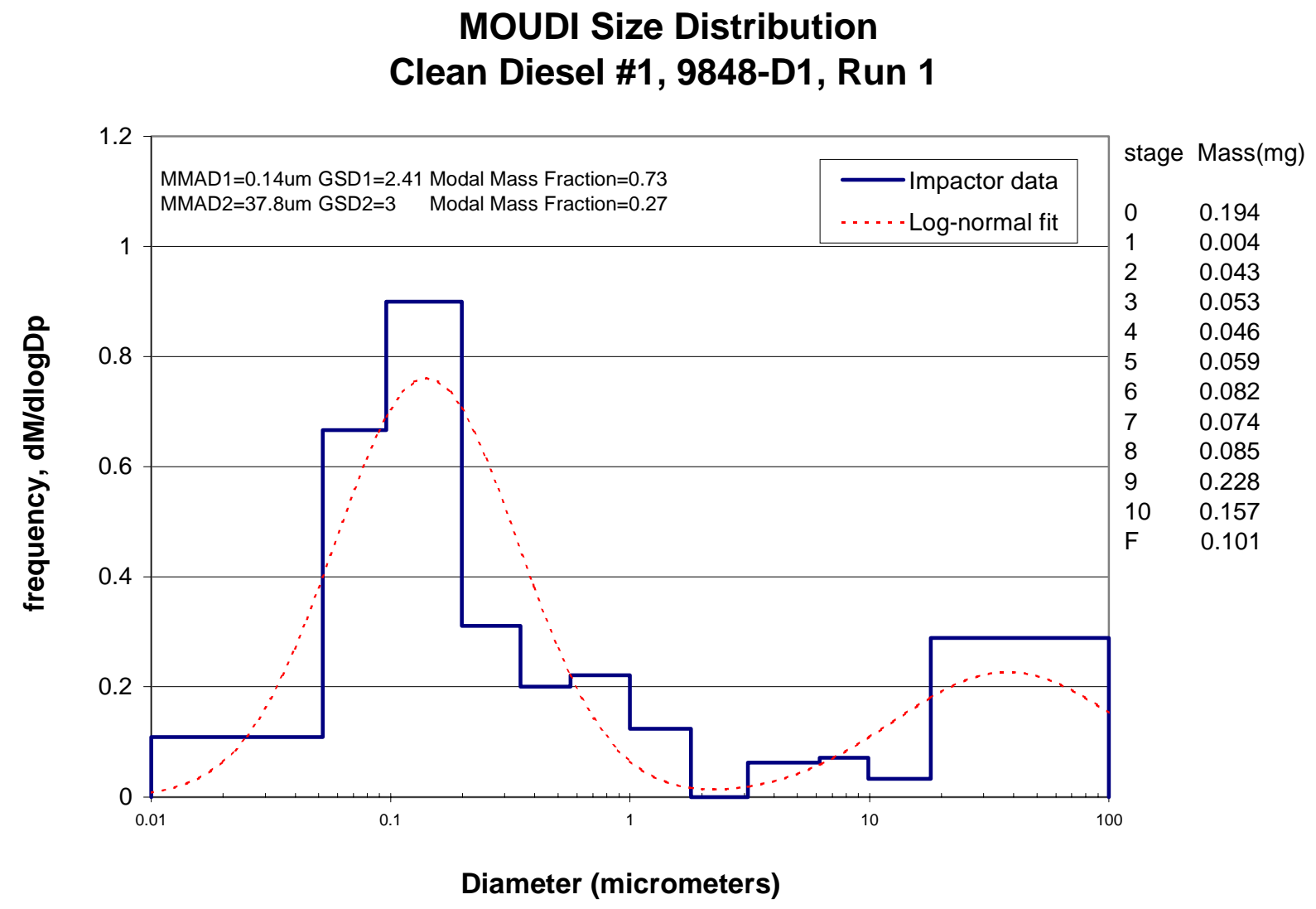

Figure 5-11 Particle Size Distribution of Bus 9848-D1 (2) 


\section{MOUDI Size Distribution \\ CNG Bus \# 1, 6001, Run 3}

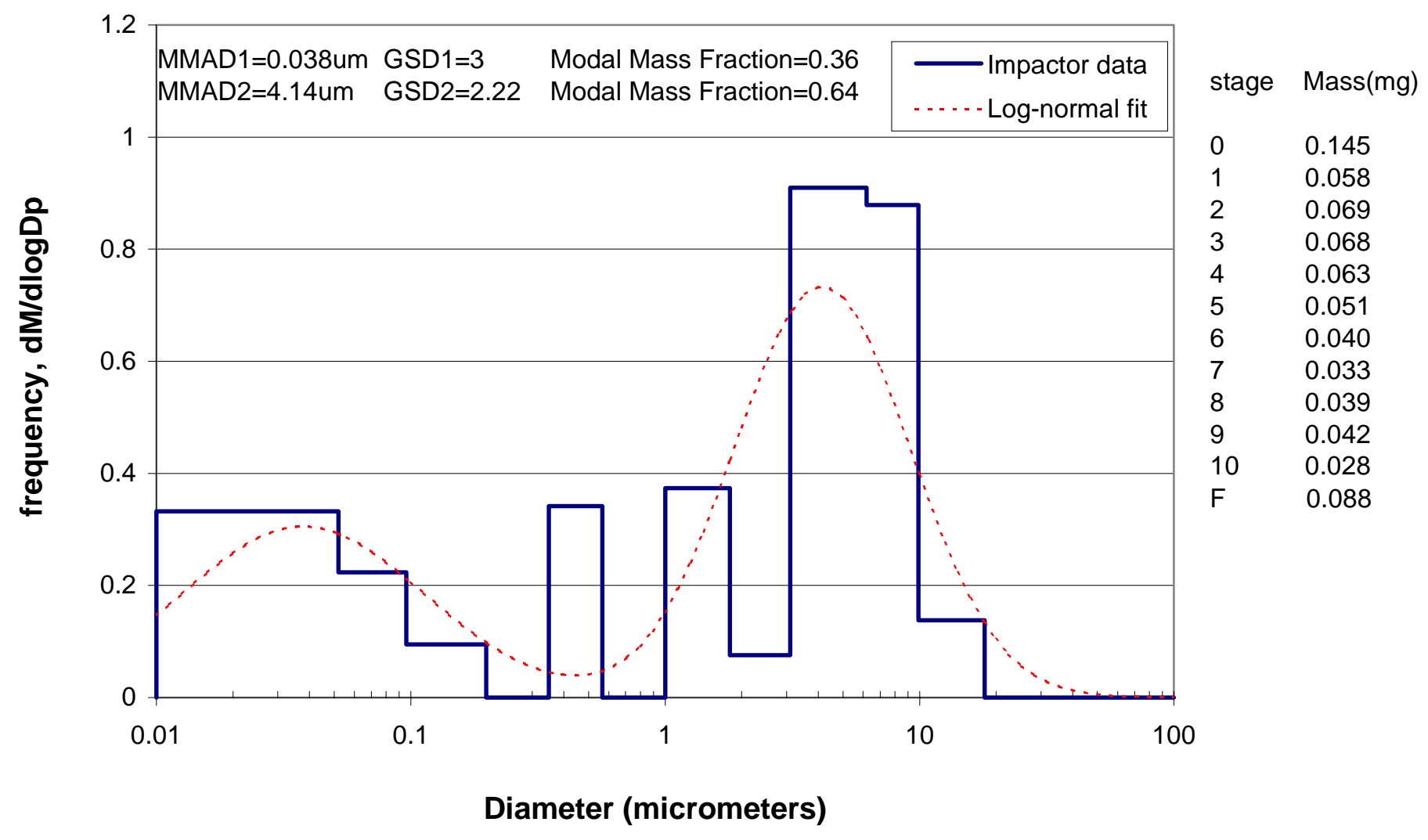

Figure 5-12 Particle Size Distribution of Bus 6001 CNG 


\section{MOUDI Size Distribution CNG Bus \#2, 6000, Run 3}

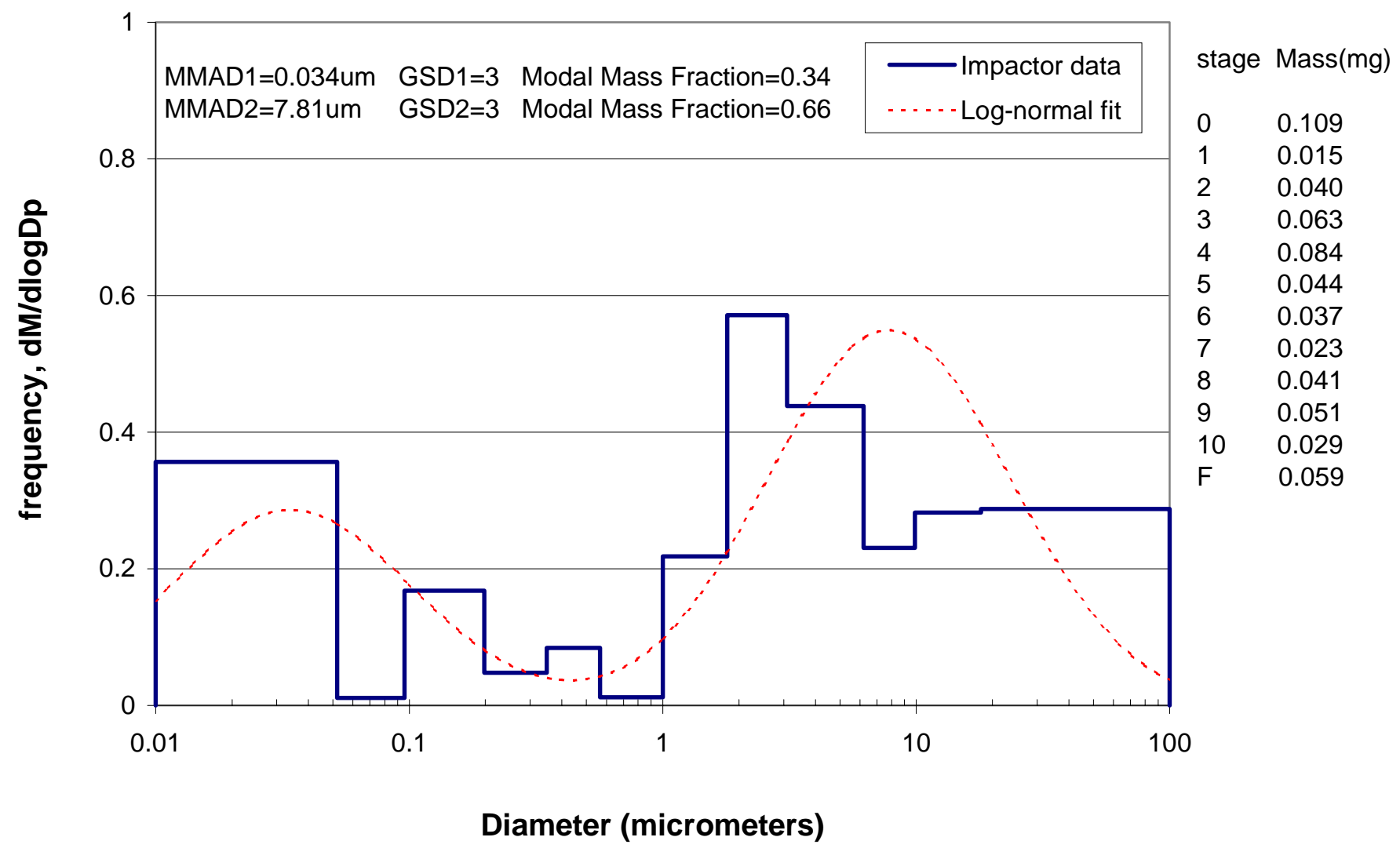

Figure 5-13 Particle Size Distribution of Bus 6000 CNG 


\section{Chapter 6 INVESTIGATION OF NANOPARTICLE EMISSIONS FROM HEAVY-DUTY DIESEL TRUCKS}

6.1 Mini-dilution Tunnel for SMPS Sampling System

The stability and reliability of two different types of exhaust dilution methods are discussed in this section. The first system is mass flow controller-based mini-dilution tunnel (similar to the secondary dilution tunnel on total exhaust CVS system). The second system is an ejector-based dilution tunnel. Investigations into the ability of these systems to dilute the exhaust without adversely affecting the physical characteristics of PM samples are repeated herein.

The Swiss Federal Material Testing Labs developed a dilution system called AVL model 472 for exhaust PM sizing with an SMPS. This model requires a vacuum pump and a compressor to draw and mix the exhaust with filtered dilution air (Mayer et al., 1995).

The mass flow controller-based mini-dilution tunnel for PM sizing studies in the WVU Transportable Laboratory is similar to the AVL model 472. Extensive testing at WVU has shown that it is difficult to maintain a stable dilution ratio over periods, in particularly for diesel engine exhaust. This chapter discusses the uncertainty in determining and maintaining a stable dilution ratio, and minimizing the error.

Graskow et al. (1998) have described a two-stage ejector based dilution system, in which a compressor and an ejector pump were used to mix the exhaust with dilution air for each stage (Graskow et al., 1998; Khalek et al., 1998). Smith (1993), Miller (1997) and Gautam et al. (1999) have discussed mini-tunnels at length. This section primarily analyzes the stability of the dilution ratio and reliability of the two dilution systems. 
6.2 Stability Analysis of Dilution Ratio for the Two Mini-dilution Systems

The two different types of dilution systems that could be designed fabricated at WVU for PM sizing studies for are shown in Figure 6-1 and Figure 6-2, respectively. The stability of their dilution ratio control is discussed below.

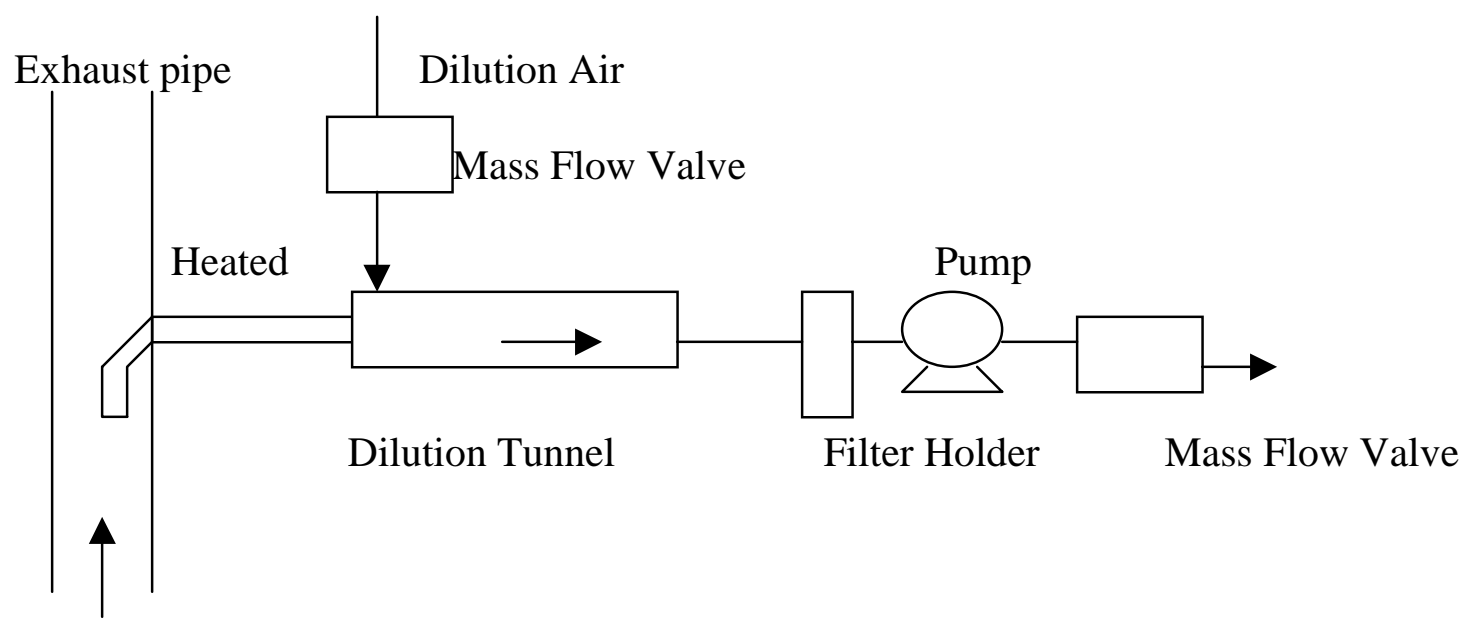

(a) AVL model 472 (Mayer et al., 1995).

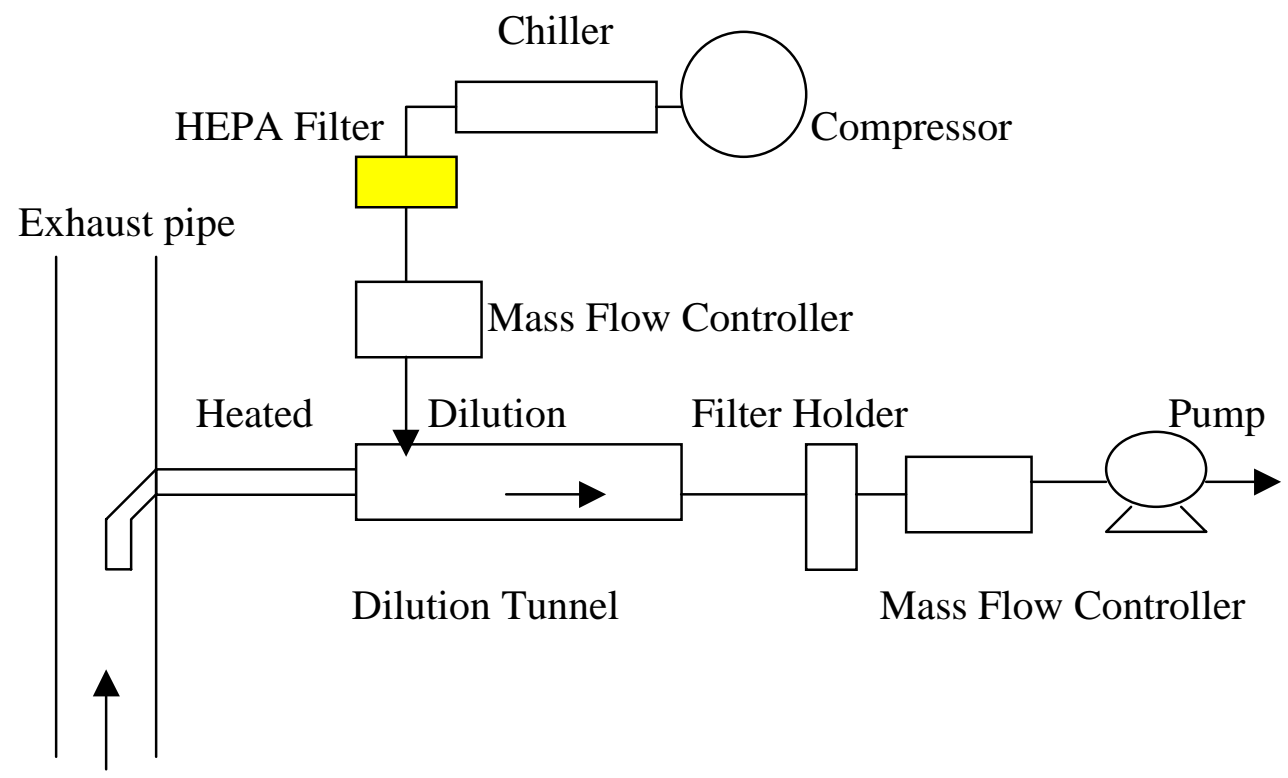

(b) Mini-Dilution System (WVU Transportable Lab)

Figure 6-1 Mass Flow Controller Based Dilution Systems 


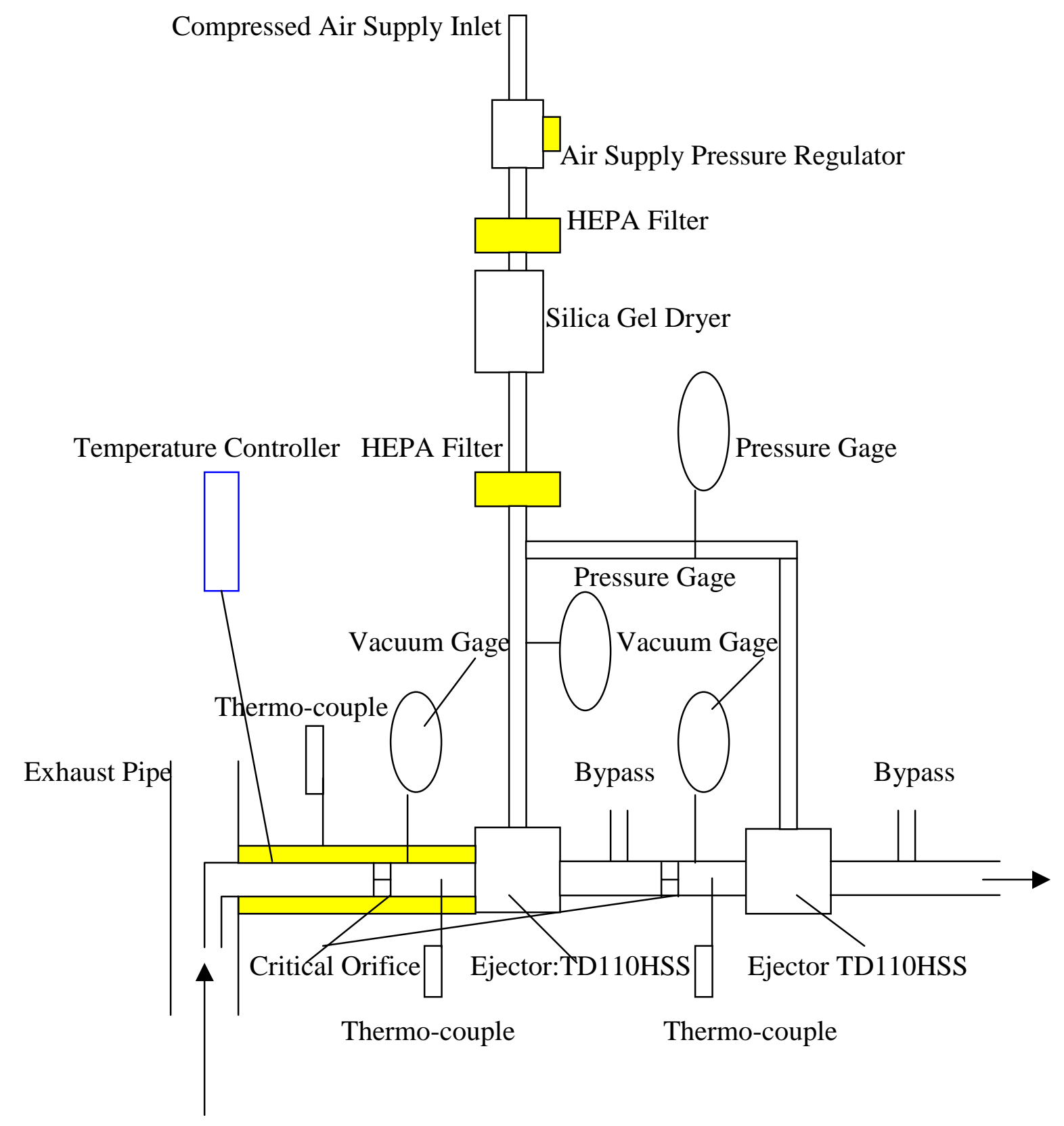

Exhaust Sample Probe

Figure 6-2. Two-stage Ejector Based Dilution System (Graskow et al., 1998) 


\subsubsection{Mass Flow Controller Based Mini-dilution System}

In this system, the dilution ratio is adjusted by two mass flow controllers, one of

which controls the dilution air flow rate $\left(F_{d i l}\right)$, while the other controls the diluted (mixed) flow rate $\left(F_{t o t}\right)$.

According to the definition, dilution ratio is expressed by

$$
D R=\frac{F_{t o t}}{F_{e x h}}=\frac{F_{t o t}}{F_{t o t}-F_{d i l}}
$$

where, $D R$ : dilution ratio, -;

$F_{t o t}, F_{e x h}, F_{d i l}: \quad$ total flow rate, exhaust flow rate, and dilution flow rate, slpm.

Taking a differential of DR, we have

$$
\frac{d D R}{D R}=(1-D R) \frac{d F_{t o t}}{F_{t o t}}+(D R-1) \frac{d F_{d i l}}{F_{d i l}}
$$

Equation (6-2) shows that the maximum rate of change of dilution ratio almost equals the summation of the rate of change of total flow and the rate of change of dilution flow, multiplied by dilution ratio.

Simply, consider a constant dilution flow case, that is $d F_{d i l}=0$. In this case, $D R$ will change with $F_{t o t}$ only, for a certain $D R$ and $F_{d i l}$, say $D R=10$ and $F_{d i l}=100$, from equation (6-1), $F_{t o t}=1000 / 9$.

Let $F_{\text {tot }}$ undergo a small change, say $1 \%$, then $D R$ will change as follows:

$$
D R=\frac{F_{t o t}(0.99 \sim 1.01)}{F_{t o t}(0.99 \sim 1.01)-F_{d i l}}=11 \sim 9.18
$$

So, $D R$ will undergo $10 \%$ change with $1 \%$ change of $F_{\text {tot. }}$ 
Table 6-1 illustrates rate of change of DR with the change of total flow rate $F_{\text {tot. }}$ When $D R$ is small, $D R=4$ for example, the change of $D R$ with the change of $F_{t o t}$, may be considered acceptable. Mayer et al. (1995) presented the data using an "AVL model 472", the dilution ratio was set at about 4 , so they didn't mention any stability problem of dilution ratio.

Table 6-1. Rate of change of dilution ratio with $1 \%$ change in the mixed flow rate

\begin{tabular}{|l|l|l|l|l|}
\hline DR & $F_{\text {dil }}$ & $F_{\text {tot }}$ & $\Delta F_{\text {tot }} / F_{\text {tot }}$ & $\Delta D R / D R$ \\
\hline 4 & 100 & $400 / 3$ & $1 \%$ & $-2.9 \% \sim+3.1 \%$ \\
\hline 10 & 100 & $1000 / 9$ & $1 \%$ & $-8.2 \% \sim+10 \%$ \\
\hline 30 & 100 & $3000 / 29$ & $1 \%$ & $-22 \% \sim+41 \%$ \\
\hline
\end{tabular}

However, from Table 6-1, if the dilution ratio is set at a value greater than 10 , then the uncertainty in dilution ratio will become a serious problem for this system. During the SMPS tests for the John Deere 6059, and 5028 engines in ERC, WVU, the dilution ratios were set between $10 \sim 30$, and the DR values were found to vary during the test.

\subsubsection{Ejector Based Mini-dilution System}

In the ejector based dilution system, the dilution airflow is controlled by the ejector and the exhaust flow is controlled by a critical orifice set on the exhaust sample tubing (Khalek et al., 1998; Graskow et al., 1998). It was reported that the dilution ratio was quiet stable. For the two stage dilution system, the dilution ratio of the first stage was set from 4 to 85 and the secondary one, is about 18 , so the overall dilution ratio was 
between $70 \sim 1530$. However, it is well established that ejector operation is critically dependent upon upstream pressure changes. The authors did not address the ejector performance issues.

Only flow rate control issues are considered in this section. For the ejector dilution system, the dilution ratio can be expressed directly by

$$
D R=\frac{F_{t o t}}{F_{e x h}}=\frac{F_{d i l}+F_{e x h}}{F_{e x h}}=1+\frac{F_{d i l}}{F_{e x h}}
$$

Take the differential of DR, we have

$$
\frac{d D R}{D R}=\left(1-\frac{1}{D R}\right)\left(\frac{d F_{d i l}}{F_{d i l}}-\frac{d F_{e x h}}{F_{e x h}}\right)
$$

From equation (6-4) we can see that if $F_{d i l}$ is fixed, $D R$ will undergo the same order of change as the change of sample exhaust flow rate. The same calculation as in the vacuum pump dilution system discussed before is illustrated in Table 6-2. Theoretically, it is seen that the relative change of dilution ratio is of the same order as the relative change of sample exhaust flow rate. So this dilution system should be more stable than the mass flow controller based dilution system discussed above.

Table 6-2. Rate of change of dilution ratio with $1 \%$ change of exhaust flow rate

\begin{tabular}{|l|l|l|l|l|}
\hline$D R$ & $F_{\text {dil }}$ & $F_{\text {exh }}$ & $\Delta F_{\text {exh }} / F_{\text {exh }}$ & $\Delta D R / D R$ \\
\hline 4 & 100 & $100 / 3$ & $1 \%$ & $<1 \%$ \\
\hline 10 & 100 & $100 / 9$ & $1 \%$ & $<1 \%$ \\
\hline 30 & 100 & $10 / 3$ & $1 \%$ & $<1 \%$ \\
\hline
\end{tabular}




\subsection{Reliability of the Two Dilution Systems}

As mentioned in Chapter 2, under certain conditions, the evaporation of organic materials will increase the number of small particles. Accordingly, desorption of organics from the PM passing through ejector throat and the subsequent cooling and the increase in saturation ratio due to mixing with dilution air, results in homogeneous nucleation. When a dilution method is evaluated, these factors should be considered.

The first dilution system dilutes the exhaust with the dilution airflow by a pressure source and a vacuum source (pump). In this dilution tunnel, the pressure remains almost unchanged. Tests have shown that the pressure in the tunnel is approximately ambient with a variation of few inches of water. So evaporation and desorption of volatile hydrocarbon are minimized.

The ejector-based dilution systems use a critical orifice at the exhaust inlet to obtain a stable exhaust flow into the tunnel. The pressure drop across the orifice at sonic conditions can be calculated by:

$$
\begin{aligned}
& \left.\left.\frac{p_{0}}{p^{*}}=\left(1+\frac{k-1}{2} M_{a}^{2}\right)^{k /(k-1)}\right)=\left(1+\frac{1.4-1}{2}\right)^{1.4 /(1.4-1)}\right)=1.894 \\
& \frac{p^{*}}{p_{0}}=0.528 \\
& p^{*}-p_{0}=-0.472 p_{0}
\end{aligned}
$$

Where, $p_{0}$ : exhaust flow pressure before the orifice;

$p^{*}: \quad$ exhaust flow pressure after the orifice;

Ma: Mach number, equals to 1 here;

$K: \quad$ specific heat ratio, equals to 1.4 here. 
Usually, the pressure of exhaust tailpipe can be considered as $1 \mathrm{~atm}$, then after the orifice, there exists a vacuum of $0.472 \mathrm{~atm}$, which is created by the ejector. The ejector used in the dilution system is TD110HSS type ejector, the technical parameters are listed in Table 6-3.

Table 6-3 Parameters of ejector TD110HSS

\begin{tabular}{|l|l|}
\hline Model Number & TD110HSS \\
\hline "A" Diameter & $9 / 64 "$ \\
\hline Vacuum Level, "Hg & 24.8 \\
\hline Vacuum Flow, SCFM & 2.3 \\
\hline Air Consumption, SCFM & 4.2 \\
\hline Weight, oz. & 9 \\
\hline Materials & 316 SS \\
\hline Air Supply Connection & $1 / 8 " \quad$ NPTF \\
\hline Vacuum Connection & $1 / 4 " \quad$ NPTM \\
\hline Exhaust Connection & $1 / 4 " \quad$ NPSM \\
\hline
\end{tabular}

Such a low pressure may result in desorption of particle bound hydrocarbons. It certainly will offer conditions that may lead to homogeneous nucleation of SOF and sulfuric acid.

Dilution of exhaust sample at very low pressures results in a low particle count environment that may lead to high saturation ratios of hydrocarbons and sulfuric acid. Whether their saturation values exceed super saturation or not is not known, however, it is very likely that sulfuric acid treated carbon particles have improved hydration properties such that these particles may now become activated at very low supersaturations of less than $0.3 \%$ (Gautam, 1999). Hence, the reduced particle count and 
higher saturation ratios may lead to homogeneous nucleation of hydrocarbons and sulfuric acid present in the exhaust sample.

The test data obtained by the ejector based dilution system (Khalek, et al., 1998) show that the concentrations of ultra fine particles (less than $20 \mathrm{~nm}$, with the $7 \mathrm{~nm}$ as the CMD) are very high in the sample data. A study on a spark ignition engine by Graskow, et al. (1998) shows that the particles formed from nuclei mode are almost completely composed of volatile material. This high concentration could be an artifact of the sample conditioning system that employed an orifice because of the existing of such a low pressure after the orifice.

The formation of ultra fine particles after a particle trap was investigated by several workers (Miller, 1983; Baumgard, 1988). Two kinds of nuclei modes were defined, one is ultra-fine nuclei mode (with the size $3 \sim 10 \mathrm{~nm}$ ) and the other is "normal" nuclei mode (with the size 10 56 nm). Six steady state test results by Miller (1983) indicated that 4 tests have particles from the ultra-fine nuclei mode, and the other two tests have particles formed from "normal" nuclei mode.

These ultra-fine particles after trap are believed to be formed by homogeneous nucleation. This is the formation of particles from a supersaturated vapor without the assistance of condensation nuclei. Whether or not these particles are formed depends on the saturation ratio, $\mathrm{r}_{\mathrm{s}}$, which is defined as:

$$
\mathrm{r}_{\mathrm{s}}=\mathrm{p}_{\mathrm{v}} / \mathrm{p}_{\mathrm{s}}
$$

Where, $\mathrm{p}_{\mathrm{v}}$ : actual vapor partial pressure;

$\mathrm{p}_{\mathrm{s}}$ : $\quad$ supersaturated vapor pressure. 
When the saturation ratio is less than 1 , molecular clusters are formed continuously but are short-lived and disintegrate. However, when the saturation ratio increases beyond 1, molecular clusters larger than a critical size become stable and grow. In the ejector based dilution tunnel, when the exhaust flow passes through the orifice and mixed with the dilution flow, the temperature of the exhaust flow decreases, the saturation ratio increases so the homogeneous nucleation condition is obtained.

Hinds (1982) has shown that homogeneous nucleation is nearly an all-or-nothing phenomenon. A plot of rate of particle formation vs. saturation ratio would show nearly a vertical line. The saturation ratio can be related to the concentration of volatile particulate matter. Back to the ejector based dilution system, with both its temperature and pressure decreasing while sample exhaust flows through the orifice, saturation ratio increases.

Based on discussion above, the likelihood of homogenous nucleation occurring in the ejector based dilution systems is very high. Hence, there is an ultra-high nucleation of nano particles in the range 10 20 nm. This impacts strongly the real particles' size distribution of the exhaust and lowers the reliability of the test results.

Because the reliability of the system is just as important as the stability of the dilution ratio, therefore the first dilution system was selected for this study. Based on the analysis above, when the mass flow controller based dilution system is used, some measures should be taken to keep both dilution flow rate and total flow rate a stable constant. To change the filter in the total flow frequently can maintain stable flows; at the same time, $\mathrm{CO}_{2}$ (raw exhaust and diluted exhaust) measurements were made to trace the actual dilution ratios. 


\subsection{Steady State Test}

Eight trucks were operated on steady-state mode and transient cycle to obtain PM size distribution data. Four of these trucks had no after-treatment devices and two of these trucks were installed with Johnson-Matthey CRT, and the other two trucks, with Engelhard DPX. The truck ID, fuel, and description of after-treatment devices are shown in Table 6-4.

Table 6-4 Description of the Trucks tested

\begin{tabular}{|c|c|c|}
\hline Truck ID & Fuel & After-treatment devices \\
\hline 5915 & CARB & No after-treatment \\
\hline 5918 & CARB & No after-treatment \\
\hline 5911 & EC Diesel & No after-treatment \\
\hline 5912 & EC Diesel & No after-treatment \\
\hline 5900 & EC Diesel & Johnson-Matthey CRT \\
\hline 5902 & EC Diesel & Johnson-Matthey CRT \\
\hline 5907 & EC Diesel & Engelhard DPX \\
\hline 5909 & EC Diesel & Engelhard DPX \\
\hline
\end{tabular}

The steady state test results are illustrated in Table 6-5. The main samples of nano-particle size distribution are shown in Figures 6-3 to 6-6.

These figures show that the Count Median Diameter (CMD) of the particles is ranged between $30 \mathrm{~nm}$ and $60 \mathrm{~nm}$. EC-Diesel fuel baseline's CMD is $33 \mathrm{~nm}$, CARB fuel 
baseline is $56 \mathrm{~nm}$; while the CMD of particle emitted from EC-Diesel fuel with Johnson Matthey CRT is $37-39 \mathrm{~nm}$ and with Engelhard DPX, 40-47 nm.

Table 6-5 lists the data from all the steady state tests. It can be seen from the table that the overall range of CMD is from $24 \mathrm{~nm}$ to $85 \mathrm{~nm}$; there is a relatively narrow range for every particular case. However, the SGSDs are less than 3.0 at all. Unlike the GSD for MOUDI sample reduction, the SGSD in this case is the statistic geometric standard deviation in terms of the geometric mean $\left(d_{g}\right)$. The geometric mean and SGSD are expressed by the following equations:

$$
\begin{gathered}
\ln d_{g}=\frac{\sum_{i=m}^{n l} \Delta N_{i} \ln \left(d_{i}\right)}{N} \\
\ln S G S D=\sqrt{\frac{\sum_{i=m}^{n l} N_{i}\left(\ln d_{i}-\ln d_{g}\right)^{2}}{N-1}}
\end{gathered}
$$

where, SGSD: $\quad$ statistic geometric standard deviation;

$$
\begin{aligned}
d g: & \text { geometric mean diameter, } \mathrm{nm} ; \\
d i: & \text { midpoint diameter for size channel } \mathrm{i}, \mathrm{nm} ; \\
N: & \text { total concentration, } \# / \mathrm{cm}^{3} ; \\
\Delta N: & \quad \text { concentration within the channel } \mathrm{i}, \# / \mathrm{cm}^{3} ; \\
m: & \text { first channel; } \\
n l: & \text { last channel. }
\end{aligned}
$$

The $C M D, S G S D$ and total concentration (tunnel) values are all given by the SMPS bulit-in program. The total concentration (engine) is equal to the total concentration in the tunnel multiplied by the dilution ratio. 
The maximum concentration values of $4.95 \times 10^{7}$ particle/cc $(\mathrm{dN} / \mathrm{dlog}(\mathrm{Dp})$ were obtained under a steady state 50mph operation, with CARB diesel and no after-treatment device. The minimum concentration value was $6.63 \times 10^{4}$ particle/cc $(\mathrm{dN} / \mathrm{d} \log (\mathrm{Dp})$ at a steady state speed 45mph, with EC Diesel and a J-M CRT (Continuously Regenerating Trap).

A rough estimate of the particle removal efficiency of the after-treatment devices could be expressed by following equation:

$$
\eta=\frac{c_{n o}-c_{a f t r}}{c_{n o}}
$$

where, $\eta$ : particle removal efficiency of the aftertreat devices;

$c_{n o}: \quad$ particle concentration of the exhaust from the engine without aftertreatment devices;

$c_{a f t r}: \quad$ particle concentration of the exhaust from the engine with an aftertreatment device.

With the estimation by equation (6-7), both the after-treatment devices have found to very high nano-particle removal efficiencies. The efficiency of Engelhard DPX was greater than $99 \%$ and the efficiency of J-M CRT was as high as $99.9 \%$. 
DDC Series 60, Tractor, DR=28:1, Steady State 45mph

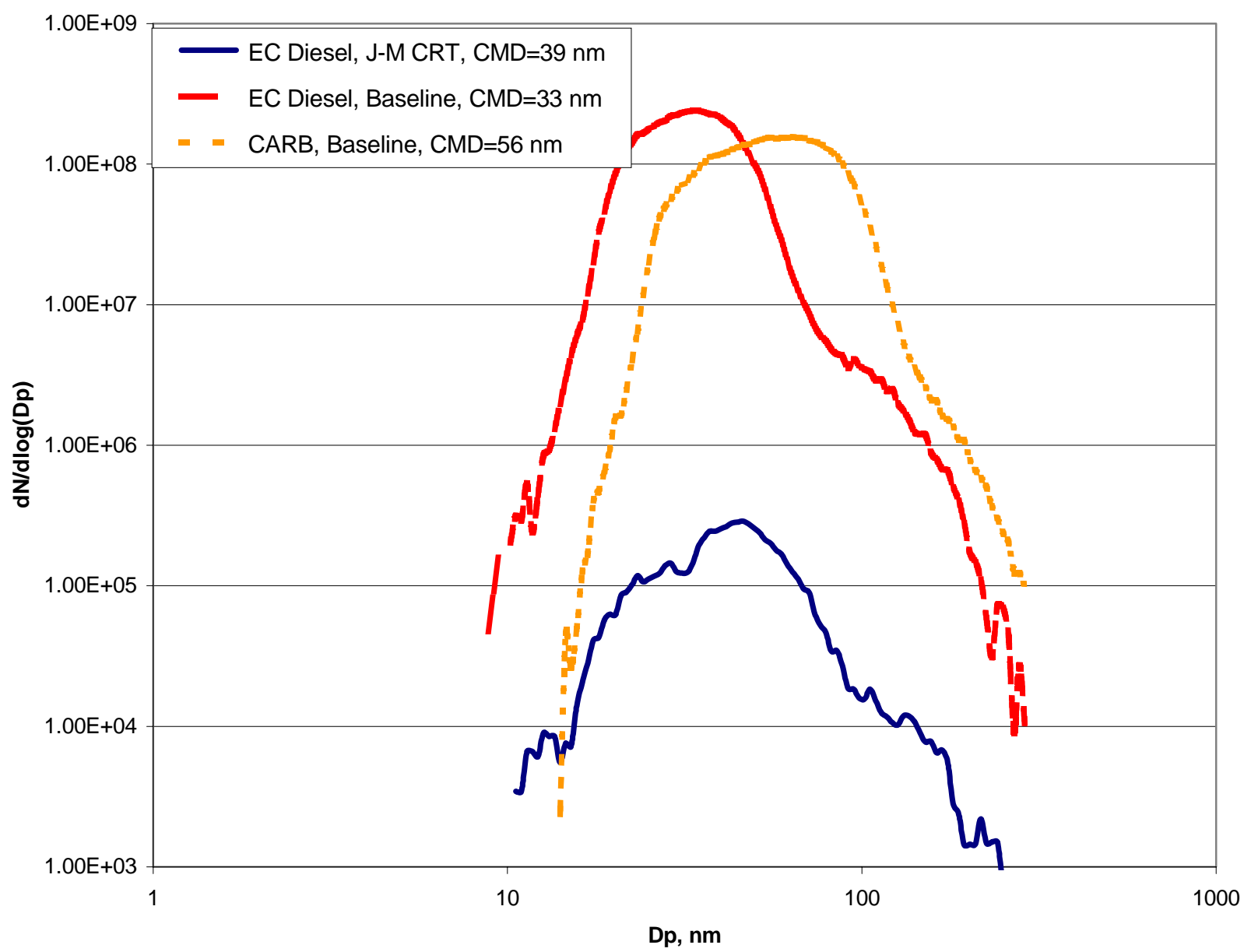

Figure 6-3 Steady State Test: Particle Size Distribution, 45mph 
DDC Series, Tractor, DR=28:1, Steady State 50mph

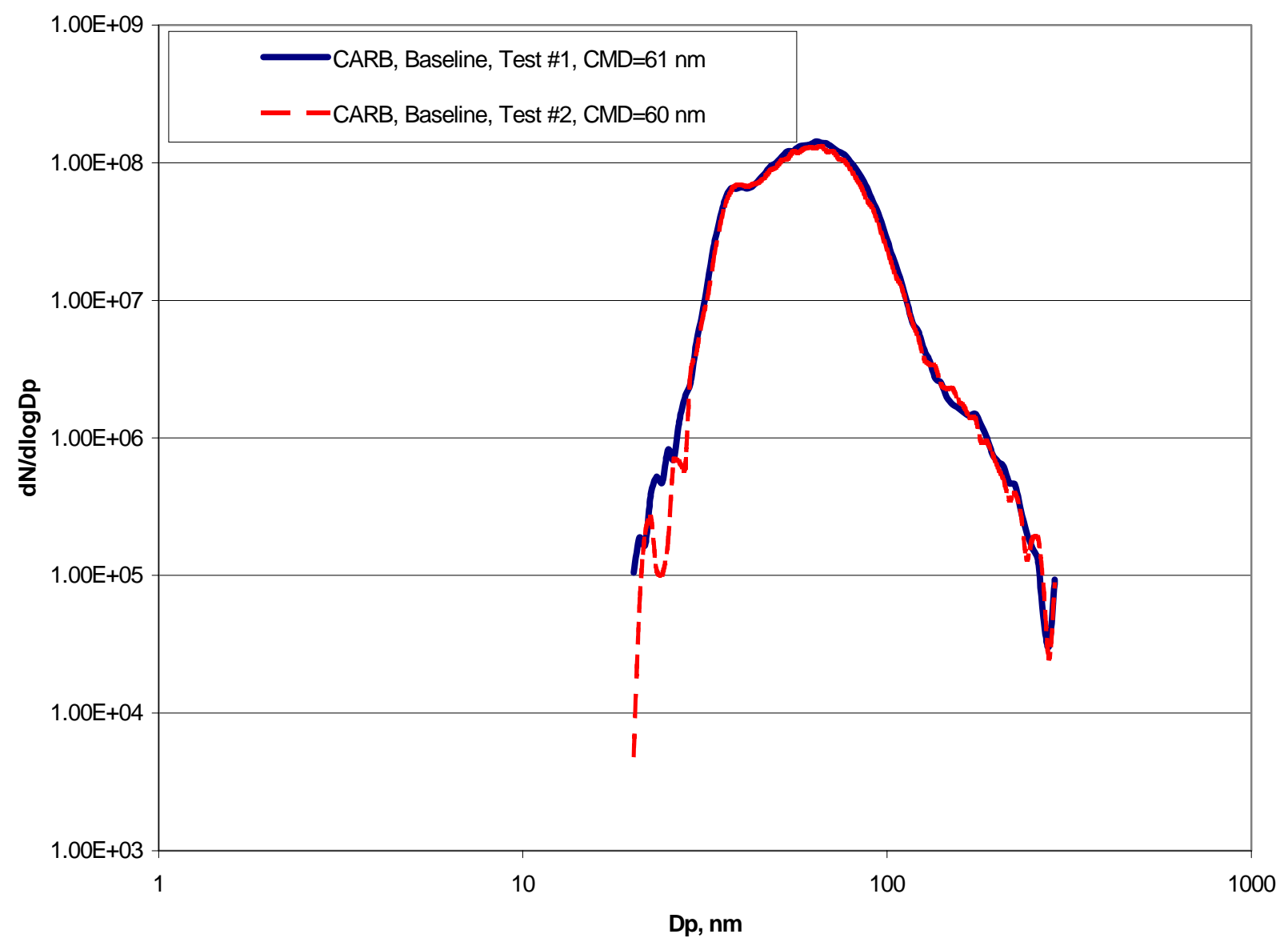

Figure 6-4 Steady State Test: Particle Size Distribution, $50 \mathrm{mph}$ 
DDC Series 60, Tructor, DR=28:1, Steady State $45 \mathrm{mph}$

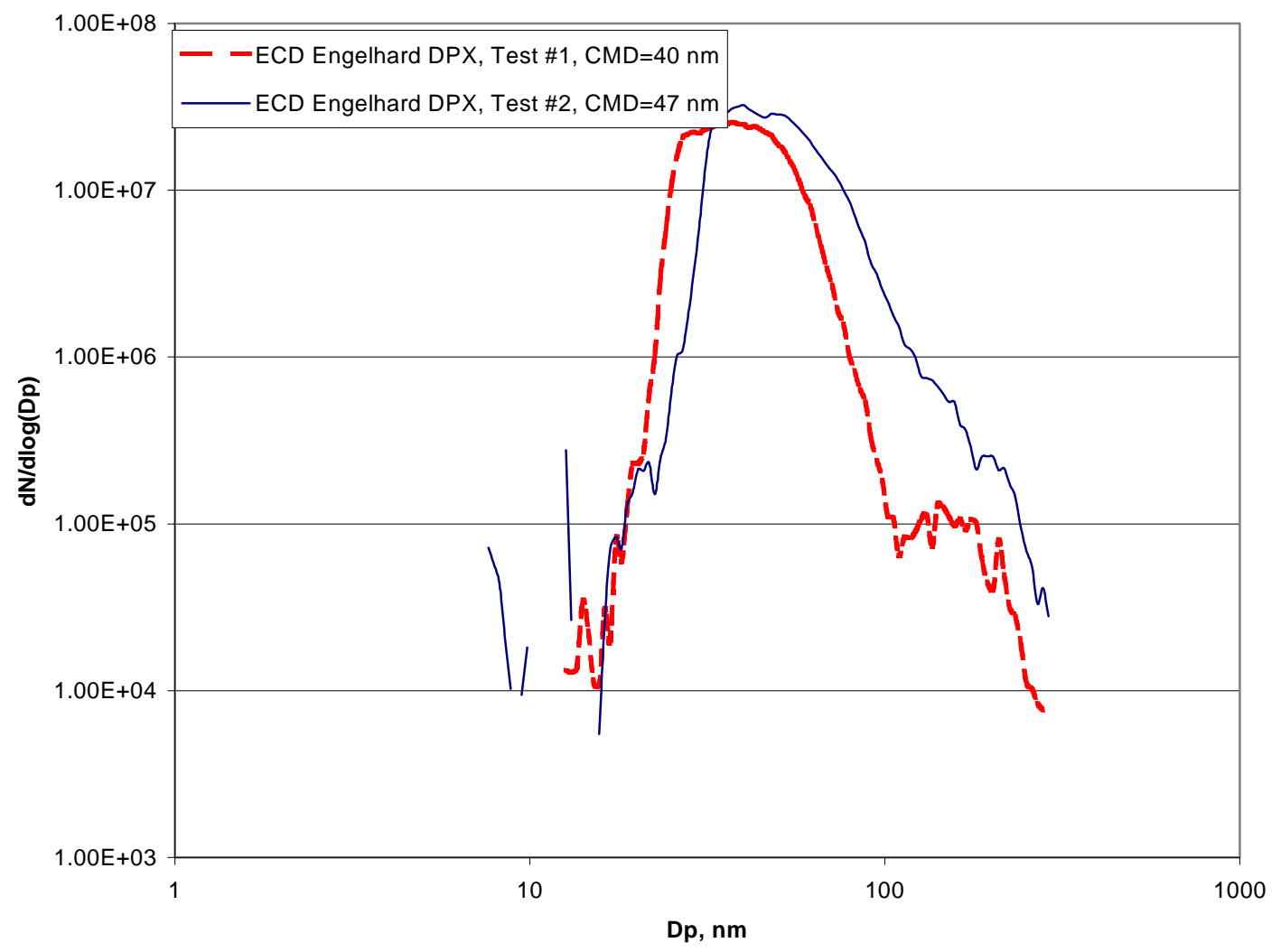

Figure 6-5 Steady State Test: Particle Size Distribution, DPX, 45mph 
DDC Series 60, Tractor, DR=28:1, Steady State 30mph

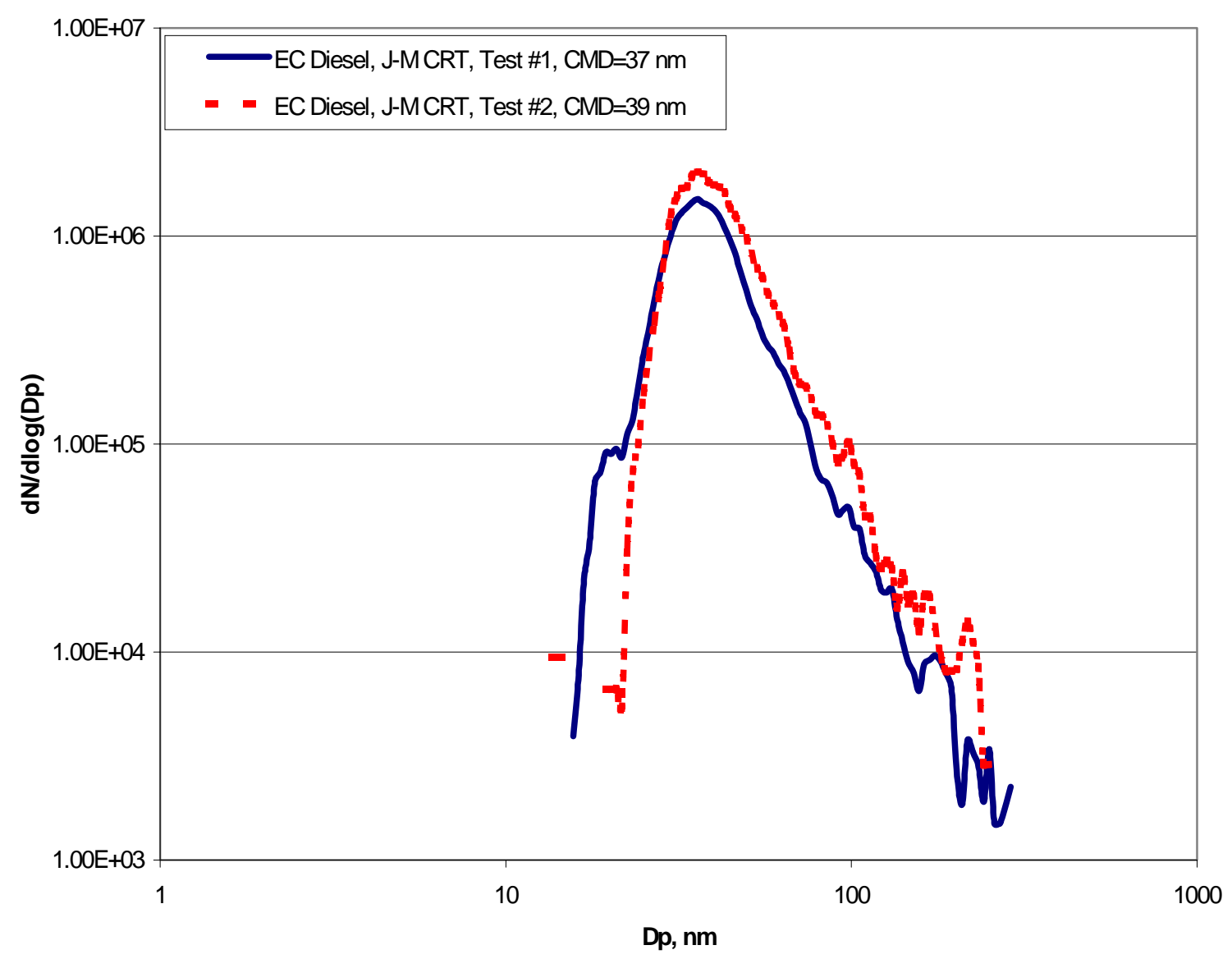

Figure 6-6 Steady State Test: Particle Size Distribution, J-M CRT, 30mph 
Table 6-5 Steady-state test data for the DDC series 60 tractor trucks, Riverside, Ca

\begin{tabular}{|c|c|c|c|c|c|c|}
\hline Test Type & CMD & SGSD & $\begin{array}{l}\text { Total Conc } \\
\text { (Tunnel)* }\end{array}$ & $\begin{array}{l}\text { Total Conc } \\
\text { (Engine)* }\end{array}$ & $\begin{array}{l}\text { Truck ID \& } \\
\text { Description }\end{array}$ & Fuel \\
\hline & $\mu \mathrm{m}$ & & $\# / \mathrm{cm}^{3}$ & $\# / \mathrm{cm}^{3}$ & & \\
\hline ss $45-1$ & 48 & 1.423 & $3.50 \mathrm{E}+05$ & $1.16 \mathrm{E}+07$ & 5915 & CARB \\
\hline ss45-2 & 60.9 & 1.344 & $7.62 \mathrm{E}+05$ & $2.51 \mathrm{E}+07$ & & \\
\hline ss50-1 & 60.8 & 1.353 & $1.64 \mathrm{E}+06$ & $4.59 \mathrm{E}+07$ & & \\
\hline ss50-2 & 60.1 & 1.352 & $1.51 \mathrm{E}+06$ & $4.23 \mathrm{E}+07$ & & \\
\hline Bkgd $1^{* *}$ & 26.2 & 1.744 & $8.07 \mathrm{E}+03$ & $2.26 \mathrm{E}+05$ & & \\
\hline ss $45-1$ & 32.5 & 1.369 & $2.79 \mathrm{E}+06$ & $7.81 \mathrm{E}+07$ & 5911 & ECD \\
\hline ss $45-2$ & 32.9 & 1.374 & $3.00 \mathrm{E}+06$ & $8.40 \mathrm{E}+07$ & & \\
\hline Bkgd1 & 30.6 & 1.784 & $1.29 \mathrm{E}+03$ & $3.61 \mathrm{E}+04$ & & \\
\hline Idle1 & 35.9 & 1.507 & $2.21 \mathrm{E}+06$ & $5.29 \mathrm{E}+07$ & & \\
\hline ss30-1 & 36.8 & 1.379 & $1.29 \mathrm{E}+04$ & $3.62 \mathrm{E}+05$ & 5900, J-M CRT & ECD \\
\hline ss30-2 & 39.1 & 1.357 & $1.82 \mathrm{E}+04$ & $5.09 \mathrm{E}+05$ & & \\
\hline ss45-2 & 25.7 & 1.678 & $2.37 \mathrm{E}+03$ & $6.63 \mathrm{E}+04$ & 5902, J-M CRT & ECD \\
\hline ss $45-3$ & 43.1 & 1.386 & $5.37 \mathrm{E}+03$ & $1.50 \mathrm{E}+05$ & & \\
\hline ss $45-1$ & 33.6 & 1.466 & $1.76 \mathrm{E}+06$ & $4.91 \mathrm{E}+07$ & 5912 & ECD \\
\hline ss45-2 & 47.1 & 1.392 & $2.15 E+06$ & $6.01 E+07$ & & \\
\hline ss $45-3$ & 28.9 & 1.423 & $1.47 \mathrm{E}+06$ & $4.12 \mathrm{E}+07$ & & \\
\hline ss $45-4$ & 31.1 & 1.428 & $1.52 \mathrm{E}+06$ & $4.26 \mathrm{E}+07$ & & \\
\hline ss $45-5$ & 24.1 & 1.37 & $1.03 E+06$ & $2.89 \mathrm{E}+07$ & & \\
\hline ss $45-6$ & 25.8 & 1.389 & $1.07 \mathrm{E}+06$ & $3.00 \mathrm{E}+07$ & & \\
\hline Bkgd & 34.4 & 1.489 & $2.56 \mathrm{E}+04$ & $7.15 E+05$ & from main tunnel & \\
\hline Idle & 15.4 & 1.511 & $2.23 \mathrm{E}+05$ & $6.24 \mathrm{E}+06$ & & \\
\hline ss $45-1$ & 57.1 & 1.286 & $1.98 \mathrm{E}+04$ & $6.52 \mathrm{E}+05$ & $\begin{array}{l}\text { 5907, Engelhard } \\
\text { DPX }\end{array}$ & ECD \\
\hline ss $45-2$ & 37.7 & 1.318 & $5.08 \mathrm{E}+05$ & $1.68 \mathrm{E}+07$ & & \\
\hline ss $45-1$ & 37.8 & 1.924 & $6.11 \mathrm{E}+03$ & $2.02 \mathrm{E}+05$ & $\begin{array}{l}\text { 5907, Engelhard } \\
\text { DPX }\end{array}$ & ECD \\
\hline ss45-2 & 53.8 & 1.433 & $2.52 \mathrm{E}+04$ & $8.32 \mathrm{E}+05$ & & \\
\hline ss45-3 & 58.4 & 1.725 & $5.18 \mathrm{E}+03$ & $1.71 \mathrm{E}+05$ & & \\
\hline ss45-4 & 63.3 & 1.628 & $8.00 \mathrm{E}+03$ & $2.64 \mathrm{E}+05$ & & \\
\hline ss45-5(fan) & 66.4 & 1.818 & $1.74 \mathrm{E}+03$ & $5.74 \mathrm{E}+04$ & & \\
\hline ss45-6(fan) & 48.5 & 1.604 & $3.85 E+03$ & $1.27 \mathrm{E}+05$ & & \\
\hline ss45-7(fan) & 55.2 & 1.759 & $1.40 \mathrm{E}+03$ & $4.62 \mathrm{E}+04$ & & \\
\hline
\end{tabular}




\begin{tabular}{|c|c|c|c|c|c|c|}
\hline Test Type & CMD & SGSD & $\begin{array}{l}\text { Total Conc } \\
\text { (Tunnel)* }\end{array}$ & $\begin{array}{l}\text { Total Conc } \\
\text { (Engine)* }\end{array}$ & $\begin{array}{l}\text { Truck ID \& } \\
\text { description }\end{array}$ & Fuel \\
\hline ss45-8(fan) & 58.5 & 1.441 & $1.02 \mathrm{E}+04$ & $3.37 \mathrm{E}+05$ & & \\
\hline ss45-9 & 20.5 & 1.289 & $5.18 \mathrm{E}+03$ & $1.71 \mathrm{E}+05$ & & \\
\hline ss45-0 & 45.3 & 1.218 & $1.66 \mathrm{E}+04$ & $5.48 \mathrm{E}+05$ & & \\
\hline Cold-idle & 62.6 & 2.01 & $4.27 \mathrm{E}+03$ & $1.41 \mathrm{E}+05$ & & \\
\hline Idle1 & 29.5 & 1.936 & $1.83 \mathrm{E}+02$ & $6.04 \mathrm{E}+03$ & & \\
\hline Idle2 & 38 & 1.959 & $1.02 \mathrm{E}+02$ & $3.37 \mathrm{E}+03$ & & \\
\hline & & & & & $\begin{array}{l}\text { 5909. Engelhard } \\
\text { DPX }\end{array}$ & ECD \\
\hline ss45-1 & 84.7 & 2.14 & $3.44 \mathrm{E}+03$ & $1.38 \mathrm{E}+04$ & $\mathrm{DR}=4: 1$ & \\
\hline ss45-2 & 27.4 & 1.518 & $5.81 \mathrm{E}+05$ & $2.32 \mathrm{E}+06$ & $\mathrm{DR}=4: 1$ & \\
\hline ss45-3 & 56.7 & 1.96 & $4.72 \mathrm{E}+03$ & $1.89 \mathrm{E}+04$ & $\mathrm{DR}=4: 1$ & \\
\hline ss $45-4$ & 78.1 & 1.758 & $1.07 \mathrm{E}+04$ & $4.28 \mathrm{E}+04$ & $\mathrm{DR}=4: 1$ & \\
\hline ss $45-5$ & 72.6 & 1.822 & $1.82 \mathrm{E}+03$ & $5.10 \mathrm{E}+04$ & $\begin{array}{l}\text { 5909, Engelhard } \\
\text { DPX }\end{array}$ & ECD \\
\hline ss45-6 & 70.3 & 1.852 & $3.49 \mathrm{E}+03$ & $9.77 \mathrm{E}+04$ & & \\
\hline Bkgd1 & 79.6 & 2.148 & $2.97 \mathrm{E}+03$ & $8.32 \mathrm{E}+04$ & from main tunnel & \\
\hline Bkgd2 & 27.5 & 1.921 & $3.45 \mathrm{E}+02$ & $9.66 \mathrm{E}+03$ & from main tunnel & \\
\hline Bkgd3 & 23.3 & 2.016 & $2.55 \mathrm{E}+02$ & $7.14 \mathrm{E}+03$ & from main tunnel & \\
\hline Cold-idle & 44.5 & 1.907 & $4.06 \mathrm{E}+02$ & $1.62 \mathrm{E}+03$ & & \\
\hline Idle1 & 71.5 & 2.116 & $6.33 E+02$ & $2.09 \mathrm{E}+04$ & & \\
\hline Idle2 & 33.3 & 1.919 & $1.24 \mathrm{E}+02$ & $4.09 \mathrm{E}+03$ & & \\
\hline Idle3 & 25.5 & 1.528 & $1.73 \mathrm{E}+03$ & $5.71 \mathrm{E}+04$ & & \\
\hline Idle4 & 47.5 & 1.785 & $7.73 E+01$ & $2.55 \mathrm{E}+03$ & & \\
\hline Idle5 & 23.2 & 1.485 & $1.55 \mathrm{E}+03$ & $5.12 \mathrm{E}+04$ & & \\
\hline Idle6 & 27.7 & 1.782 & $5.58 \mathrm{E}+02$ & $1.56 \mathrm{E}+04$ & & \\
\hline Idle7 & 37.4 & 2.365 & $1.44 \mathrm{E}+02$ & $4.03 \mathrm{E}+03$ & & \\
\hline Idle8 & 23.9 & 1.847 & $2.77 \mathrm{E}+02$ & $7.76 \mathrm{E}+03$ & & \\
\hline Idle9 & 16.7 & 1.882 & $3.11 \mathrm{E}+02$ & $8.71 \mathrm{E}+03$ & & \\
\hline Bkgd-a & 18.1 & 2.191 & $1.51 \mathrm{E}+04$ & & Ambient, 1 scan & \\
\hline Bkgd-d & 17.9 & 2.023 & $1.13 \mathrm{E}+03$ & & Diluted, 1 scan & \\
\hline Bkgd-a2 & 27.6 & 1.585 & $2.47 \mathrm{E}+04$ & & Ambient, 2 scans & \\
\hline Bkgd1-d2 & 27.9 & 1.804 & $8.66 \mathrm{E}+02$ & & Diluted, 2 scans & \\
\hline Bkgd2-d2 & 32.3 & 1.679 & $5.51 \mathrm{E}+02$ & & Diluted, 2 scans & \\
\hline Bkgd3-d2 & 27.8 & 1.848 & $4.12 \mathrm{E}+02$ & & Diluted, 2 scans & \\
\hline Bkgd1-d3 & 34.5 & 2.018 & $7.44 \mathrm{E}+02$ & & Diluted, 3 scans & \\
\hline Bkgd2-d3 & 39.6 & 1.854 & $7.94 \mathrm{E}+02$ & & Diluted, 3 scans & \\
\hline Bkgd3-d3 & 33.5 & 2.105 & $6.56 \mathrm{E}+02$ & & Diluted, 3 scans & \\
\hline ss 45 & 55.7 & 1.459 & $2.54 \mathrm{E}+06$ & $7.11 \mathrm{E}+07$ & 5918 & CARB \\
\hline Cold-idle & 30.1 & 1.517 & $6.80 \mathrm{E}+05$ & $1.90 \mathrm{E}+07$ & & \\
\hline
\end{tabular}




\begin{tabular}{|c|c|c|c|c|c|c|}
\hline Test Type & CMD & SGSD & $\begin{array}{l}\text { Total Conc } \\
\text { (Tunnel)* }\end{array}$ & $\begin{array}{l}\text { Total Conc } \\
\text { (Engine)* }\end{array}$ & $\begin{array}{l}\text { Truck ID \& } \\
\text { description }\end{array}$ & Fuel \\
\hline Idle1 & 25.7 & 1.384 & $2.94 \mathrm{E}+05$ & $8.23 \mathrm{E}+06$ & & \\
\hline Idle2 & 25.3 & 1.536 & $3.03 \mathrm{E}+05$ & $1.00 \mathrm{E}+07$ & & \\
\hline Idle3 & 24.1 & 1.856 & $1.67 \mathrm{E}+05$ & $5.51 \mathrm{E}+06$ & & \\
\hline Idle4 & 24.2 & 1.571 & $2.24 \mathrm{E}+05$ & $7.39 \mathrm{E}+06$ & & \\
\hline Bkgd1 & 19.5 & 1.896 & $7.95 \mathrm{E}+03$ & $2.23 \mathrm{E}+05$ & 2 scans & \\
\hline \multirow[t]{2}{*}{ Bkgd2 } & 41.4 & 1.88 & $4.34 \mathrm{E}+03$ & $1.22 \mathrm{E}+05$ & 2 scans & \\
\hline & & & & & $\begin{array}{l}\text { 5909, Engelhard } \\
\text { DPX }\end{array}$ & ECD \\
\hline ss 45 & 61.3 & 1.328 & $7.75 \mathrm{E}+04$ & $2.17 \mathrm{E}+06$ & $\mathrm{~T} 2=103 \mathrm{~F}$ & \\
\hline ss 45 & 46.7 & 1.383 & $3.23 \mathrm{E}+05$ & $9.04 \mathrm{E}+06$ & $\mathrm{~T} 2=83 \mathrm{~F}$ & \\
\hline Bkgd1 & 50 & 2.502 & $4.00 \mathrm{E}+02$ & $1.32 \mathrm{E}+04$ & 2 scans & \\
\hline Bkgd2 & 54.6 & 2.451 & $3.96 \mathrm{E}+02$ & $1.31 \mathrm{E}+04$ & 2 scans & \\
\hline Cold-idle & 39.6 & 1.715 & $5.47 \mathrm{E}+03$ & $1.81 \mathrm{E}+05$ & & \\
\hline Idle1 & 31.9 & 1.661 & $1.07 \mathrm{E}+03$ & $3.53 \mathrm{E}+04$ & & \\
\hline \multirow[t]{2}{*}{ Idle2 } & 33.2 & 1.515 & $1.29 \mathrm{E}+03$ & $4.26 \mathrm{E}+04$ & & \\
\hline & & & & & 5909, EH DPX & ECD \\
\hline ss $45-1$ & 47.8 & 1.884 & $7.94 \mathrm{E}+02$ & $7.94 \mathrm{E}+03$ & $\mathrm{DR}=10: 1$ & \\
\hline ss $45-2$ & 29.8 & 1.332 & $5.97 \mathrm{E}+03$ & $5.97 \mathrm{E}+04$ & $\mathrm{DR}=10: 1$ & \\
\hline ss $45-3$ & 26.7 & 1.525 & $5.35 \mathrm{E}+03$ & $5.35 \mathrm{E}+04$ & $\mathrm{DR}=10: 1$ & \\
\hline ss45 & 47 & 1.816 & $8.66 \mathrm{E}+03$ & $8.66 \mathrm{E}+04$ & $\mathrm{DR}=10: 1,\left(103^{\circ} \mathrm{F}\right)$ & \\
\hline Idle1 & 40.6 & 1.567 & $4.91 \mathrm{E}+02$ & $4.91 \mathrm{E}+03$ & $\mathrm{DR}=10: 1$ & \\
\hline Idle2 & 40.4 & 1.816 & $1.98 \mathrm{E}+02$ & $1.98 \mathrm{E}+03$ & $\mathrm{DR}=10: 1$ & \\
\hline
\end{tabular}

Note: * the total concentration is the summation of the sample data from $7.6 \mathrm{~nm}$ to $299 \mathrm{~nm}$ (view range by SMPS)

**Bkgd in the Table means Background.

\subsection{Transient Test}

\subsubsection{Test Arrangement}

The CSHVR (City/Suburban Heavy Vehicle Route cycle) was chosen for the basic transient tests. For the vehicles with after-treatment device, the 5-mile truck cycles were also performed. CPC count program was used to record the PM concentration of certain particle diameter vs. the time. The particle diameter to be investigated was determined from the PM distribution graph of steady state test. Usually, five particle diameters were chosen to perform the transient test, which included one maximum point of the distribution curve, two side transient points and two middle points between the 
maximum and the side points. For the vehicles without after-treatment devices, only three different diameters were chosen, one maximum point and two side points.

\subsubsection{Test Result}

Transient test results are shown in Figures 6-7 to 6-18. For certain diameters, the particle concentrations ranged over a two to three power of $10\left(10^{5}-10^{8}\right.$ to $\left.10^{3}-10^{5}\right)$. However, the emissions from the vehicle with after-treatment devices had a two to three order lower than those of without after-treatment devices. The ranges of the concentrations are listed in the Table 6-6. The particle removal efficiencies of the aftertreatment devices were very similar to the steady state tests.

Table 6-6 Summary of Transient Test Results (see Figure 6-7 6-17 for details)

\begin{tabular}{|l|l|l|l|l|}
\hline \multicolumn{1}{|c|}{$\begin{array}{c}\text { After-treatment } \\
\text { Device }\end{array}$} & Truck Number & \multicolumn{1}{|c|}{ Fuel } & $\begin{array}{c}\text { Transient } \\
\text { Test Cycle }\end{array}$ & $\begin{array}{c}\text { Particle } \\
\text { Concentration }\end{array}$ \\
\hline No After-treatment & RA GRO-5912 & EC Diesel & CSHVR & $3 * 10^{5}-1.5^{*} 10^{8}$ \\
\hline No After-treatment & RA GRO-5918 & CARB & CSHVR & $7 * 10^{5}-8 * 10^{7}$ \\
\hline Johnson-Matthey CRT & RA GRO-5900 & EC Diesel & $2 * 5$ miles & $1 * 10^{3}-6^{*} 10^{4}$ \\
\hline Johnson-Matthey CRT & RA GRO-5900 & EC Diesel & CSHVR & $1 * 10^{3}-1 * 10^{5}$ \\
\hline Johnson-Matthey CRT & RA GRO-5902 & EC Diesel & $2 * 5$ miles & $1 * 10^{3}-1 * 10^{5}$ \\
\hline Johnson-Matthey CRT & RA GRO-5902 & EC Diesel & CSHVR & $1 * 10^{3}-1 * 10^{5}$ \\
\hline Engelhard DPX & RA GRO-5909 & EC Diesel & $2 * 5$ miles & $1 * 10^{3}-7 * 10^{5}$ \\
\hline Engelhard DPX & RA GRO-5909 & EC Diesel & CSHVR & $1 * 10^{3}-4 * 10^{5}$ \\
\hline Engelhard DPX & RA GRO-5907 & EC Diesel & $2 * 5$ miles & $1 * 10^{3}-4 * 10^{5}$ \\
\hline Engelhard DPX & RA GRO-5907 & EC Diesel & CSHVR & $1 * 10^{3}-2 * 10^{5}$ \\
\hline
\end{tabular}


The comparison between the emission concentration trace graphs and the vehicle operating speed trace of CSHVR are shown in Figures 6-14 to 6-17. It can be seen from those Figures that, the particle concentrations were proportional to the vehicle speed; and the concentration was maintained large values when the vehicle speed was changing.

\subsection{Summary}

(1) For the eight Ralphs' diesel trucks tested, the Count Median Diameter (CMD) of the particles is ranged between $30 \mathrm{~nm}$ and $60 \mathrm{~nm}$. EC-Diesel baseline's CMD is $33 \mathrm{~nm}$, while CARB's baseline is $56 \mathrm{~nm}$; and JM-CRT's CMD is 37-39 nm and Engelhard DPX's CMD is 40-47 $\mathrm{nm}$.

(2) Both steady state and transient tests show that the two after-treatment devices have very high nano-particle removal efficiency. The efficiency of Engelhard DPX is greater than $99 \%$ and the efficiency of J-M CRT is up to $99.9 \%$.

(3) The particle concentrations changed in sympathy with engine power. 
Tractor Truck, DDS60, EC Diesel, DR=28:1, 2`5miles, Johnson-Matthey CRT, 02/29

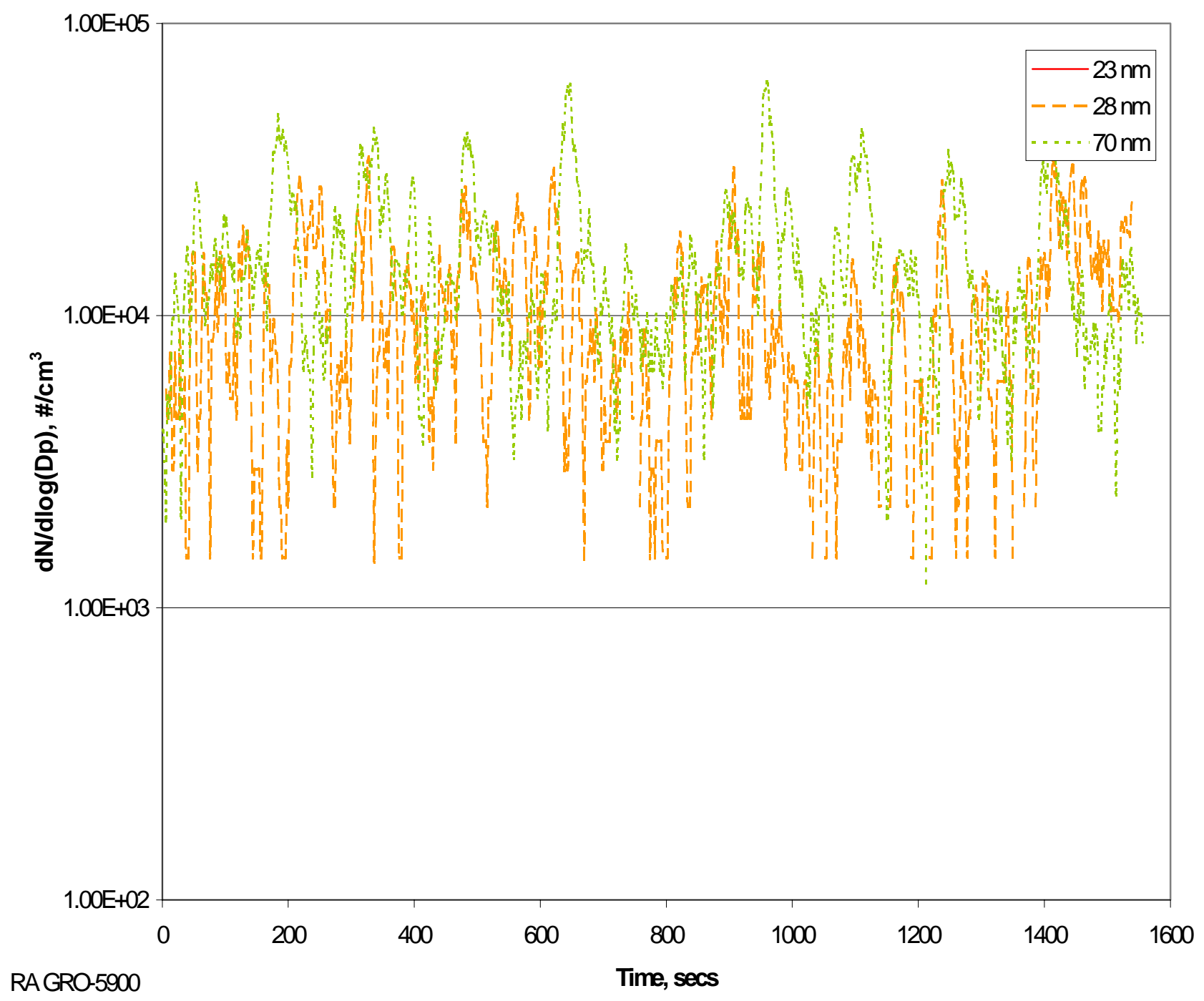

Figure 6-7. Transient Test: $2 * 5$ miles, J-M CRT 
Tractor Truck, DDS 60, EC Diesel, DR=28:1, 2`CSHMR, Johnson-Matthey CRT, 02/29

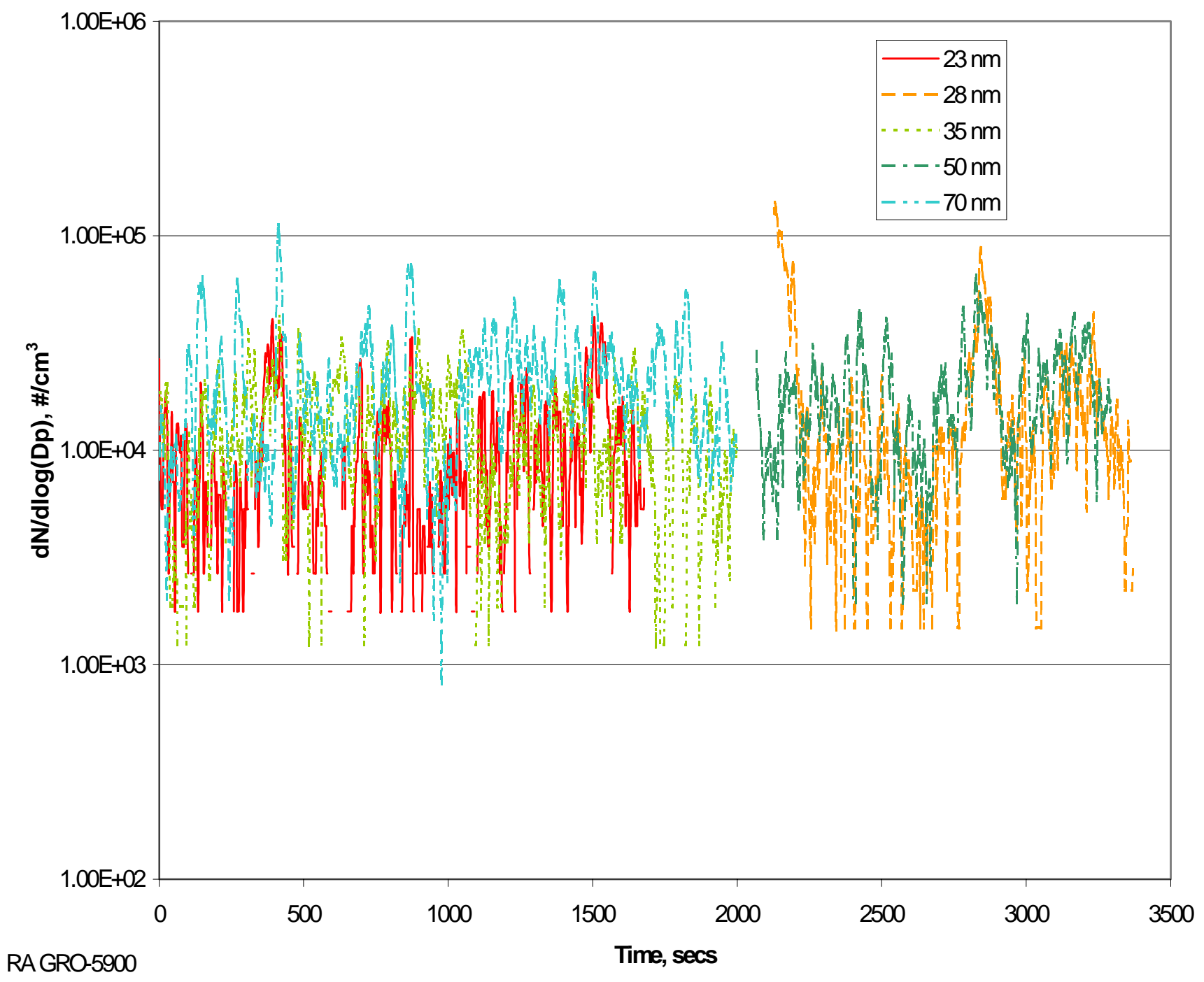

Figure 6-8. Transient Test: $2 *$ CSHVR, J-M CRT 
Tractor Truck, DDS6, ECDiesel, DR=28:1, 2CSHR, Johnson-Matthey CRT, 0301

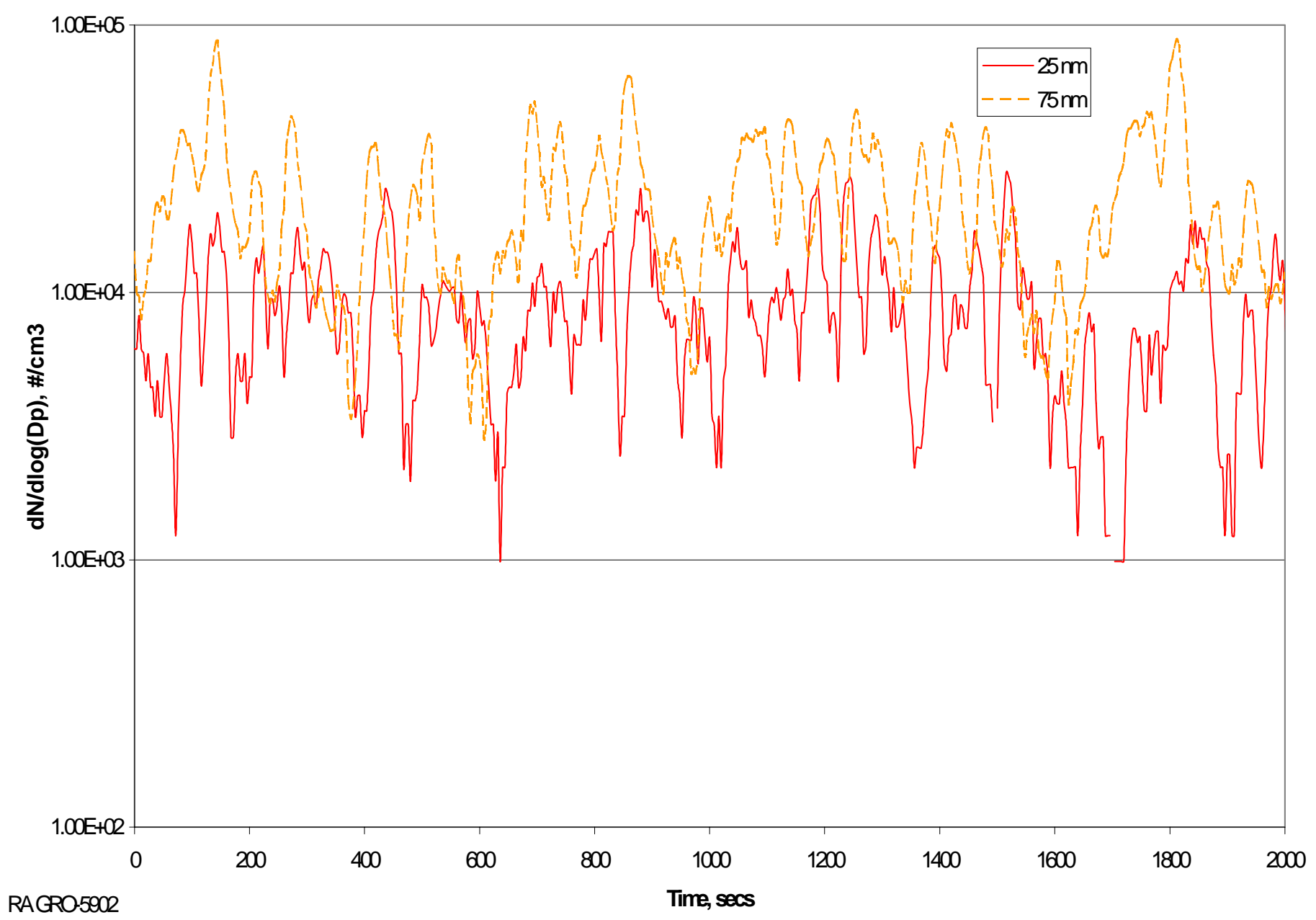

Figure 6-9. Transient Test: $2 *$ CSHVR, J-M CRT 
Tractor Truck, DDS60, ECDiesel, DR=28:1, 2'CSHMR, Johnson-Metthey CRT, 0301

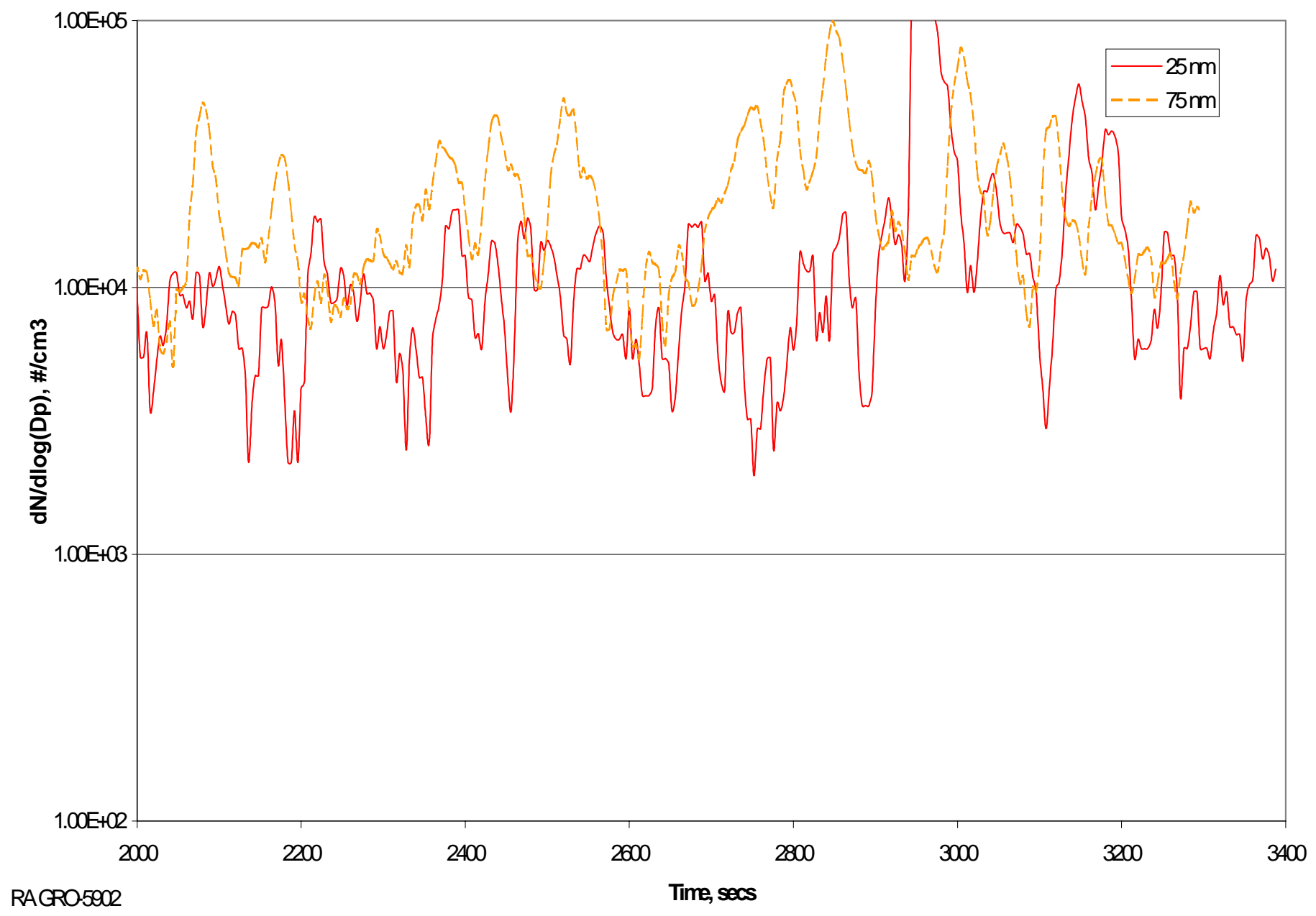

Figure 6-10. Transient Test: $2 *$ CSHVR, J-M CRT 
Tractor Truck, DDS 60, EC Diesel, DR=28:1, 2`5miles, Johnson-Matthey CRT, 03/02

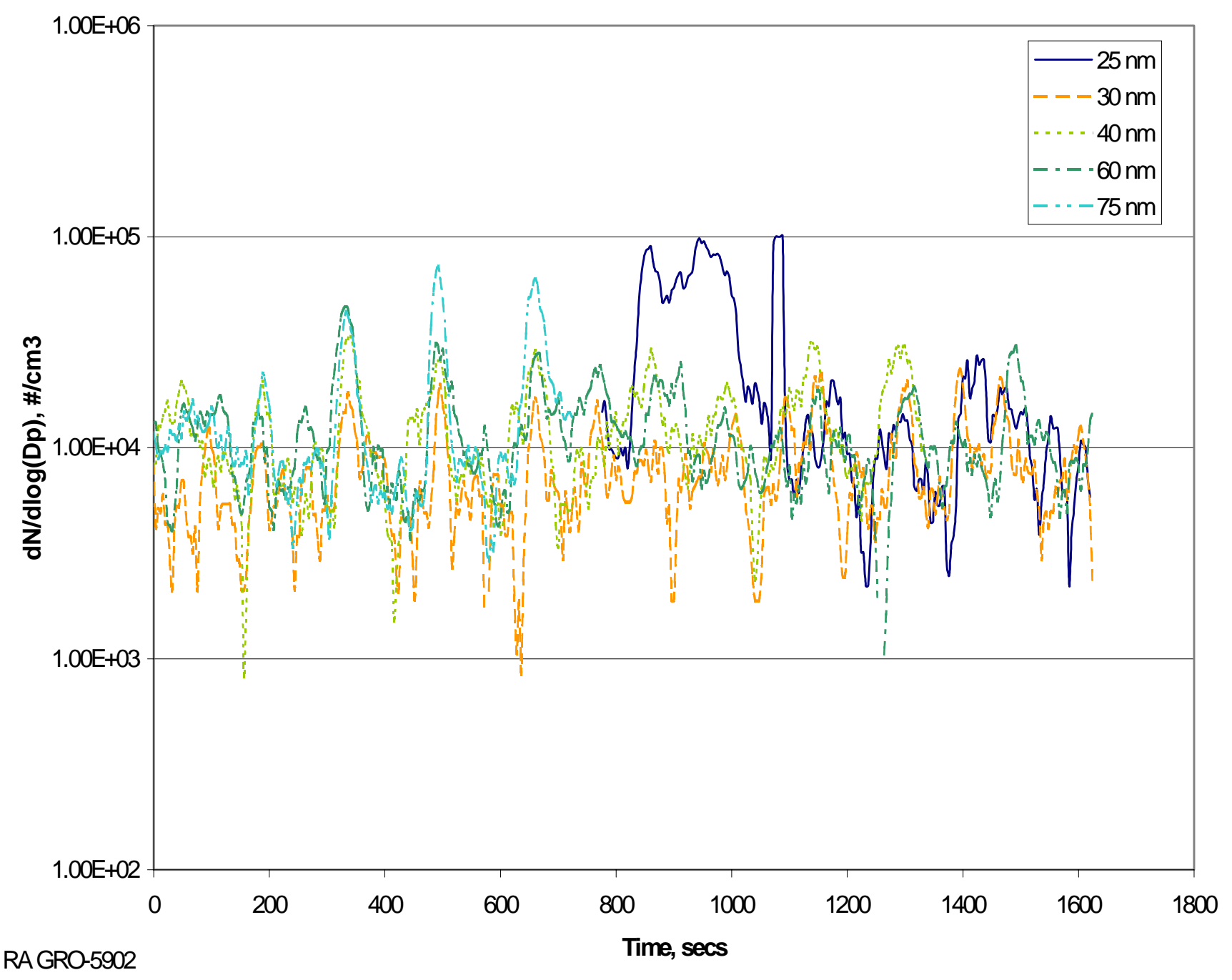

Figure 6-11. Transient Test: $2 * 5$ miles, J-M CRT 


\section{Tractor Truck, DDS 60, EC Diesel, DR=28:1, CSHNR, No After-treatment, 03/03}

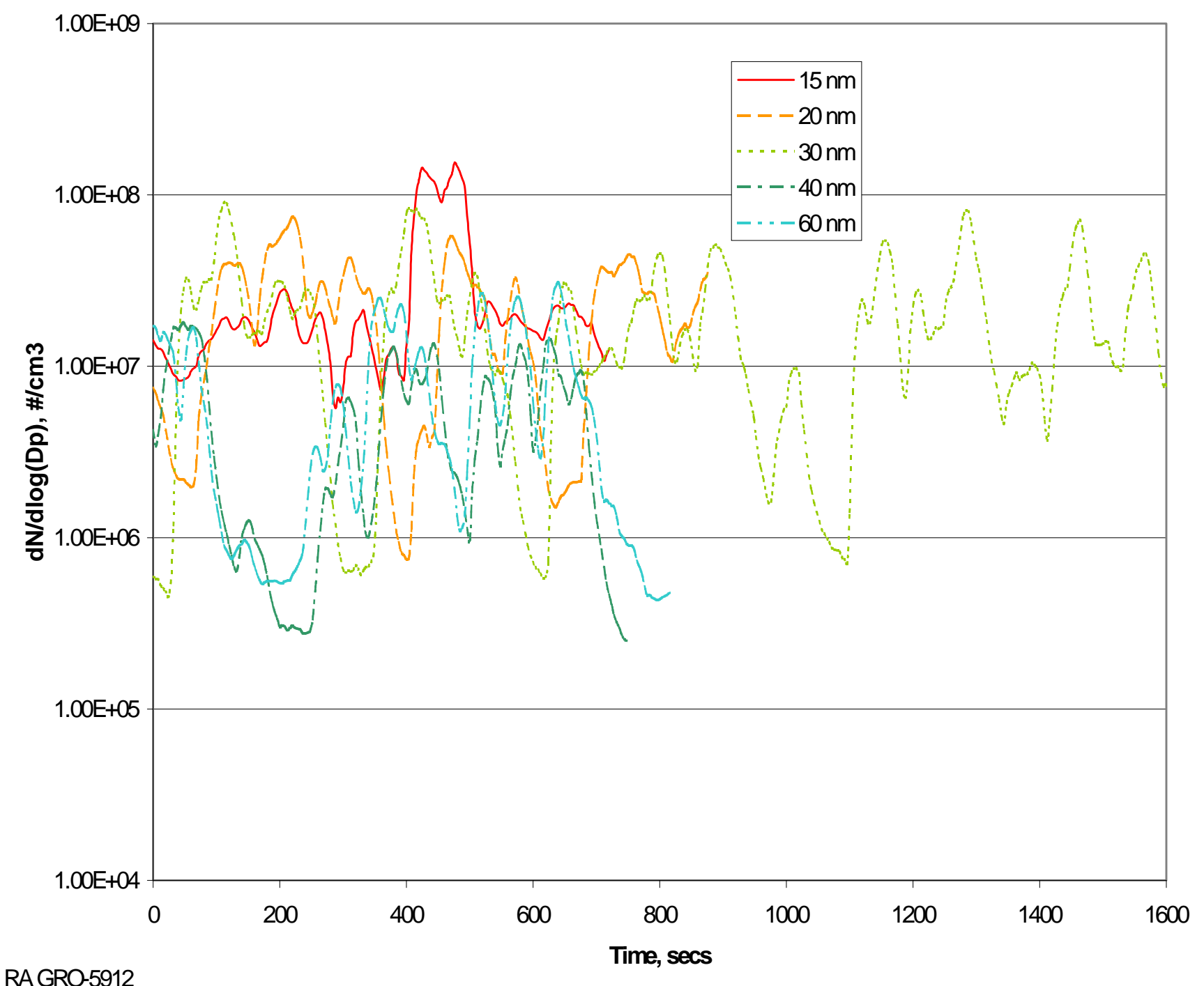

Figure 6-12. Transient Test: CSHVR, No Aftertreatment 


\section{Tractor Truck, DDS60, EC Diesel, DR=33:1, 2`5miles,Engelhard DPX, 03/04}

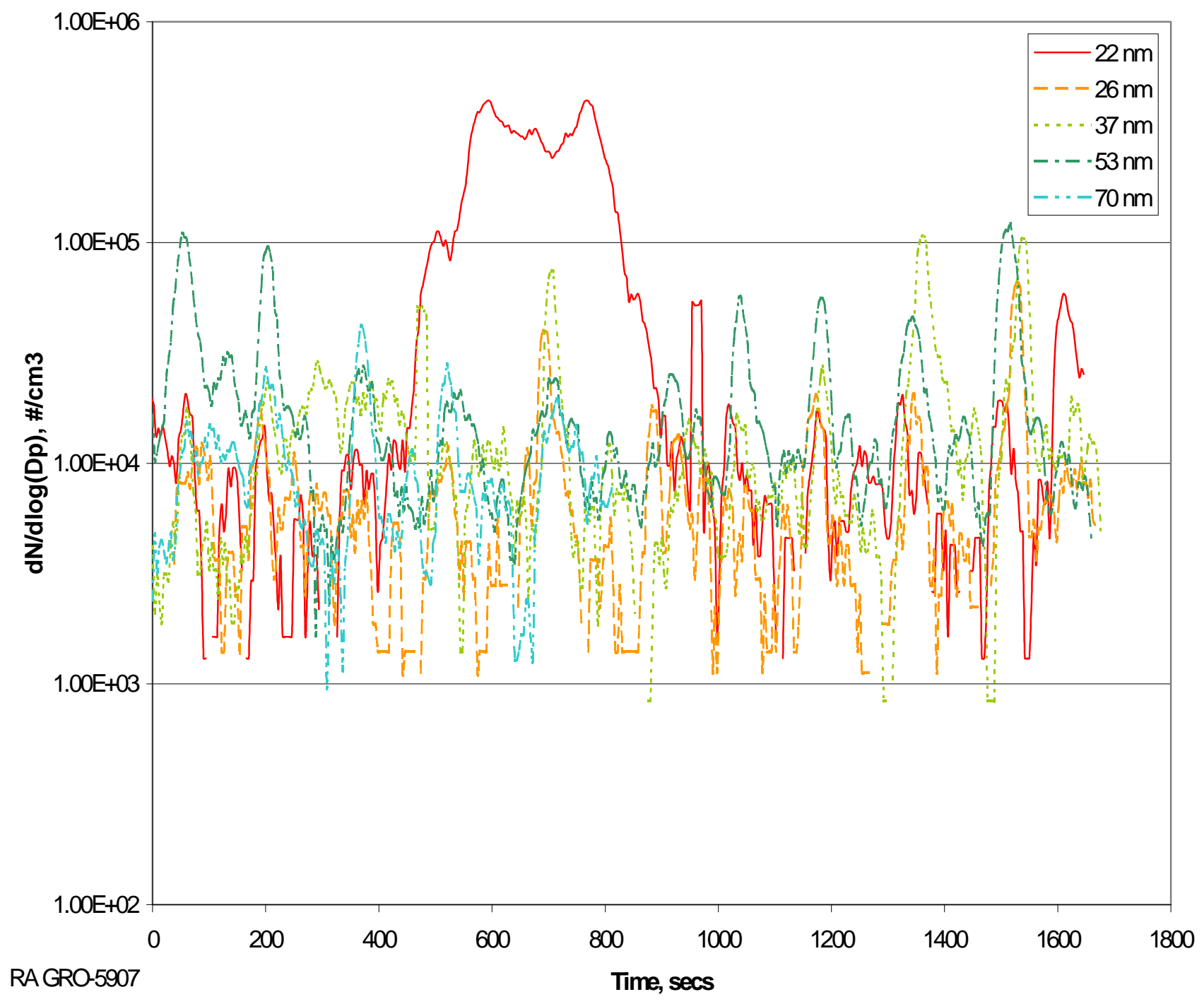

Figure 6-13. Transient Test: 2*5miles, DPX 
Tractor Truck, DDS 60, EC Diesel, DR=28:1, 2`5miles, Engelhard DPX, 03/07

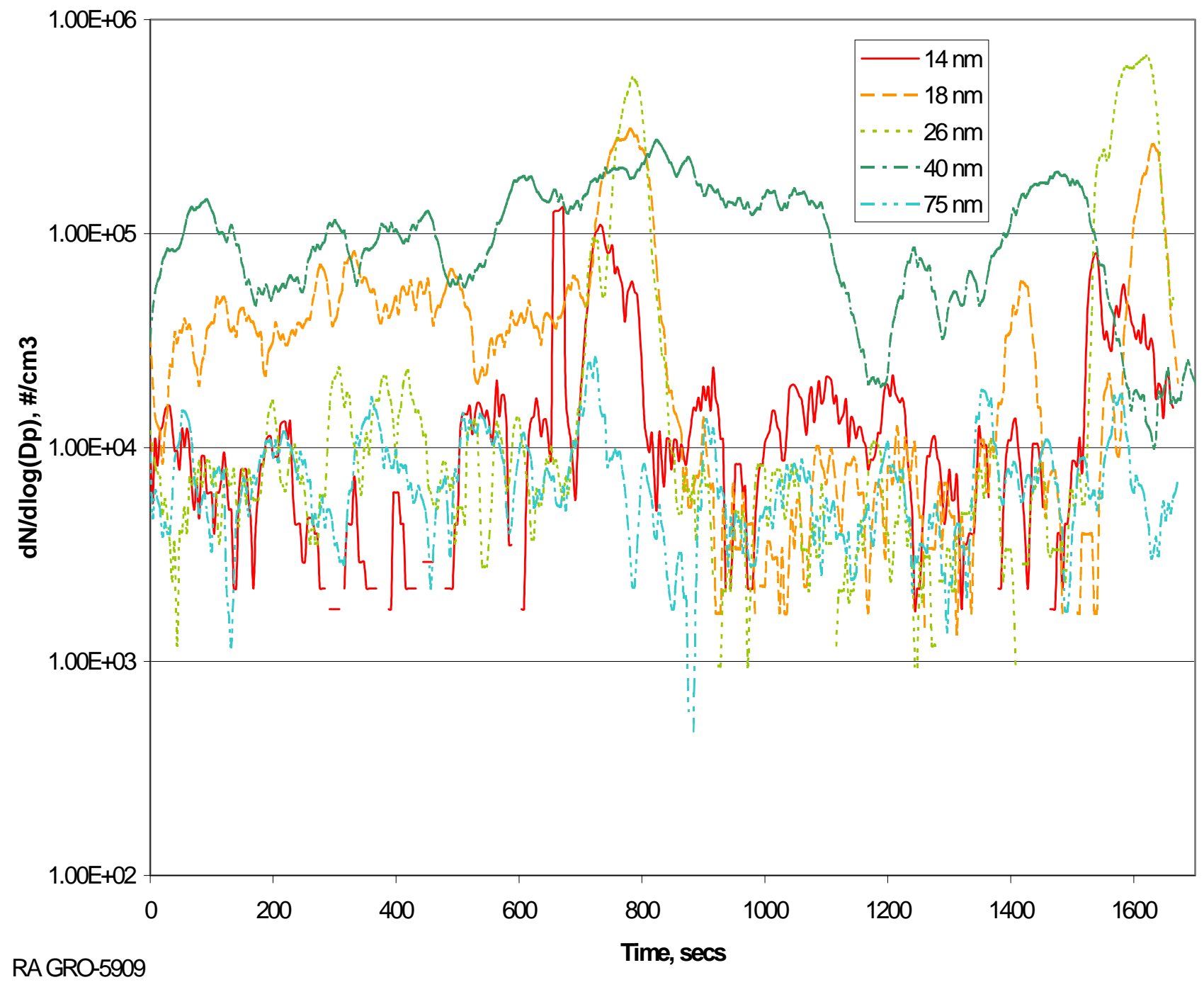

Figure 6-14. Transient Test: 2*5miles, DPX 
Tractor Truck, DDS 60, CARB Diesel, DR=28:1, CSHVR, No After-treatment, 03/09

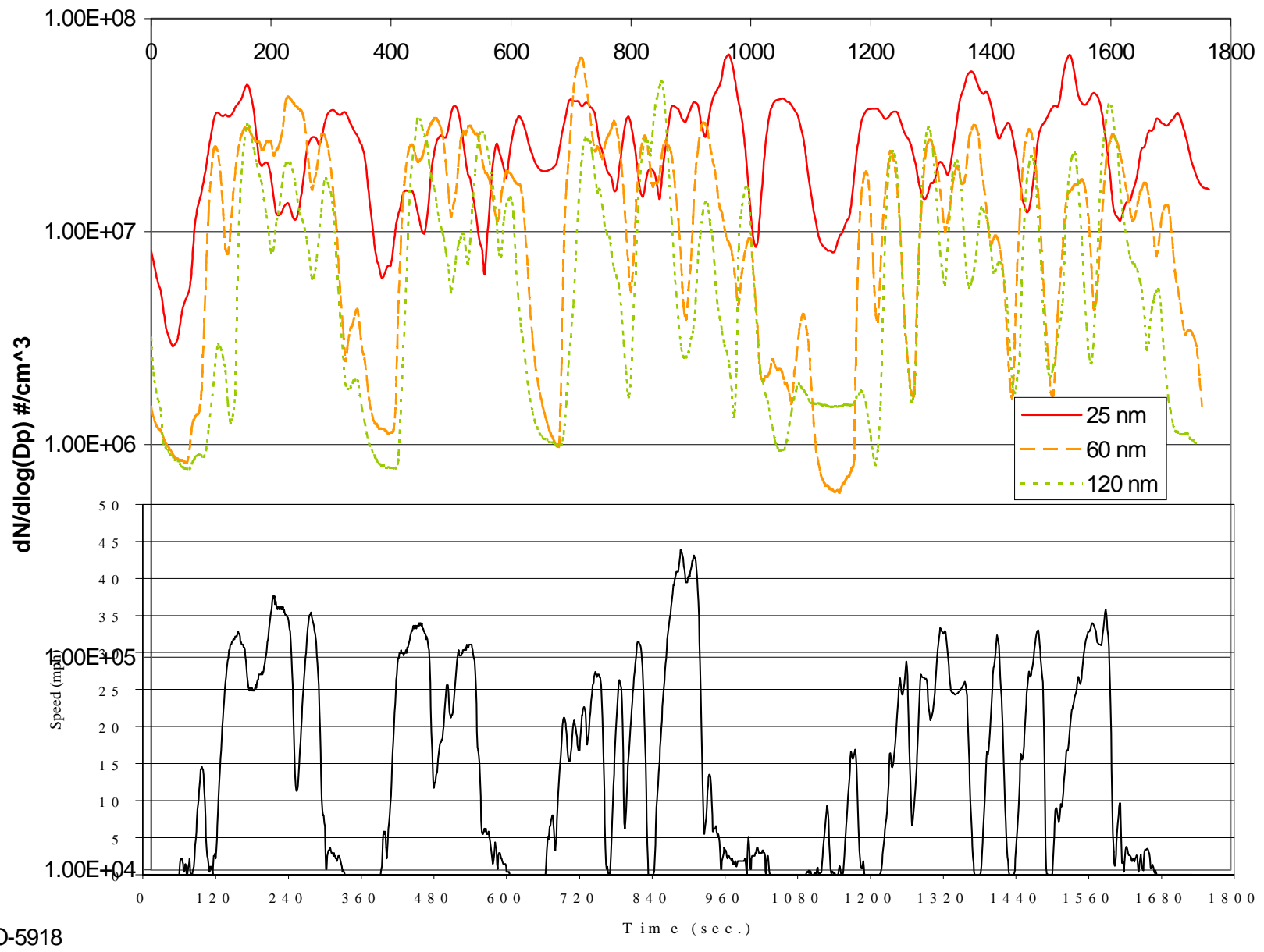

Figure 6-15. Transient Test: CSHVR, No Aftertreatment

(Compared with vehicle speed) 
Tractor Truck, DDS 60, EC Diesel, DR=33:1, 2*CSHVR, Engelhard DPX, 03/07

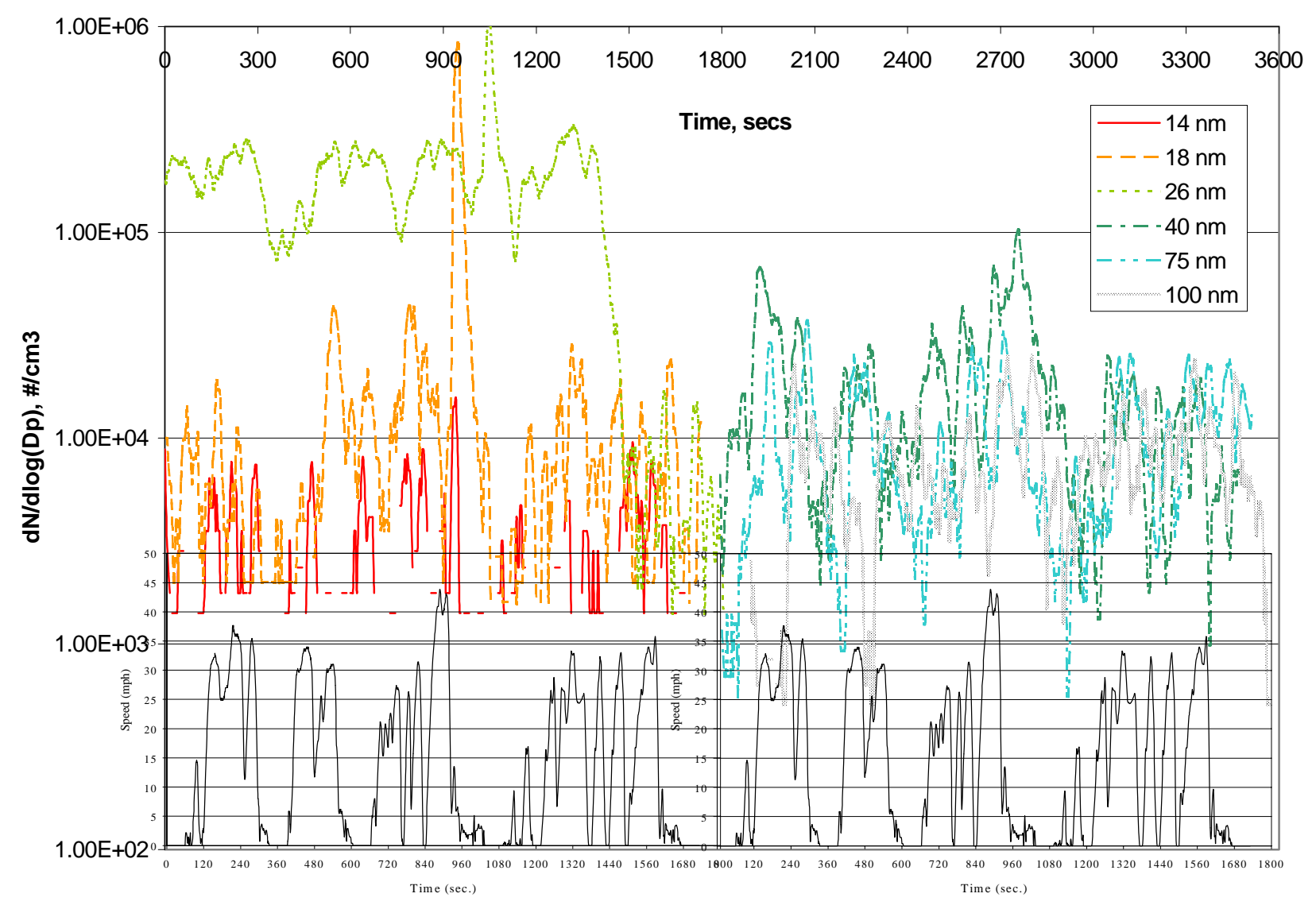

RA GRO-5909

Figure 6-16. Transient Test: $2 *$ CSHVR, DPX

(compared with vehicle speed) 
Tractor Truck, DDS 60, EC Diesel, DR=33:1, 2*CSHVR, Engelhard DPX, 03/06

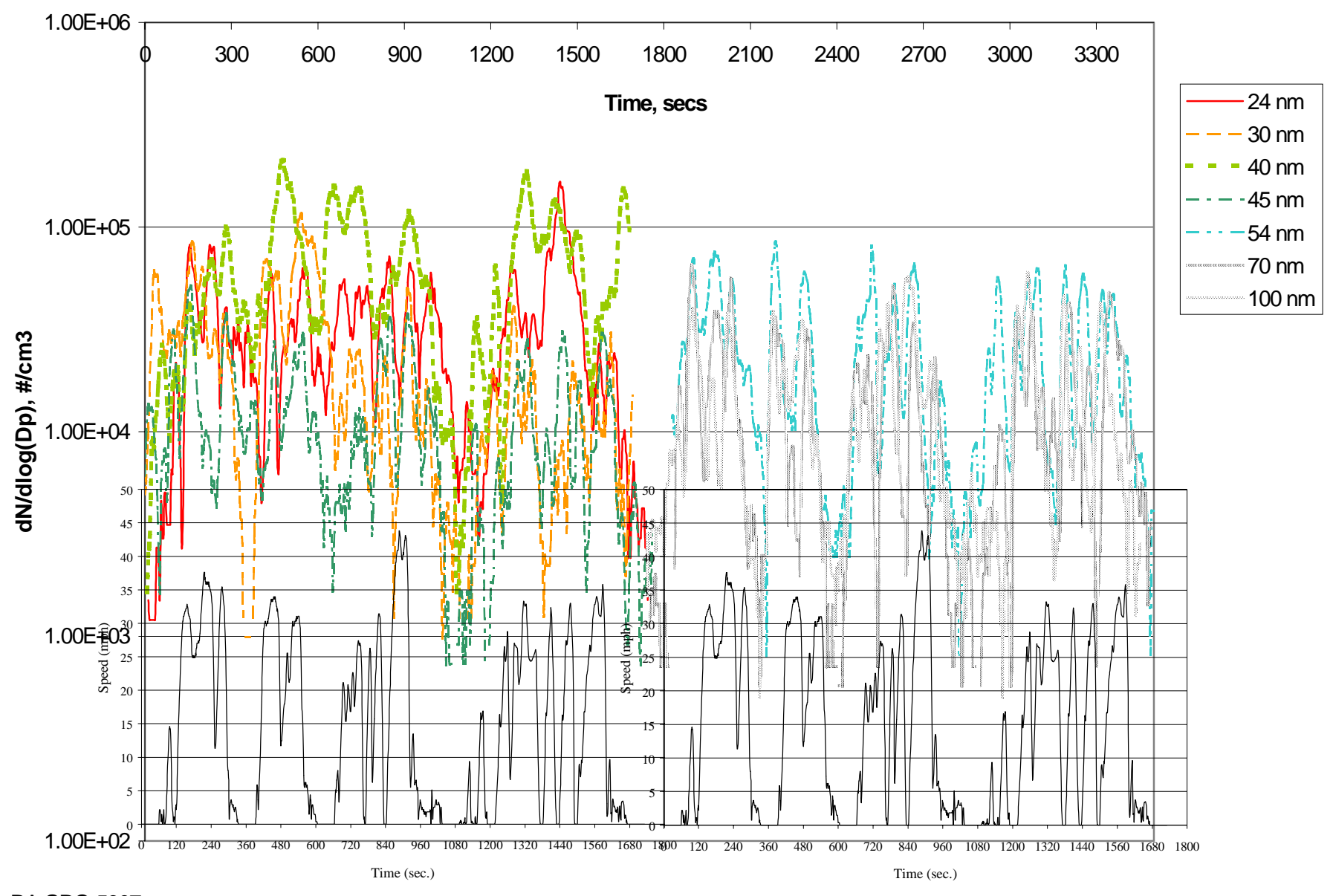

Figure 6-17. Transient Test: $2 *$ CSHVR, DPX

(Compared with vehicle speed) 
Tractor Truck, DDS 60, EC Diesel, DR=33:1, 2*CSHVR, Johnson-Matthey CRT 03/02

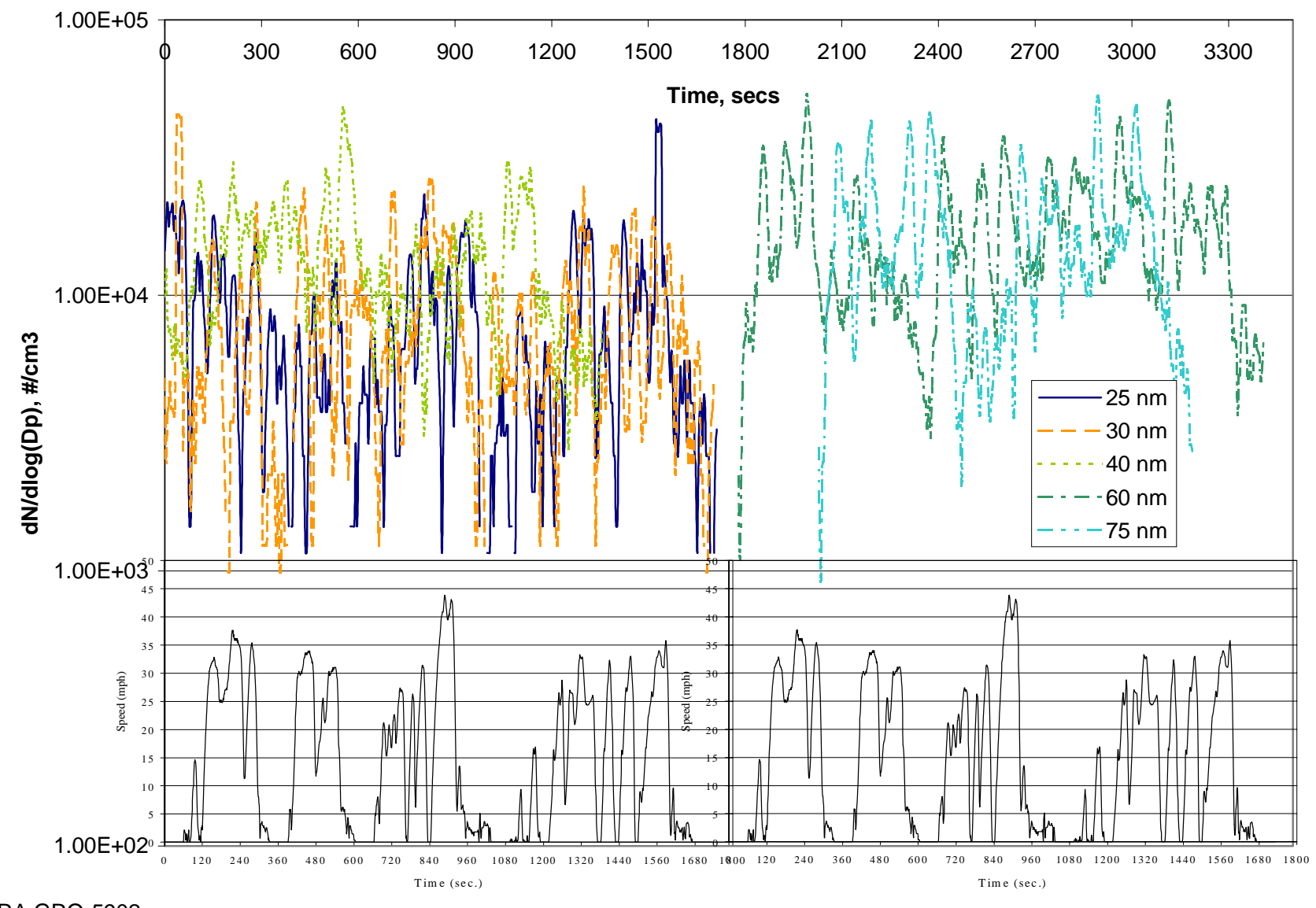

RA GRO-5902

Figure 6-18. Transient Test: 2*CSHVR, J-M CRT

(Compared with vehicle speed) 


\section{Chapter 7 CONCLUTIONS AND RECOMMENDATIONS}

\subsection{Conclusions}

(1) This study put forward a method to predict the concentration field in the plume of a heavy-duty truck, operating at highway speed. It provided information regarding computation of dispersion coefficients in the area near a stack. The most relevant components included the determination of the imaginary source point of the plume and the modification of Pasquill-Gifford model for the calculation of the dispersion coefficients. Based upon these, the above-centerline portion of the plume concentration field, near the stack, could be successfully predicted by the Gaussian plume equations, the horizontal dispersion coefficient could be calculated by the Pasquill-Gifford equation, and the vertical dispersion coefficient could be calculated by the Modified Pasquill-Gifford formula that was put forth in this report.

(2) From the experimental study, an empirical model for predicting the concentration field in the region below the centerline of the plume had also been obtained.

(3) The numerical cumulative frequency fit method obtained in this study provided an effective and quick means for determining the distribution parameters, MMADs and GSDs of MOUDI sample data, especially for the multi-modal distribution. The MOUDI data from transit buses suggested the following: The particle size distribution of the two CNG buses was characterized by bi-modal distribution, the smaller MMD (Mass Median Diameter) ranges from $0.034 \mu \mathrm{m}$ to $0.038 \mu \mathrm{m}$ and the larger MMD, 2.2-7.8 $\mu \mathrm{m}$. The two clean diesel buses had a uni-modal particle size distribution with the MMD of 0.14-0.17 $\mu \mathrm{m}$. All of the buses had a uni-modal particle size distribution when the mass data were converted to count data. The Count Median 
Diameters (CMD) for the two CNG buses are 0.018 and $0.022 \mu \mathrm{m}$; the two clean diesel buses, 0.032 and $0.034 \mu \mathrm{m}$.

(4) Size-selective PM sampling study using $\mathrm{PM}_{2.5}$ and $\mathrm{PM}_{1.0}$ cyclones showed that the $\mathrm{PM}_{1.0}$ fractions of the total PM were $73.6 \%, 69.1 \%, 80.4 \%$, and $78.9 \%$ for $\mathrm{CNG}$, clean diesel, hybrid, and conventional diesel buses, respectively; the $\mathrm{PM}_{2.5}$ fractions of the total PM were $91.2 \%, 79.7 \% 88.8 \%$, and $90.1 \%$ for $\mathrm{CNG}$, clean diesel, hybrid, and conventional diesel buses, respectively.

(5) The eight heavy-duty diesel trucks, exhibited the Count Median Diameter (CMD) values ranging from $30 \mathrm{~nm}$ to $60 \mathrm{~nm}$. EC-Diesel baseline test yielded a CMD of 33 $\mathrm{nm}$; CARB's baseline was at $56 \mathrm{~nm}$; JM-CRT's had a CMD of 37-39 nm, and Engelhard DPX had a CMD of 40-47 nm.

(6) Both steady state and transient tests showed that the two after-treatment devices had very high nano-particle removal efficiency. The efficiency of Engelhard DPX was greater than $99 \%$ and the efficiency of J-M CRT was as high as $99.9 \%$. The particle concentrations changed in sympathy with engine power.

\subsection{Recommendations}

(1) For exhaust dispersion study, the continuous scanning sample method used in Chapter 4 is recommended as a primary choice. If the response speed of particle sample equipment (SMPS) can match the probe moving speed, the continuous scan mapping can also be used in the particle dispersion study;

(2) Controlling the dilution air flow rate and the exhaust flow rate can yield more stable dilution ratio than by controlling the dilution flow rate and the total flow rate. The 
ejector-based dilution system is stable in terms of flow rate control, but its reliability is suspect because of the high vacuum that it produces at the ejector throat. The mass flow controller-based dilution system is more reliable, but steps should be taken to maintain both dilution air flow rate and total flow rate constant. For example, if an error of less than $5 \%$ in the dilution ratio is expected, the variation of both dilution flow rate and total flow rate controlled by mass flow controllers should not exceed $0.1 \%$. 


\section{REFERENCES}

1 Seinfeld, J. H., (1986), Atmospheric Chemistry and Physics of Air pollution. John Wiley \& Sons, New York, pp 561-585.

2 American Society of Mechanical Engineers, (1973), Recommended Guide for the prediction of the Dispersion of Airborne Effluents, $2^{\text {nd }}$ ed., ASME, New York.

3 Klug, W. A., (1969), "Method for Determining Diffusion Conditions from Synoptic Observations", Staub-Reinhalt. Luft, 29, pp14-20.

4 Martin, D O., (1976), "Comment on the Change of Concentration Standard Deviations with Distance", Journal of Air Pollution Control Association, 26, pp145-6.

5 Turner, D B., (1969), Workbook of Atmospheric Diffusion Estimates, USEPA 999-AP-26. U S Environmental Protection Agency, Washington, D. C.

6 Wang, Y. M., (1994), Mine Aerodynamics and Ventilation Systems, Metallurgy Industry Press, Beijing, PRC (In Chinese).

7 Okabayashi, K., Ide, Y., Takahashi, H., Kane, N., Okamoto, S., and Kobayashi, K., (1991), "A New Wind Tunnel Technique for Investigating Gas Diffusion Behind a Structure". Atmospheric Environment, Vol. 25A, No. 7, pp 1227-1236.

8 Huber, A. H., (1991), "Wind Tunnel and Gaussian Plume Modeling of Building Wake Dispersion”. Atmospheric Environment, Vol. 25A, No. 7, pp 1237-1249.

9 Singh, S., Fulker, M. J., and Marshall, G., (1994), "A Wind-tunnel Examination of the Variation of Sigma Y and Sigma Z with Selected Parameters". Atmospheric Environment, Vol. 28, No. 11, pp 1837-1848.

10 Zhang, G., (1987), Aerosol Dynamics. Chinese Environmental Science Press, Beijing, PRC (in Chinese). 
11 Bennett, M., Sutton, S., and Gardiner, D., (1992), "Measurements of Wind Speed and Plume Rise with A Rapid-scanning LIDAR”. Atmospheric Environment, Vol. 26A, No. 9, pp167588.

12 Hanna, S. R., Chang, J. C., (1993), “Hybrid Plume Dispersion Model (HPDM) Improvements and Testing at Three Field Sites". Atmospheric Environment, Vol. 27A, No. 9, pp 1491-508.

13 Hernandez, J. F., Cremades, L., and Baldasano, J. M., (1995), "Dispersion Modeling of a Tall Stack Plume in the Spanish Mediterranean Coast by a Particle Model”. Atmospheric Environment, Vol. 29, No. 11, pp 1331-41.

14 Erbrink, H. J., (1994), "Plume Rise in Different Atmospheres: a Practical Scheme and Some Comparisons with LIDAR Measurements". Atmospheric Environment, Vol. 28, No. 22, pp $3625-3636$.

15 Rickel, C., Lamb, B., Guenther, A., and Allwine, E., (1990), “An Infrared Method for Plume rise Visualization and Measurement". Atmospheric Environment, Vol. 24a, No. 11, pp 283538.

16 Sykes, R. I., Henn, D. S., and Parker, S. F., (1992), "Large-Eddy Simulation of a Turbulent Reacting Plume". Atmospheric Environment, Vol. 26a, No. 14, pp2565-74.

17 Okabayashi, K., Ide, Y., (1991) “A New Wind Tunnel Technique for Investigating Gas Diffusion Structure". Atmospheric Environment, Vol. 25a, No. 7, pp 1227-36.

18 Noel de Nevers., (1995) Air Pollution Control Engineering. McGraw-Hill, Inc.

19 Clark, N., Gautam, M., and Ayala, A., (2000), "Diesel Particulate Sampling Methodology". Draft Final Report, CDC Project Number E-43 proposal (Participating Investigators: Boyce, J., Mehta, S., Xie, W., Xu, Z., Kuhlman, J., Jarret, R).

20 Lippmann, M., Gurman, J., (1983), “Role of Particle Deposition in Occupational Lung Disease". Aerosols in the Mining and Industrial Work Environment, Vol. 1: Fundamentals 
and Status, Ed. By Virgil A., Benjamin Y., and Liu H.: Ann Arbor Science Publishers, Ann Arbor, Michigan, Vol. 1 pp119-38.

21 Marple, V., (1991) “Microorifice Uniform Deposit Impactor”. Aerosol science and Technology, Vol. 14, pp434-446.

22 Hinds, W. C., (1986), Data Analysis, In: Cascade Impactor. American Industrial Hygiene Association Monograph Series. AIHA, Akron, $\mathrm{OH}$.

23 Burkhart, J., McCawley, M. A., and Wheeler, R. W., (1987), "Particle Size Distribution in Underground Coal Mines". American Industrial Hygiene Association Journal, 48:122-126.

24 Reist, P. C. (1984), Introduction to Aerosol Science. MacMillan Publishing Company, New York.

25 Dallavalle, J. M., Orr, C., and Blocker, H. C., (1951) "Fitting Bimodal Particle Size Distribution Curves". Industrial Engineering Chemistry. 43(6):1377-80.

26 Crump, J. G., Seinfeld, J. H., (1982), “A New Algorithm for Inversion of Aerosol Size Distribution Data". Aerosol Science Technology, 1:15-34.

27 Puttock, J. S. (1981), “Data Inversion for Cascade Impactors: Fitting Sums of Log-Normal Distributions". Atmospheric Environment, 15:1709-16.

28 Hewett, P., McCawley, M. A., (1991), “A Microcomputer Spreadsheet Technique for Analyzing Multimodal Particle Size Distributions". Applied Occupation Environment Hygiene, No.6, pp865-73.

29 Byers, R. J., (1999), “Measurement of Particulate Matter Size, Concentration and Mass Emissions from In-use Heavy Duty Vehicles”, Thesis, Department of Mechanical and Aerospace Engineering, West Virginia University.

30 Kittelson, D., Watts, W., and Arnold, M. (1998), "Review of Diesel Particulate Sampling Methods: Supplemental Report No. 2 Aerosol Dynamics, Laboratory and On-Road Studies.” University of Minnesota. 
31 Ferguson, C., (1986), Internal Combustion Engines: Applied Thermosciences. John Wiley \& Sons, New York.

32 Kreso, A., Johnson, J., (1998), “ A Study of the Effects of Exhaust Gas Recirculation on Heavy-Duty Diesel Engine Emissions.” SAE Technical Paper, No. 981422.

33 William, L., (1980), Air Polution Control Engineering, Basic Calculations for Particulate Collection. John Wiley \& Sons, New York.

34 Mayer, A, Egli, H., Burtscher, H., Czerwinski, J., and Gehrig, D., (1995), "Particle Size Distribution Downstream Traps of Different Design”, SAE Technical Paper, No. 950373 pp134-144.

35 Abdul-Khalek, I. S., Kittelson, D. B., Graskow, B. R., Wei, Q., and Brear, F. , (1998), "Diesel Exhaust Particle Size: Measurement Issues and Trends", SAE Technical Paper, No. 980525, pp132-145.

36 Graskow, B. R., Kittelson, D. B., Abdul-Khalek, I. S., Ahmadi, M. R., and Morris, J. E., (1998), "Characterization of Exhaust Particulate Emissions from a Spark Ignition Engine", SAE Technical Paper, No. 980528, pp154-165.

37 Baumgard, K. J., (1988), “The influence of a Ceramic Particle Trap on the Size Distribution of Diesel Particles". Thesis, The Graduate School, The University of Minnesota, pp43-66.

38 Eastlake, A., (1999),“The Latest Developments in Heavy Duty Vehicle Aftertreatment Testing for Real World Emissions and Fuel Economy”. SAE Technical Paper, 1999-01-0470.

39 Miller, P., School, J., Bagley, S., Leddy, D., and Johnson, J., (1983), “The Effects of a Porous Ceramic Particulate Trap on the Physical, Chemical and Biological Character of Diesel Emissions”. SAE Paper No. 830457, pp158-87.

40 Hinds, W., (1982), Aerosol Technology-Properties, Behavior, and Measurement of Airborne Particles. John Wiley and Sons, New York.

41 Johnson, T. V., (2000), "Diesel Emission Control-Last 12 Months in Review". SAE Technical Paper 2000-01-2817. 
42 Gautam, M., (1999), "Particulate Matter and Nox Emissions from In-Use Heavy-Duty Diesel Vehicles", World Truck Conference, May 2-4, 1999, Monterey, Ca.

43 Gautam, M., Mehta, S., Bugarski, A., Byers, R., Clark, N., and Lyons, D., (1999), "Particle Size Distributions from In-Use Heavy-Duty Diesel Vehicles", $9^{\text {th }}$ CRC On-Road Vehicle Emissions Workshop, April 19-21, 1999, San Diego, Ca.

44 Smith II, C., (1993), “Comparison of Heavy Duty Diesel Engine Transient Emissions Measurements Using a Mini- and Full-flow Dilution Tunnel”, Thesis, Department of Mechanical and Aerospace Engineering, West Virginia University.

45 Miller, S., (1997), "Measurement of Diesel Particulate Matter Emissions with a Modified Multi-tube Type Mini-dilution Tunnel”, Thesis, Department of Mechanical and Aerospace Engineering, West Virginia University.

46 Gautam, M., Smith, R. C., Miller, E. S., Hirakouchi, N., and Shouji, T., (1998), "Split Ratio Control in Mini-Dilution Tunnels for Measurement of Steady State and Transient Emissions from Heavy Duty Diesel Engines”, International Journal of Vehicle Design, Vol. 5, No. 3 / 4. 